\title{
Zeyve Höyük -Porsuk : rapport préliminaire sur la campagne 2012
} Dominique Beyer, Françoise Laroche-Traunecker, Julie Patrier, Aksel Tibet

\section{Citer ce document / Cite this document :}

Beyer Dominique, Laroche-Traunecker Françoise, Patrier Julie, Tibet Aksel. Zeyve Höyük -Porsuk : rapport préliminaire sur la campagne 2012. In: Anatolia Antiqua, Tome 21, 2013. pp. 201-234;

doi : 10.3406/anata.2013.1351

http://www.persee.fr/doc/anata_1018-1946_2013_num_21_1_1351

Document généré le 15/05/2016 


\author{
Dominique BEYER* ${ }^{*}$, Françoise LAROCHE-TRAUNECKER* ${ }^{*}$, Julie PATRIER ${ }^{*}$ et \\ Aksel TIBET $^{* *}$
}

\title{
ZEYVE HÖYÜK - PORSUK : RAPPORT PRELIMINAIRE SUR LA CAMPAGNE 2012
}

La mission 2012 à Porsuk a eu lieu cette année du 22 juillet au 13 septembre. Cependant la fouille proprement dite, en raison de difficultés financières, a été arrêtée avec nos ouvriers plus tôt que prévu, soit le 4 septembre. Le reste du séjour a été alors consacré aux différents relevés et études ainsi qu'à des tâches de préservation et de mise en valeur du site (cf. ci-dessous partie IV).

Comme lors des campagnes précédentes, ce sont les deux chantiers situés aux deux extrémités du site, à l'Ouest et à l'Est, qui ont fait l'objet de nos recherches (Fig. 1). Il s'agissait à chaque fois de poursuivre les travaux en profondeur, l'épaisseur des couches étant particulièrement importante sur le site, ou d'étendre un sondage précédent pour compléter de manière optimale les informations que réclamait notre programme de recherche. En outre, cette année, un nouveau secteur a été ouvert, dans la zone des fortifications ouest, initialement confié à notre directrice-adjointe turque, mais que nous avons repris à notre compte' ${ }^{1}$.
D'autre part, l'équipe romaine' que forment habituellement Stéphane Lebreton, Isabelle Chalier et Françoise Kirner n'ayant pu nous rejoindre sur le terrain, nous n'avons donc pas pu ouvrir les secteurs qu'il était prévu initialement de leur confier dans les couches supérieures du chantier IV2.

En dehors de la fouille proprement dite, nous avons réalisé un certain nombre de consolidations de murs et augmenté la protection de la tour nordest du chantier ouest. La signalétique a fait aussi l'objet des attentions de la mission.

\section{OPERATION CHANTIER II NORD}

Ce secteur était placé, comme les années précédentes, sous la responsabilité d'Aksel Tibet.

Les travaux sur le chantier II ont été conduits en 2012 principalement dans le sondage profond en H07. Parallèlement à cela, un second sondage de contrôle a été ouvert à l'intérieur de la 'Maison aux pithoi' en H07-I07 et quelques travaux de consolidation

*) UMR 7044, Strasbourg.

**) IFEA-USR 3131, Istanbul.

1) Nous avons eu en effet à déplorer la défection de notre directrice-adjointe, Madame Olcay Zengin Koşan, qui n'a pas pu réellement participer à nos travaux pour des raisons d'ordre privé. Elle devait en particulier s'occuper du dossier du relevé géomagnétique que nous n'avons pas pu entreprendre de toute façon faute de moyens suffisants. Nous n'abandonnons naturellement pas ce projet de relevé géomagnétique qui concerne en priorité la zone ouest ainsi que celle du centre sud du site, où serait sans doute à retrouver une porte de la ville, permettant un accès direct à la rivière.

Nos crédits provenaient pour l'essentiel, comme lors des années précédentes, du Ministère français des Affaires Etrangères.

2) Les dossiers habituels de ces membres ont été malencontreusement égarés quelque part dans le circuit administratif entre Strasbourg et Ankara. Le calendrier des procédures d'une part, celui des opérations de la mission d'autre part, n'ont pas permis leur participation. En compensation, la mission prévuc pour 2013 devrait concentrer ses efforts de fouille sur les objectifs initialement envisagés par l' 'équipe romaine'.

Autour du directeur, la mission comportait comme archéologues Aksel Tibet, responsable des publications à l'IFEA d'Istanbul, et le Dr. Julie Patrier, post-doctorante, UMR 7044, Strasbourg, et boursière à la Eberhards Karls Universität, Tübingen. Participaient également à la fouille comme archéologues-stagiaires deux doctorantes strasbourgeoises, Hiba Bizreh et Sarah Dermech.

Françoise Laroche-Traunecker, architecte-archéologue de l'UMR 7044 avait, comme les années précédentes, la lourde responsabilité des relevés d'architecture et des divers travaux de consolidation et de mise en valeur des vestiges.

Alexis Beyer et Ayşe Özkan étaient en charge du dessin du matériel archéologique. La réalisation des panneaux didactiques a en outre bénéficié des efforts d'Alexis Beyer.

La mission a bénéficé de l'aide bienveillante et de la compréhension de son Temsilci, en l'occurrence de M. Vahap Kaya, du Musée des Civilisations anatoliennes d'Ankara.

Comme les années précédentes, l'IFEA d'Istanbul nous a prêté l'indispensable véhicule qui rend toujours de multiples services. Que son nouvcau dirccteur, M. Jean-François Pćrouse, en soit vivement remercié. 


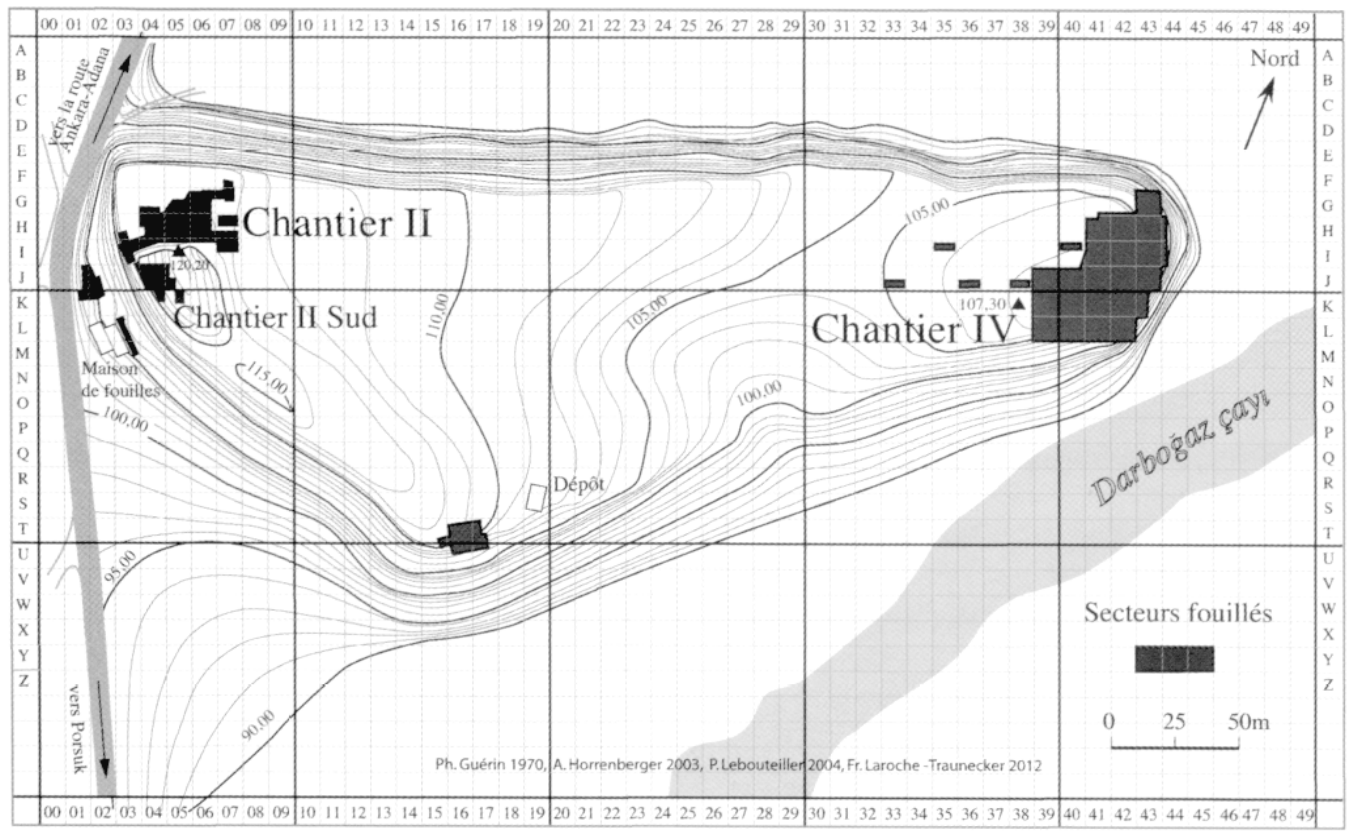

Fig. 1 : Plan topographique du site avec localisation des chantiers.

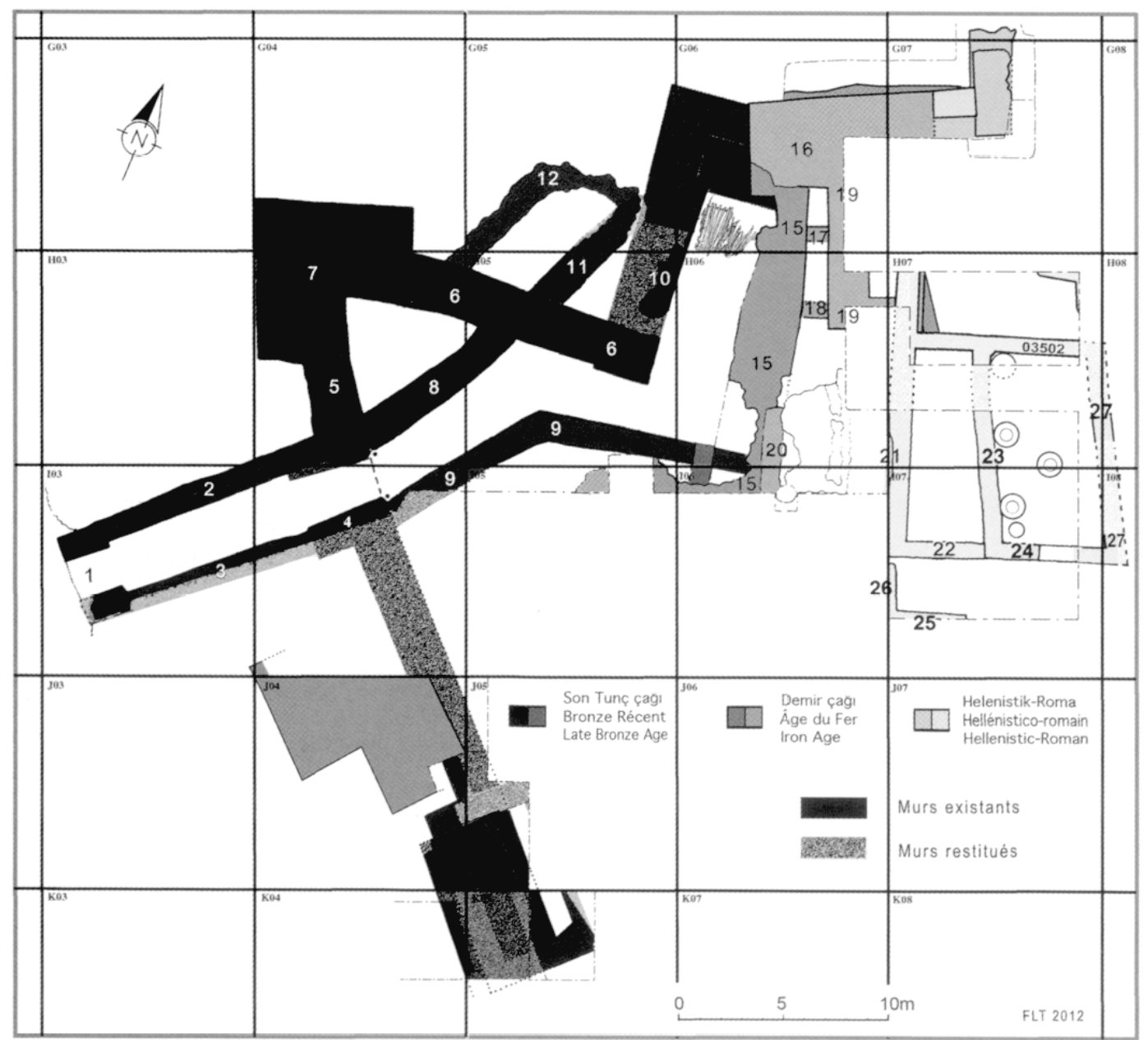

Fig. 2 : Chantier II. Plan schématique (F. Laroche-Traunecker). 
ont été effectués à l'intérieur de la 'poterne' et contre la tour Nord des fortifications du Bronze Récent en G06 (Fig. 2).

L'attribution à une période donnéc des phases par le biais du matériel qui leur est associé peut être assez délicate lorsqu'on travaille dans un sondage relativement exigu où il est difficile de repérer des sols bien établis. L'apparition inattendue dans la progression de la fouille d'une trouvaille diagnostique peut causer la révision des attributions qui avaient été faites les années précédentes. Ce fut justement le cas dans notre sondage profond en $\mathrm{H} 07$. La découverte cette année de deux briques circulaires de pilette d'hypocauste utilisées pour caler le fond du pithos 03516, une des jarres entreposées dans la 'Maison aux pithoi', nous a amené à changer la datation de cet édifice. Alors que dans les chroniques précédentes nous l'avions daté de la phase la plus récente de la période hellénistique (Porsuk IIa), nous pensons, à la suite de cette découverte, qu'il devrait plutôt appartenir à la phase la plus ancienne du niveau romain (Porsuk Ic). Ce changement a entraîné la modification de l'apellation des phases du niveau II (hellénistique) : ainsi, la phase IIb est devenue IIa, la phase IIc est devenue IIb, etc. Par ailleurs, il nous a paru utile de tenter de faire une distinction entre les différentes phases du niveau romain : la phase la plus récente dont la plupart des traces est disparue par l'action du bulldozer cn 1962 a été nommée Ia. La phase Ib qui lui est antérieure est représentée par la cuve 03504 , la surface 03505 , les murs 03512 et 03513 . La phase Ic qui est la phase la plus ancienne du niveau romain correspond à la construction de la 'Maison aux pithoi' et est représentée dans le sondage par les murs 03502/03508, 03511,03558 et 03559 , les jarres 03515 et 03516 et la bassine ou le compartiment 03517 . Pour empêcher toute confusion, nous avons décidé d'indiquer dans un tableau récapitulatif les attributions anciennes et nouvelles des principales unités de fouille (Tableau 1).

\section{I.1. Sondage profond en $\mathrm{HO} 7$}

Les travaux dans ce sondage de $4 \mathrm{~m} \times 8 \mathrm{~m}$, situé dans la moitié nord du carré H07, avaient été initiés en $2008^{3}$ et poursuivis en $2009^{4}$ et $2011^{5}$ avec le but d'établir la séquence stratigraphique complète du
Tableau 1 : Attributions anciennes et nouvelles des principales UF dans le sondage profond en H07.

\begin{tabular}{|c|c|c|c|}
\hline UF & Nature & $\begin{array}{c}\text { Attr. } \\
\text { ancienne }\end{array}$ & $\begin{array}{c}\text { Attr. } \\
\text { nouvelle }\end{array}$ \\
\hline 03502 & Mur & Ila & Ic \\
\hline 03504 & Cuve & I & $\mathrm{Ib}$ \\
\hline 03505 & Surface & I & $\mathrm{Ib}$ \\
\hline 03507 & Mur & $\mathrm{IIb}$ & IIa \\
\hline 03508 & Mur & IIa & Ic \\
\hline 03511 & Mur & Пla & Ic \\
\hline 03512 & Mur & I & $\mathrm{Ib}$ \\
\hline 03513 & Mur & $\mathrm{I}$ & $\mathrm{Ib}$ \\
\hline 03515 & Jarre & IIa & Ic \\
\hline 03516 & Jarre & IIa & Ic \\
\hline 03517 & $\begin{array}{l}\text { bassine ou } \\
\text { compariment }\end{array}$ & I & Ic \\
\hline 03520 & Podium & $\mathrm{IIb}$ & IIa \\
\hline 03521 & Four & $\mathrm{IIb}$ & $\mathrm{IIa}$ \\
\hline 03522 & Sol & $\mathrm{IIb}$ & IIa \\
\hline 03523 & Mur & $\mathrm{IIb}$ & IIa \\
\hline 03525 & Dallage & $\mathrm{IIb}$ & IIa \\
\hline 03529 & Sol & $\mathrm{IIb}$ & IIa \\
\hline 03532 & Structure de pierres & IIc & $\mathrm{IIb}$ \\
\hline 03533 & Mur & IIIa & IIIa \\
\hline 03534 & Four & IId & IIc \\
\hline 03535 & Couche gypseuse & IIc & $\mathrm{Ilb}$ \\
\hline 03538 & Fosse & IIc ou IIb & IIb ou IIa \\
\hline 03541 & Couche gypseuse & IIc & $\mathrm{IIb}$ \\
\hline 03542 & Eboulis & IIIa & IIIa \\
\hline 03544 & Eboulis & IIIa & IIIa \\
\hline 03545 & Massif de pierres & IId & IIc \\
\hline 03549 & Eboulis & $\mathrm{IIIb}$ & $\mathrm{IIIb}$ \\
\hline 03550 & Mur & IIIc & IIIc \\
\hline 03551 & Sol & $\mathrm{IIIb}$ & $\mathrm{IIIb}$ \\
\hline 03555 & Eboulis & IIIc & IIIc \\
\hline 03556 & Eboulis & IIIc & IIIc \\
\hline 03558 & Mur & I & Ic \\
\hline 03559 & Mur & IIa & Ic \\
\hline
\end{tabular}

site dans un secteur relativement à l'écart des fortifications. En 2012 nous avons poursuivi la fouille dans la moitié orientale du sondage pour atteindre l'alandier du four 03534 de la phase IIc qui avait été découvert en $2011^{6}$. Pour ce faire nous avons démonté le mur 03502 (et son extension vers l'Ouest 03508) appartenant à la phase Ic qui constitue la limite nord de la "Maison aux pithoi" fouillée en grande 


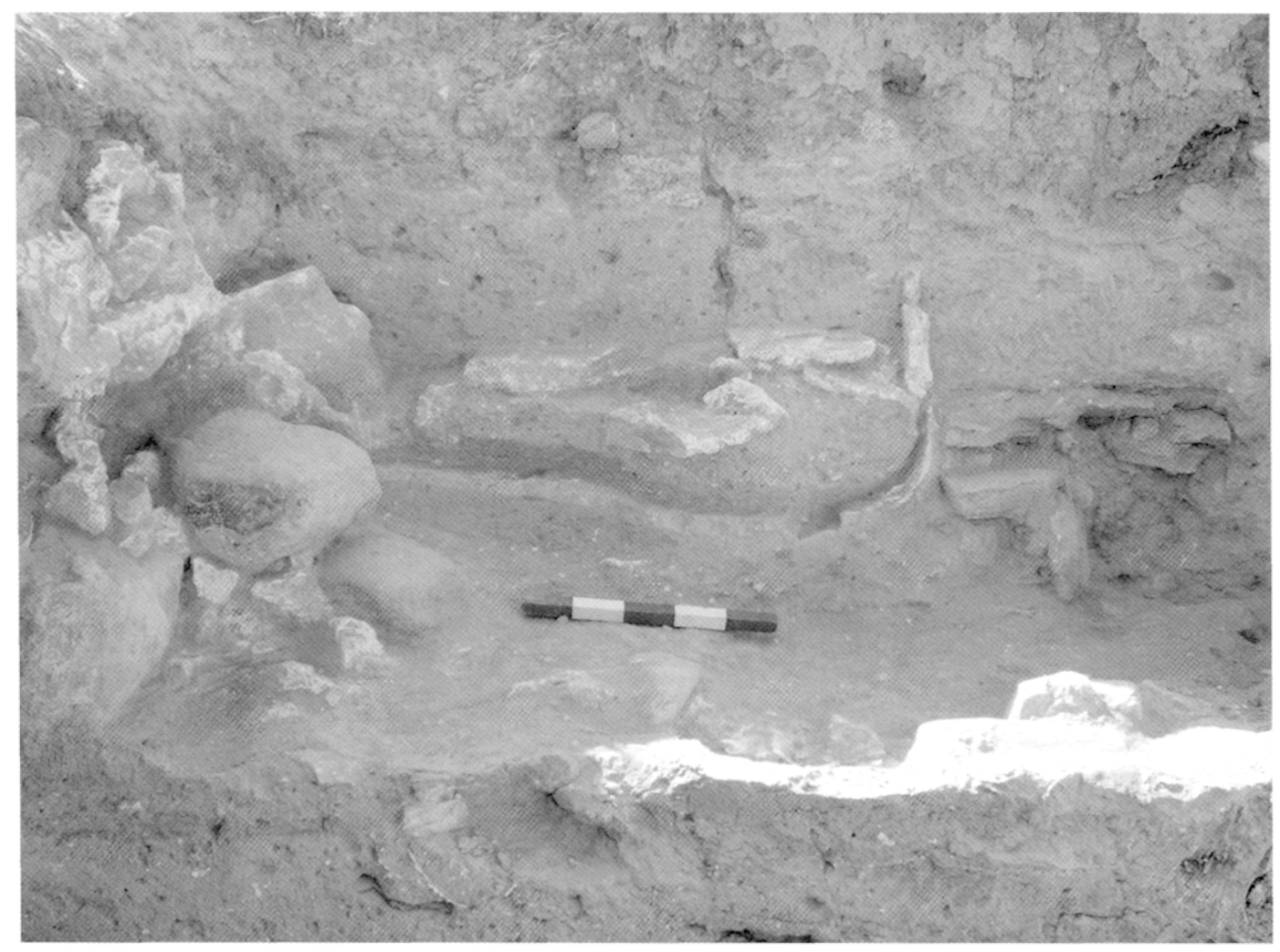

Fig. 3 : Chantier II Nord. Berme sud du sondage profond en H07 avec, en coupe, l'installation 03517.

partie dans les années 1970. Le démontage du mur 03502 a fait apparaître en coupe dans la berme sud du sondage une installation (03517) partiellement repérée en 2009 qui avait été alors interprétée comme un bassin et datée de la phase $I^{8}$ (Fig. 3). Comme elle reste en grande partie au-delà des limites du sondage, nous ne savons toujours pas sa nature avec précision : il s'agit d'un enduit de chaux épais de 4 à $5 \mathrm{~cm}$ appliqué sur la face sud du mur 03502 . A l'Ouest, cet enduit tourne vers le Sud contre un mur de plaques de grès et de pisé orienté nord/sud qui pénètre à l'intérieur de la berme. Une ligne blanche horizontale observée en coupe dans la berme semble constituer le fond de cette installation. Plusieurs fragments d'enduit tombés vraisemblablement des parties hautes se trouvent dans la terre qui la remplit. S'agit-il d'un bassin de plan quadrangulaire ajouté postérieurement comme supposé en 2010 ou bien tout simplement d'une petite pièce (ou plutôt d'une cellule) de la "Maison aux pithoi" (Fig. 4) dont les parois et le sol étaient entièrement recouverts d'un enduit ? La découverte de quelques fragments d'enduit similaire dans le sondage ouvert à l'intérieur de la maison un peu plus à l'Ouest en H07-I07 (UF
03574) semble nous faire pencher plutôt vers cette seconde hypothèse. Par ailleurs, la situation de la ligne d'enduit horizontale - qui serait donc plutôt un sol - par rapport au fond du pithos 03516 visible dans la berme fait penser que ces deux pourraient être contemporains et appartenir à la phase Ic.

La phase IIa est représentée par un dallage de plaques de grès $(03525)$ - démonté en début de la campagne 2012 -, délimité par les murs 03523 orienté nord/sud et 03561 orienté est/ouest. De même, le podium 03520 et le four 03521 associés à un sol en terre battue (03522) appartiennent aussi à cette phase. L'ensemble de ces éléments avait été déjà repéré en $2009^{9}$. Les travaux de 2012 nous ont permis de compléter nos connaissances sur cette phase. La découverte d'une grande dalle dans l'angle sud-est du sondage a montré que le dallage 03525 continuait au Sud du mur 03561, du moins dans sa partie orientale (Fig. 5). Nous avions observé en 2009 que le podium 03520 et le four 03521 passaient au-dessous de l'assise de fondation du mur 03502 de la phase Ic. Le démontage de ce dernier nous a permis de voir que ces deux installations sont en relation avec un mur de la phase IIa (03572) qui se 


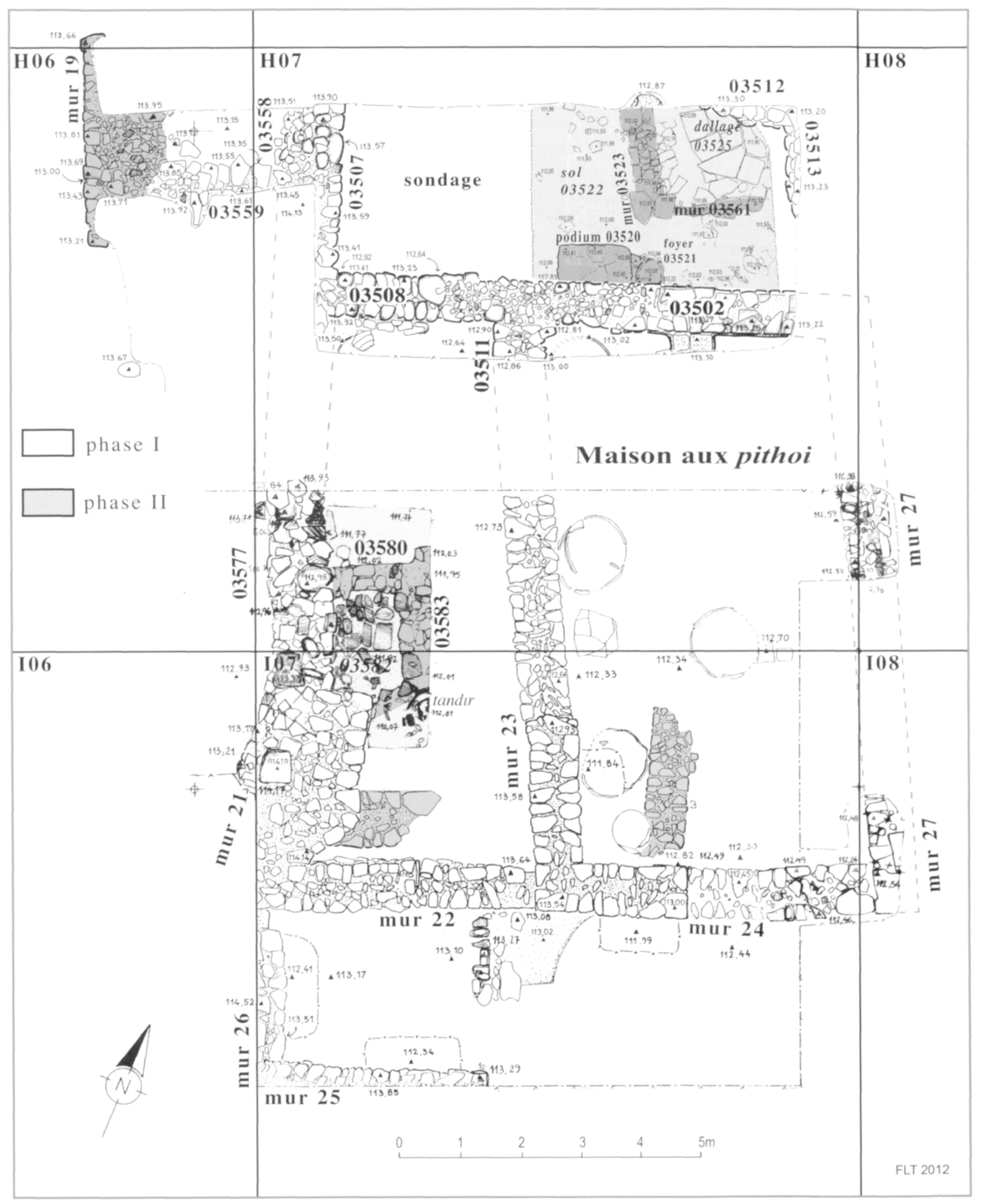

Fig. 4 : Chantier II Nord. H-I 06-07. Plan des des phases Ic et IIa (F. Laroche-Traunecker). 
trouve sous le mur 03502, un peu en retrait par rapport à celui-ci et d'orientation légèrement différente - d'une dizaine de degrés vers le Sud (Fig. 6). Il s'agit d'un mur construit essentiellement avec des blocs de gypse de taille moyenne (en parement) et petite (à l'intérieur) disposés en assises irrégulières en parement. Son parement sud se trouve en dehors de la limite sud du sondage. Les gros galets de l'assise de fondation du mur 03502 sont posés directement sur les blocs de sommet du mur 03572, au moins dans la partie est du sondage. Son assise de fondation présente un pendage ascendant de l'Est vers l'Ouest (111,12 m à l'Est, 111,64 m à l'Ouest). Le mur 03572 est donc trop profondément fondé pour appartenir à la phase IIa (le dallage 03525 est situé à $112 \mathrm{~m}$ en moyenne). Il a été construit très probablement à la phase antérieure (IIb) et réutilisé à la phase IIa où il fonctionne avec le dallage 03525 , le sol 03522 , les murs 03523 et 03561 , le four 03521 et le podium 03520 .

A la phase IIb qui correspond donc à la construction du mur 03572 le long de la berme sud du sondage appartiennent aussi un aménagement de type plate-forme (03563) et une surface gypseuse (03564) qui semble lui être associée (Fig. 7). La "plate-forme" 03563 dégagée à l'Est du sondage est faite de blocs de gypse de taille moyenne et petite et de quelques galets de taille moyenne disposés en 2 assises irrégulières de façon à former un rectangle de $2 \mathrm{~m} \times 1,50 \mathrm{~m}$ environ dont la surface supérieure (située à 111,72 m en moyenne) n'est pas régulière. Elle semble se prolonger vers l'Est au-delà de la limite du sondage. Sa fonction n'a pas pu être définie mais elle rappelle par son irrégularité et son aspect désorganisé les aménagements (03532) appartenant à la même phase mis au jour en 2011 dans la partie ouest du sondage ${ }^{10}$. Comme c'était le cas dans la moitié ouest $(03535,03541)$, cet aménagement est ici aussi associé à une surface (03564) très évanescente caractérisée par une couche plus ou moins épaisse de fines particules et de cailloutis de gypse que l'on observe par endroits et dont l'altitude varie de $111,38 \mathrm{~m}$ à $111,43 \mathrm{~m}$.

La phase IIc, qui correspond à la construction d'un four de plan rectangulaire de grandes dimensions (03534) dégagé en 2011 dans la moitié ouest du

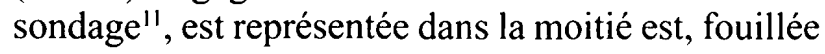
cette année, par une surface argileuse irrégulière (03567) située à $110,68 / 110,72 \mathrm{~m}$ environ qui a pu être suivie au centre du secteur fouillé (Fig. 8). Cette surface est à mettre en relation avec un cailloutis ou radier de gypse (03568) situé à $110,62 / 110,95 \mathrm{~m}$, qui a été observé sur la presque totalité de la zone fouillée avec plus ou moins de densité (Fig. 9). L'alandier 03570 du four 03534 (Fig. 10), dont les vestiges ont été mis au jour cette année dans la partie ouest de la zone fouillée, semble aussi fonctionner avec les surfaces 03567 et 03568 . Celles-ci formaient très probablement le sol d'un espace ouvert qui se trouvait devant le four (c'est-àdire à l'Est) au moment de son fonctionnement et par où l'on accédait à l'alandier 03570 qui était en partie souterrain. Ce dernier, adossé au four, se présente sous forme d'un canal voûté en berceau (Fig. 11) d'une largeur de près de $1 \mathrm{~m}$ qui se prolonge dans la masse du mur oriental du four pour se raccorder à l'Ouest au conduit médian de la chambre de chauffe (Fig. 12) mis au jour en 2011 (Fig. 13). Délimité au Sud et au Nord par un muret de pierres recouvert d'un enduit de terre, le canal de l'alandier présente un pendage ascendant vers l'Est (Fig. 14) jusqu'à une ouverture plus ou moins rectangulaire en forme de puits qui servait très probablement à introduire le combustible et à évacuer les cendres (Fig. 15-16). Des couches successives de cendres dont la plus haute (03575) culmine à $111,10 \mathrm{~m}$, ont été mises au jour dans la partie sud du sondage. Il s'agit sans doule des cendres évacuées de l'alandier. L'analyse au ${ }^{14} \mathrm{C}$ d'un fragment de charbon de bois recueilli en 2011 dans le conduit médian du four 3534 a donné une date autour des $I^{\mathrm{c}}-\mathrm{III}^{\mathrm{e}} \mathrm{s}$. av. J.-C. ${ }^{12}$. Cette datation a été confirmée cette année par la découverte dans les décombres de l'alandier 03570 de trois monnaies d'argent qui étaient collées ensemble. Il s'agit d'une tétradrachme et de deux drachmes aux types d'Alexandre le Grand avec au droit la tête d'Héraclès imberbe à droite, couverte de la peau de lion et au revers Zeus trônant vers la gauche, les jambes croisées, tenant un sceptre de la main gauche, le bras droit tendu, soutenant dans la main un aigle à droite (Fig. 18-19). La frappe de ce type de monnaie d'argent très célèbre a été initiée par Alexandre le Grand à la suite de la victoire d'Issos en $333 \mathrm{av}$. J.-C., et poursuivie après sa mort par les Diadoques au cours du $\mathrm{III}^{\mathrm{e}} \mathrm{s}$. av. J.-C. ${ }^{13}$. Plusieurs villes d'Asie Mineure ont continué à les frapper jusqu'au milieu du $\mathrm{II}^{\circ} \mathrm{s}$. av. J.-C. et en ce qui concerne la région pontique jusqu'au

10) Beyer et al. $2012: 171-180$ et Fig. 3 b, Fig. 5.

11) Beyer et al. $2012: 180-184$ et Fig. 6 à 11.

12) Rapport d'analyse de l'IFAO n'IFAO_0454 sur l'échantillon 2011-PKII.03534.2:354-291 BC cal $2 \sigma$.

13) Metcalf $2012: 178-181$. Vuir aussi Augé, Davesne et Ergeç 1997. 


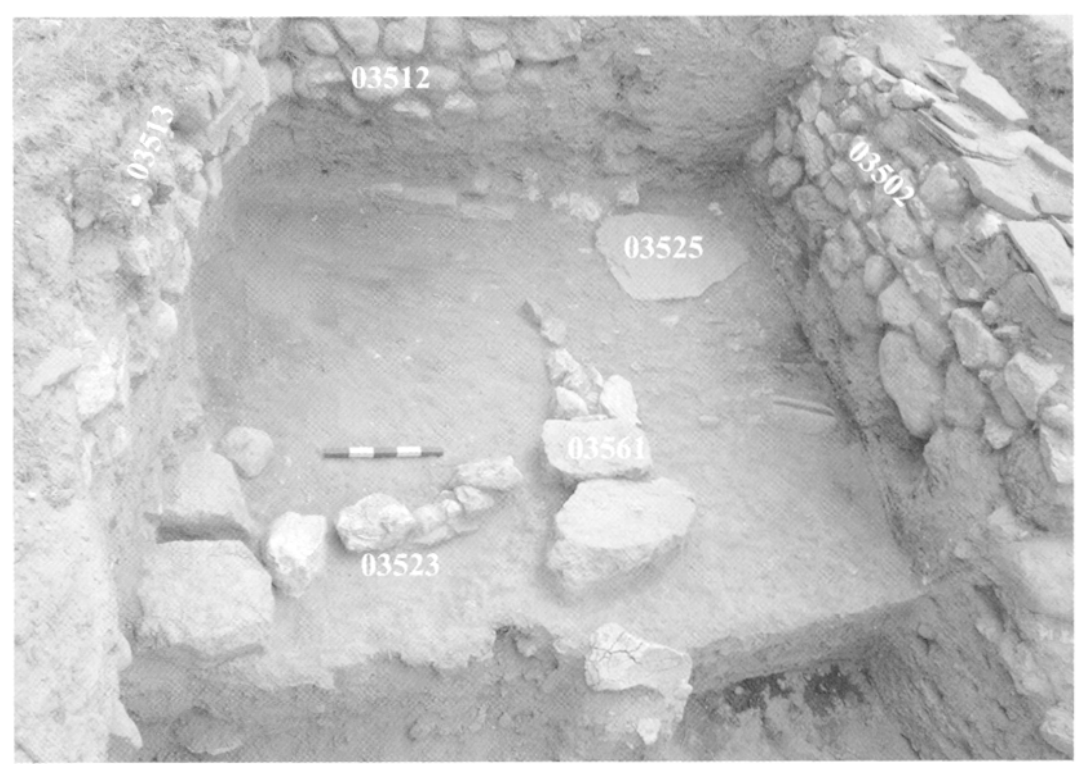

Fig. 5 : Chantier II Nord. H07. Vue du sondage vers l'Est avec à droite le mur 03502, à gauche au fond les murs 03512 et 03513 de la phase Ic ; au centre, les murs 03523 et 03561 et une des dalles du dallage 03525 de la phase IIa.

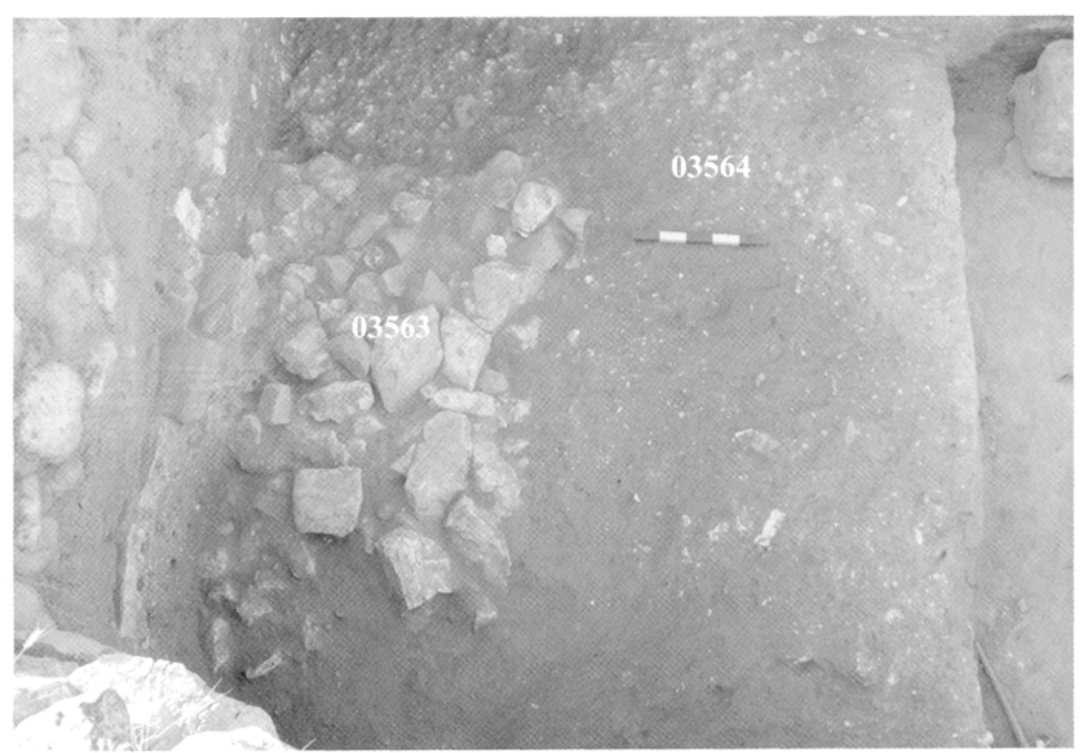

Fig. 7 : Chantier II Nord. H07. Plate-forme 03563 et surface gypseuse 03564 de la phase IIb. Vue d'en haut. On aperçoit à gauche dans la paroi est du sondage le mur 03512 de la phase Ic et ce qui reste du dallage 03525 de la phase IIa.

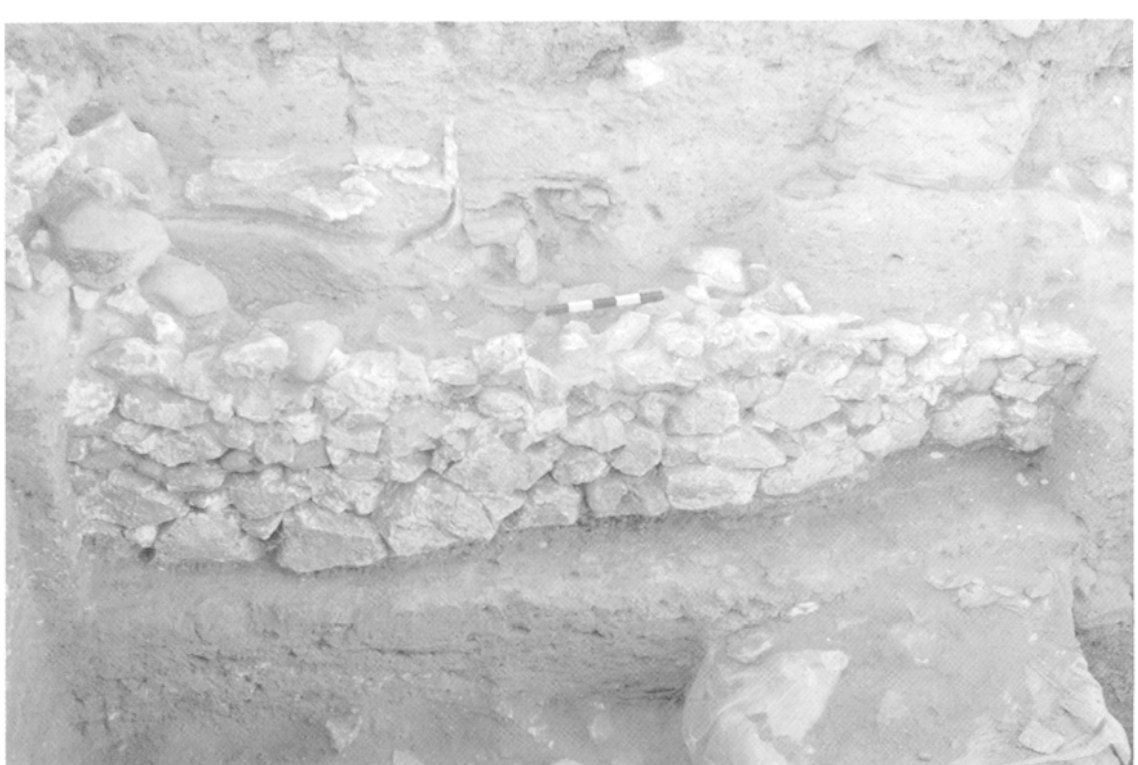

Fig. 6 : Chantier II Nord. H07. Mur 03572 construit à la phase IIb et réutilisé à la phase IIa. Vue vers le Sud. On aperçoit à l'extrême gauche les pierres du mur 03502 démonté de la phase Ic.

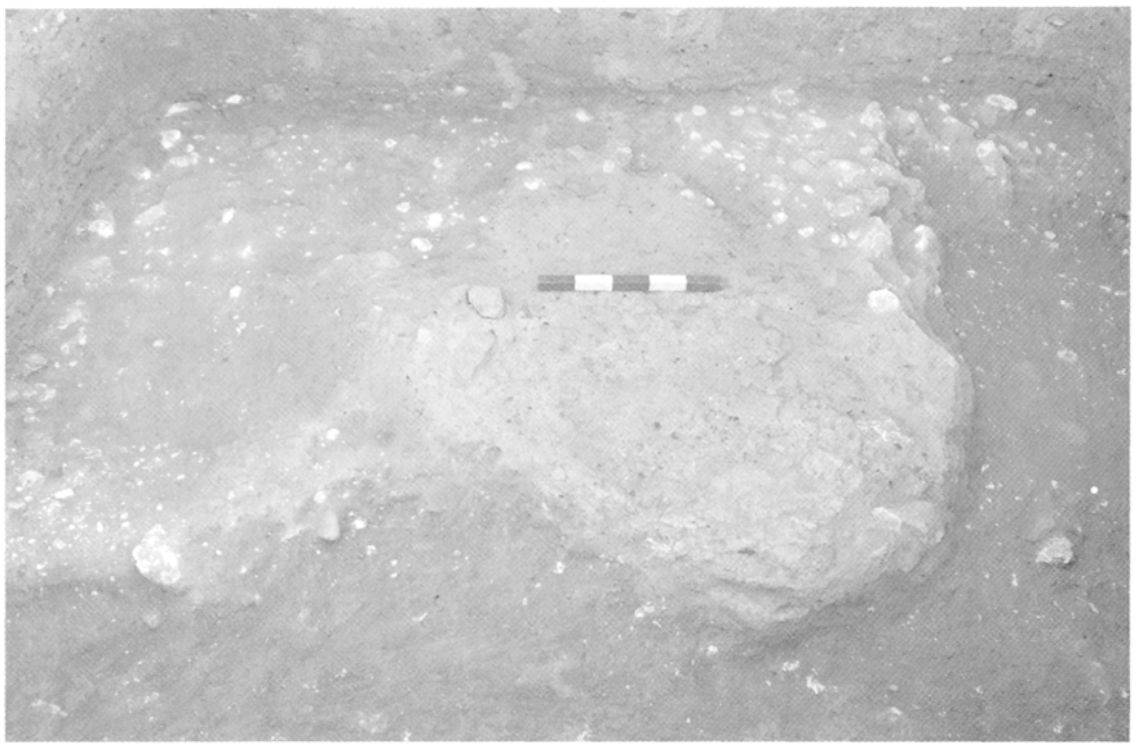

Fig. 8 : Chantier II Nord. H07. Surface argileuse 03567 de la phase IIc. Vue d'en haut. 


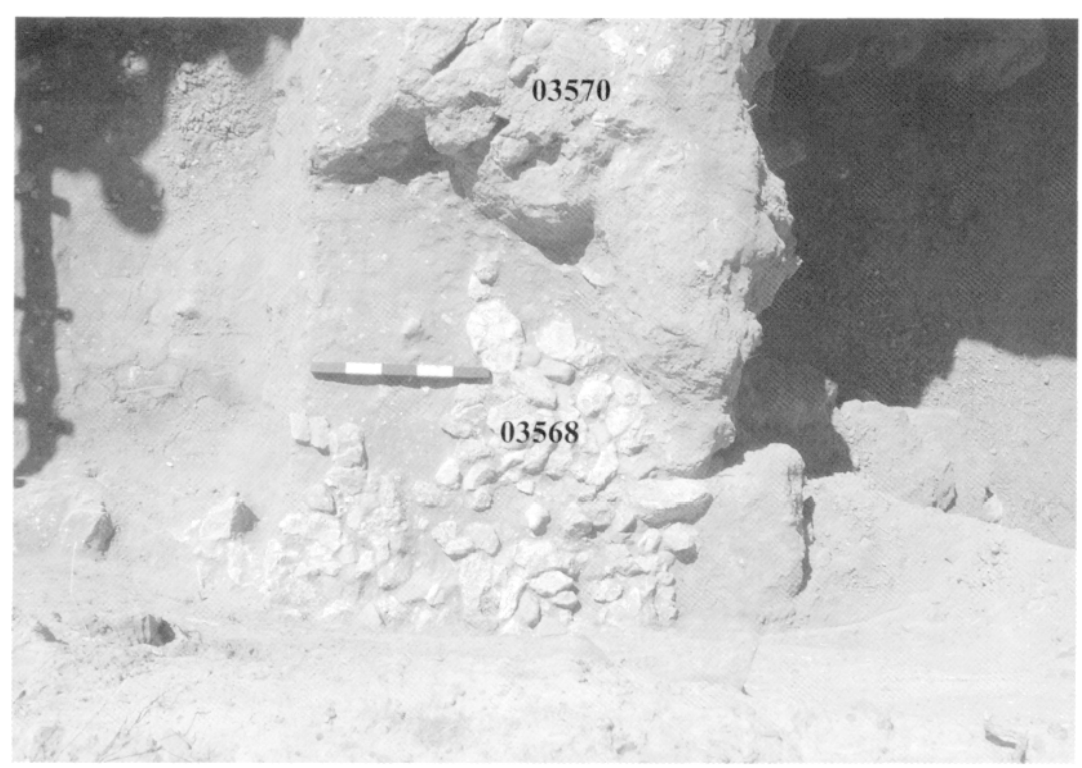

Fig. 9 : Chantier II Nord. H07. Radier de cailloutis de gypse 03568 et éléments de couverture de l'alendier 03570 de la phase IIc. Vue d'en haut.

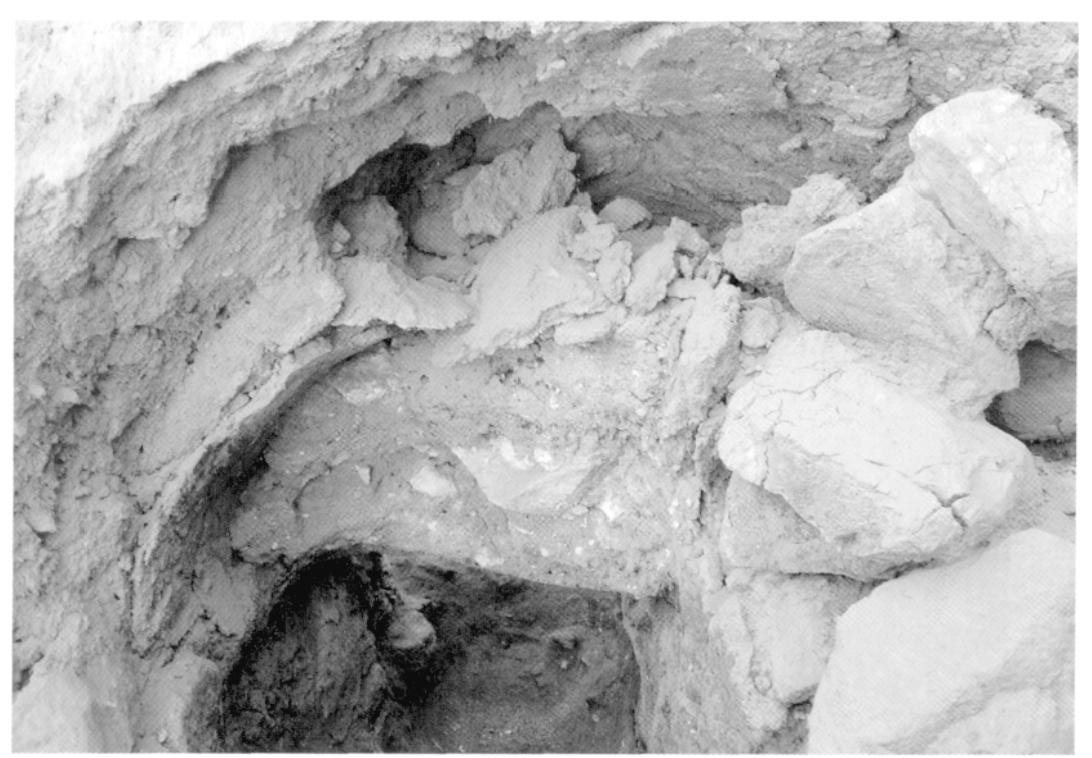

Fig. 11 : Chantier II Nord. H07. Canal voûté de l'alendier 03570. Vue vers l'Ouest.

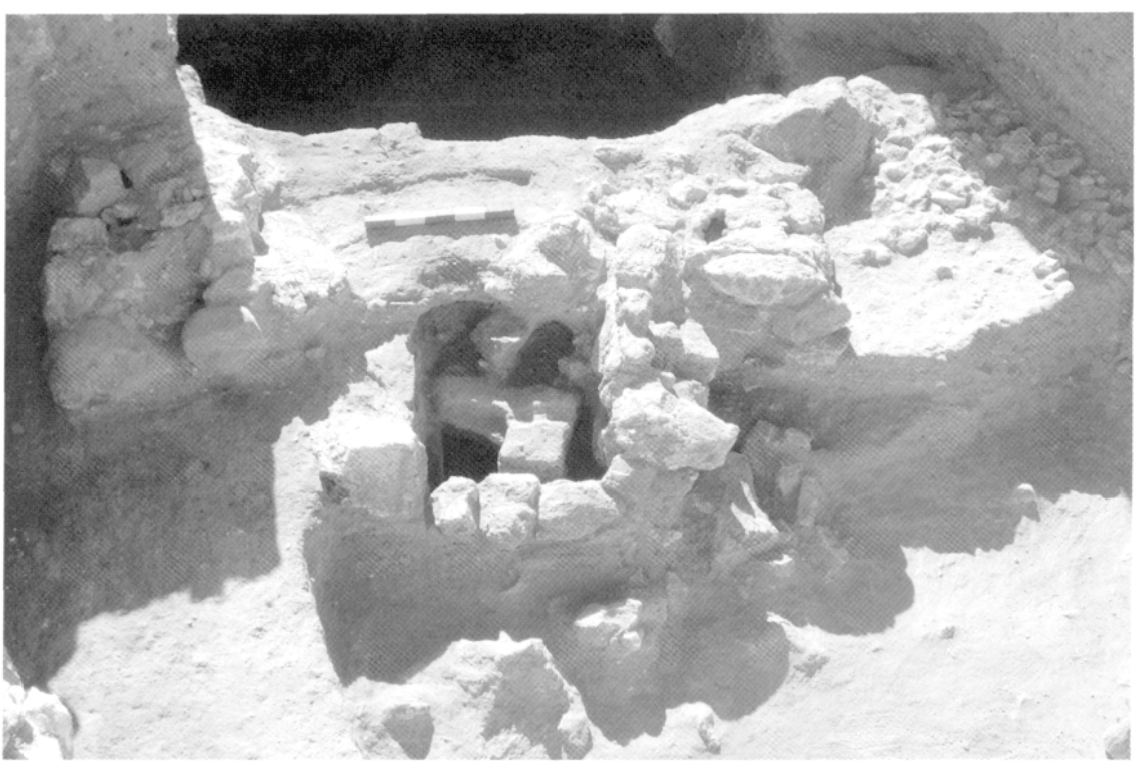

Fig. 10 : Chantier II Nord. H07. L'alendier 03570 du four 03534 de la phase IIc. Vue vers l'Ouest. On aperçoit à gauche l'infrastructure en pierres du mur sud du four.

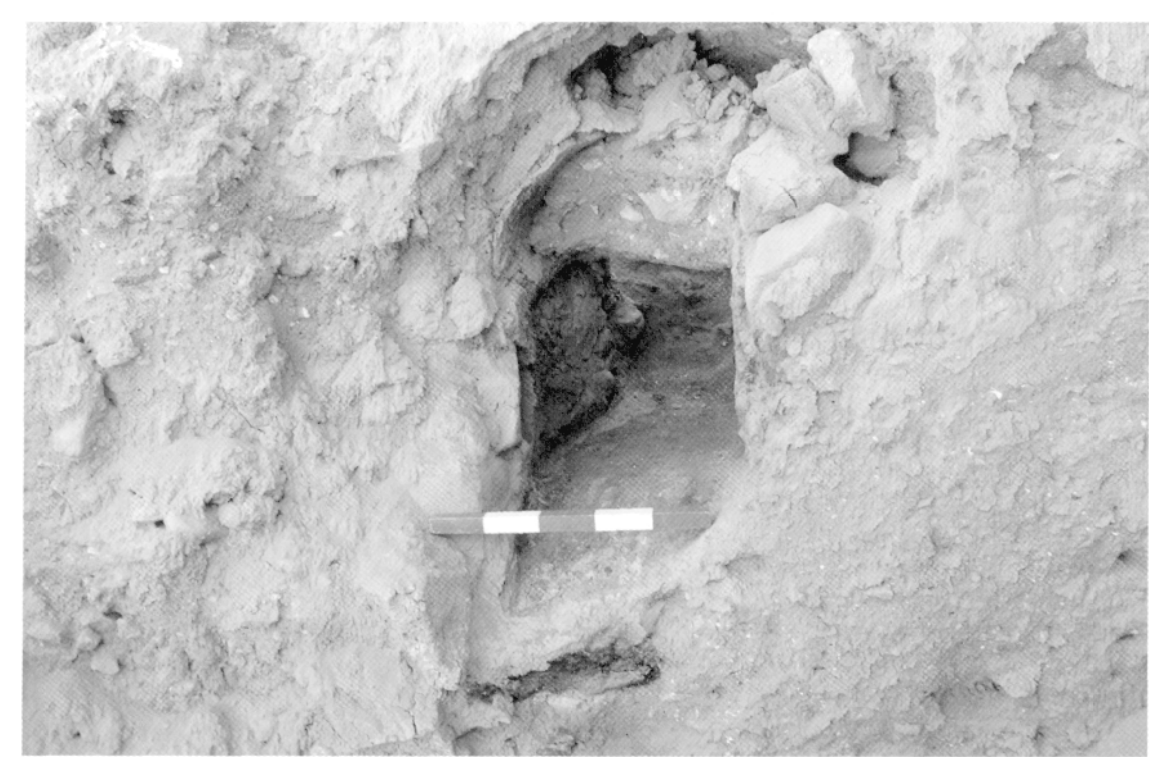

Fig. 12 : Chantier II Nord. H07. Ouverture de l'alendier 03570 vers le canal médian du four 03534 . Vue vers l'Est. 


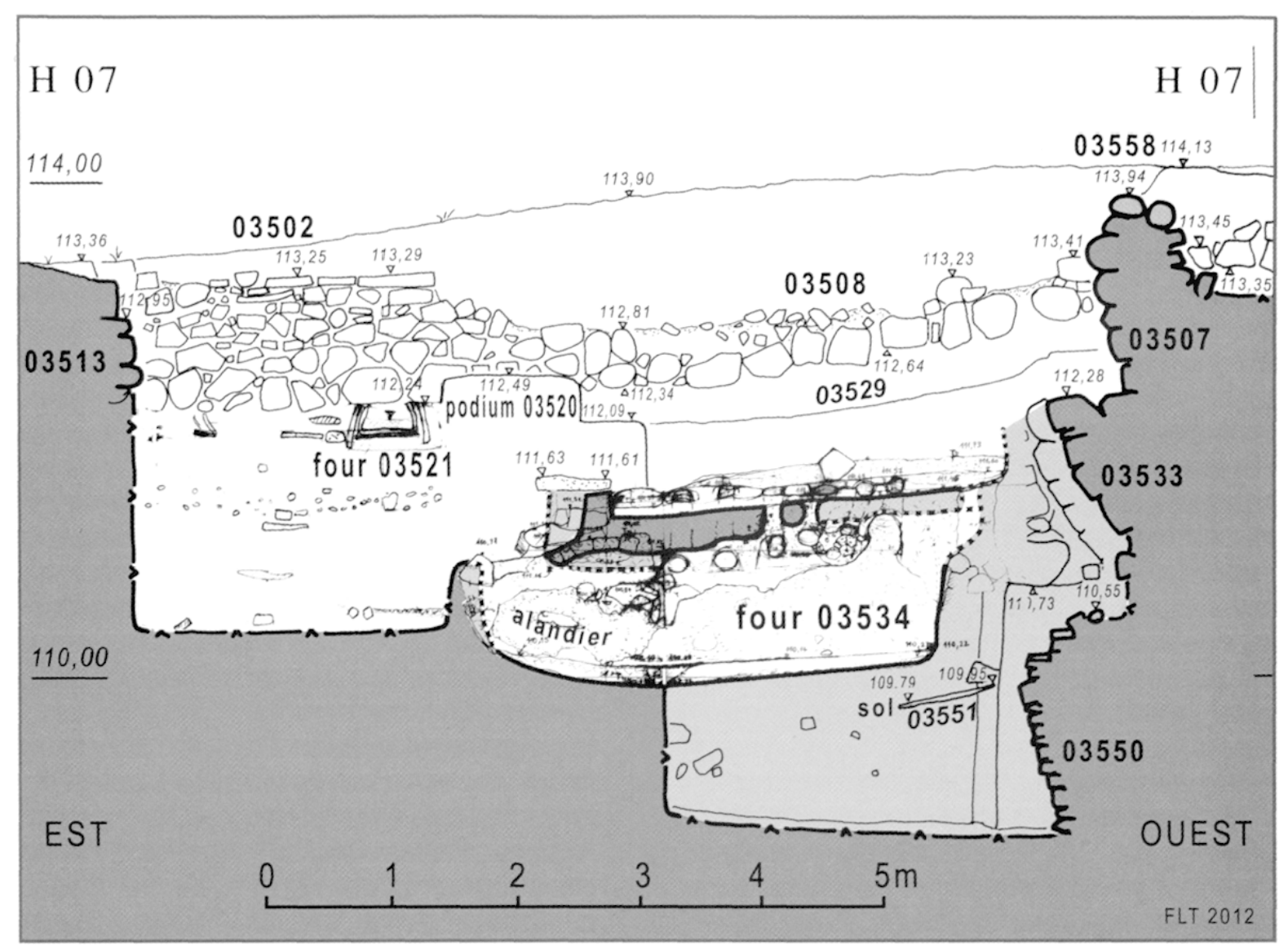

Fig. 13 : Chantier II Nord. H07. Coupe Est-Ouest du sondage profond (F. Laroche-Traunecker).

$\mathrm{I}^{\text {er }}$ S. av. J.-C. ${ }^{14}$. Le mauvais état de conservation des spécimens trouvés à Zeyve Höyük-Porsuk ne nous permet malheureusement pas de déterminer à première vue leur lieu de frappe, notamment à cause de la disparition de la légende et du monogramme qui nous permettraient de mieux les identifier.

La fouille de l'alandier 03570 a montré que le fond du canal comportait plusieurs couches successives de remplissage constituées de cendres et de terre compactées (Fig. 17) qui font penser à une longue durée d'utilisation. Mais la poursuite de la fouille a permis de déterminer que la structure qui venait d'être démontée correspondait à un état remanié de l'alandier. En effet, une dizaine de centimètres plus bas on trouve sur un lit de pierres une autre zone cendreuse 03587 (Fig. 20) de 1,50 m x 1,20 m environ qui, passant sous la paroi nord du canal de l'alandier, se prolonge vers la paroi nord du sondage où l'on aperçoit en coupe la trace d'un lit de pierres associé à une couche cendreuse similaire (Fig. 21). Ne pourrait-on pas penser à l'existence d'un premier état de l'alandier (Fig. 22b) qui, contrairement à l'alandier remanié qui est orienté est/ouest (Fig. 22a), donc perpendiculaire au four, serait installé le long du mur oriental du four avec une ouverture au Nord (comme d'ailleurs la chambre de cuisson du four 03534) en dehors des limites du sondage ? L'orientation de ce premier alandier parallèle au four aurait été changée à un moment donné pour une raison inconnue, en construisant un muret orienté est/ouest qui constitue la paroi nord du nouvel alandier qui est perpendiculaire au four. La poursuite de la fouille dans les prochaines campagnes devrait pouvoir fournir une réponse à cette question.

\section{I.2. Sondage en H07-I07 à l'intérieur de la 'Maison aux pithoi'}

Un nouveau sondage de $3 \mathrm{~m} \times 4 \mathrm{~m}$ a été ouvert en H07-I07 à l'intérieur de la 'Maison aux pithoi' principalement avec l'objectif de dégager le parement est du mur 21 et par là, déterminer son épaisseur réelle (Fig. 4). En effet ce mur - qui sera nommé ici 


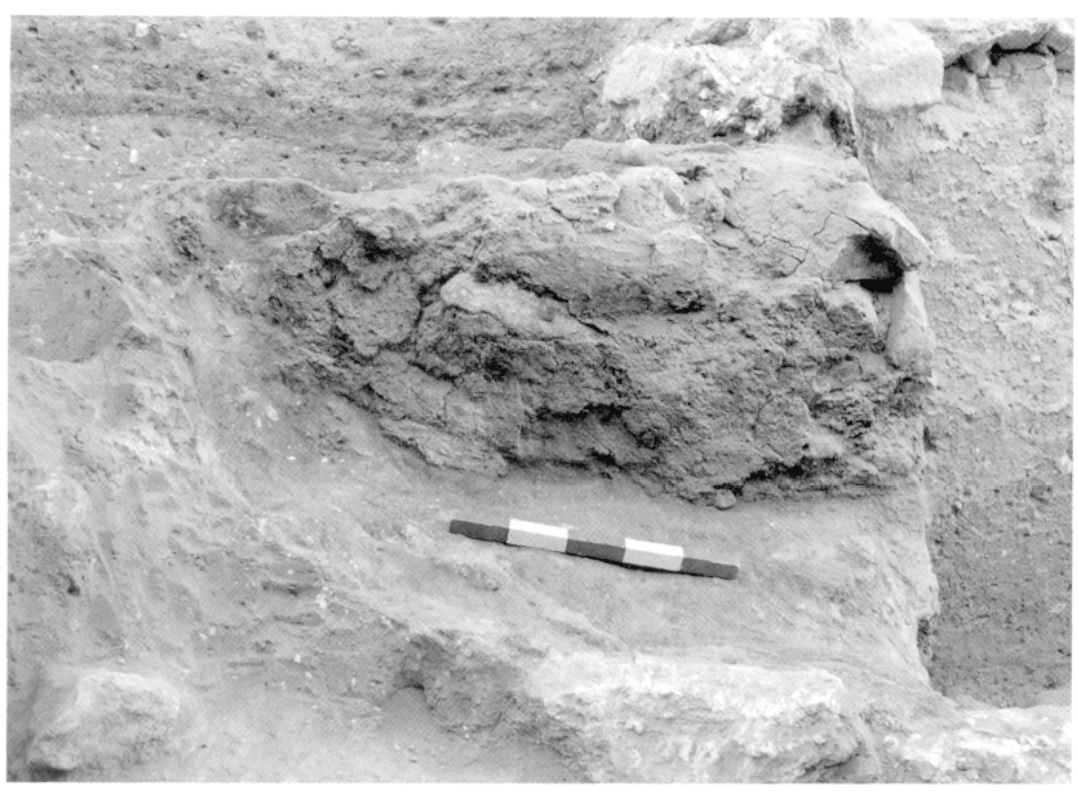

Fig. 14 : Chantier II Nord. H07. L'alendier 03570 en cours de démontage. Vue vers le Sud.

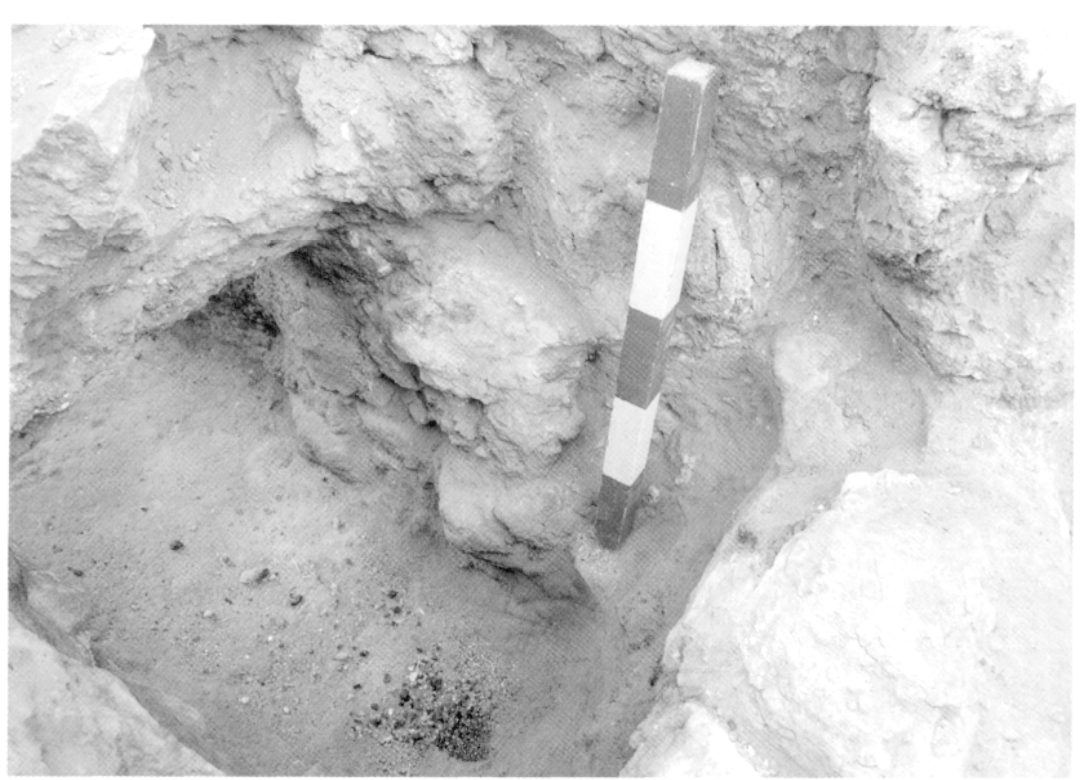

Fig. 16 : Chantier II Nord. H07. L'ouverture de l'alendier 03570. Vue d'en haut.

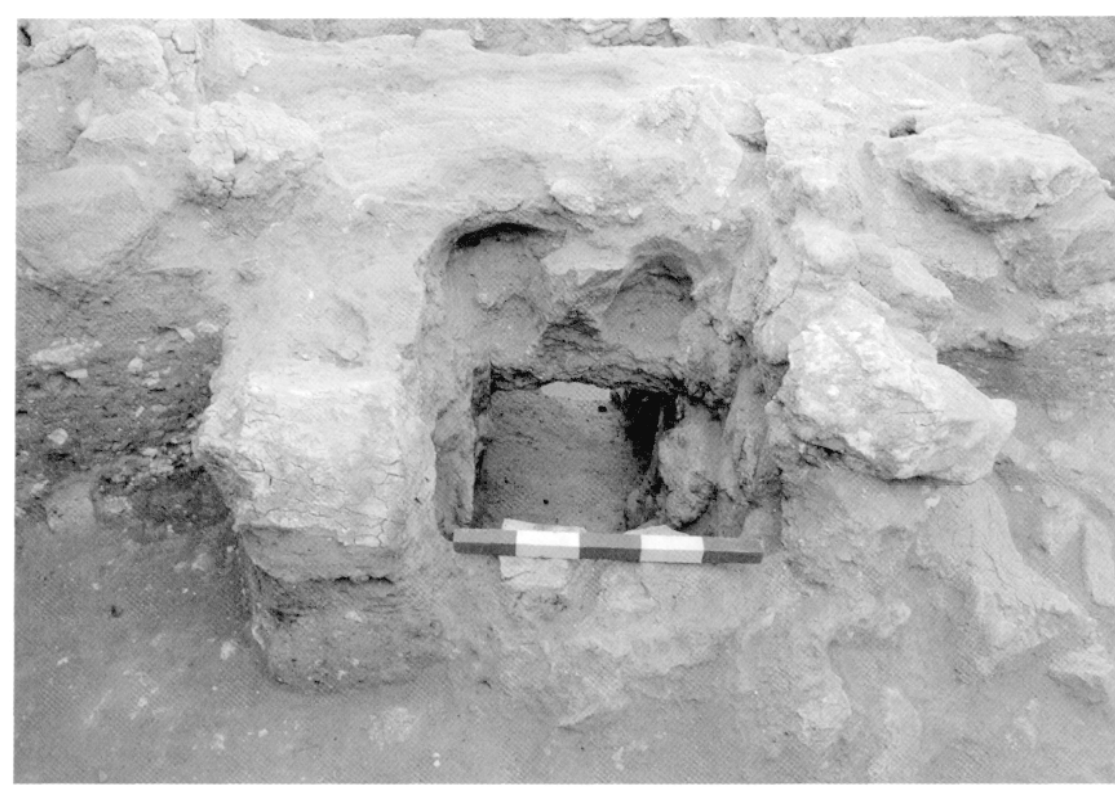

Fig. 15 : Chantier II Nord. H07. L'ouverture de l'alendier 03570. Vue vers l'Ouest.

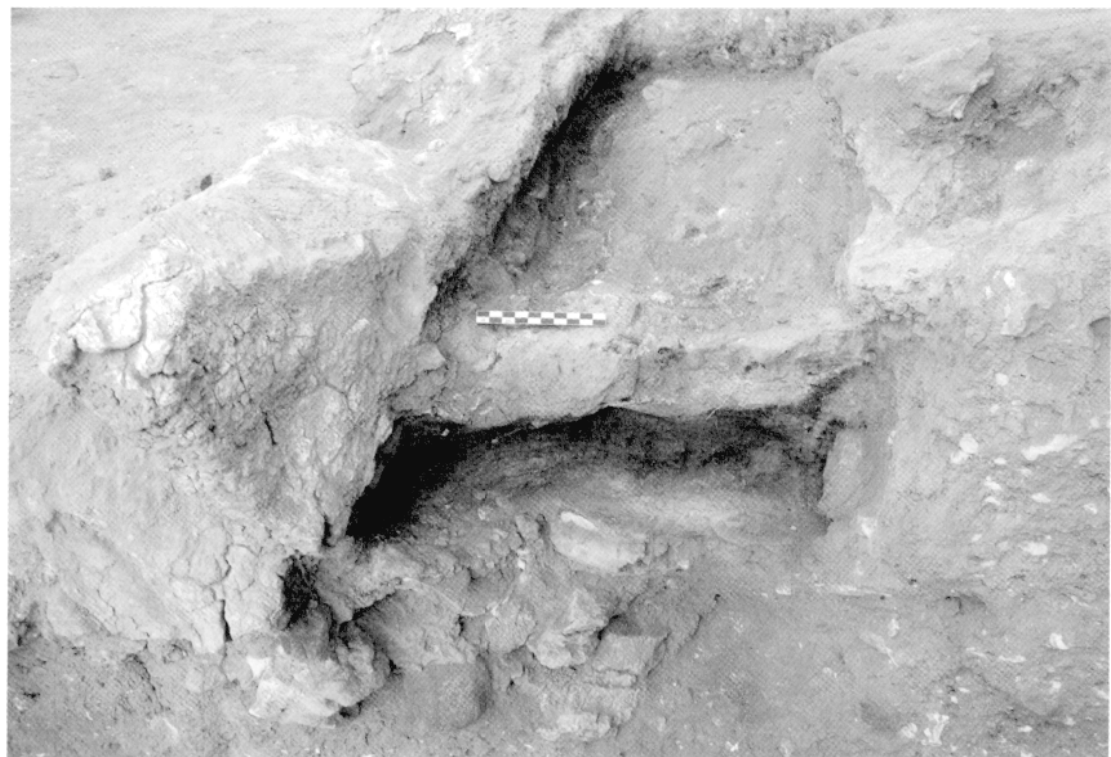

Fig. 17 : Chantier II Nord. H07. Remplissage du canal de l'alendier 03570. Vue vers l'Est. 


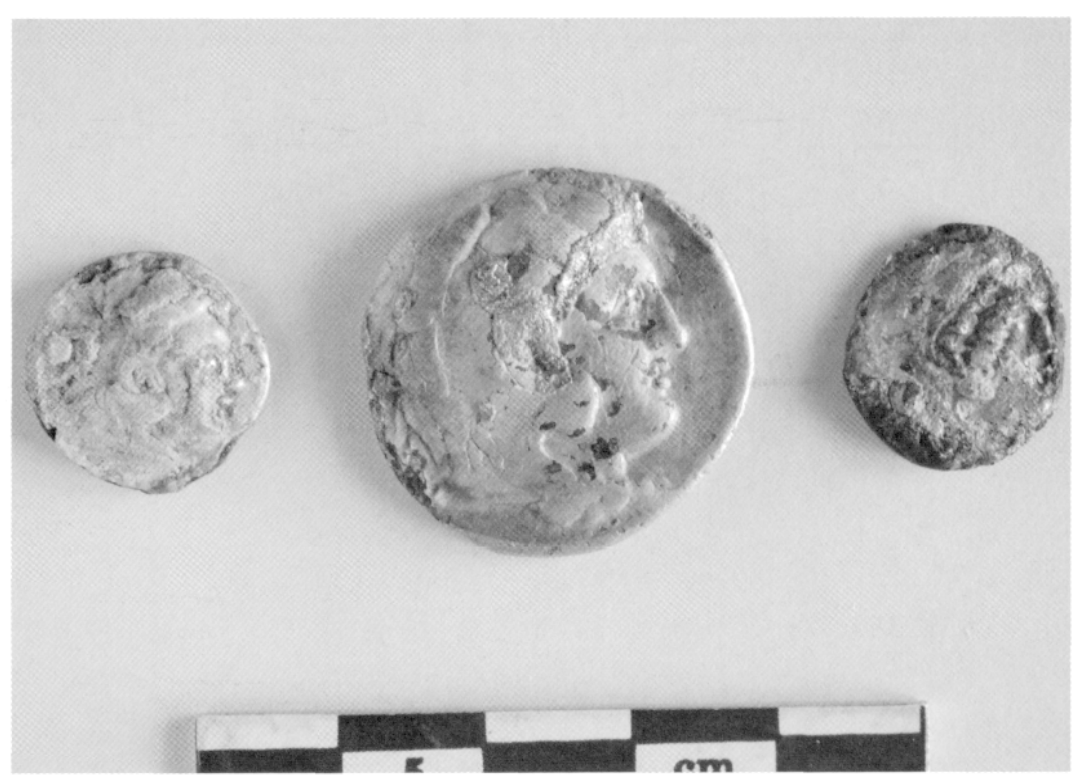

Fig. 18 : Tetradrachme et drachmes d'argent aux types d'Alexandre le Grand. Droit.

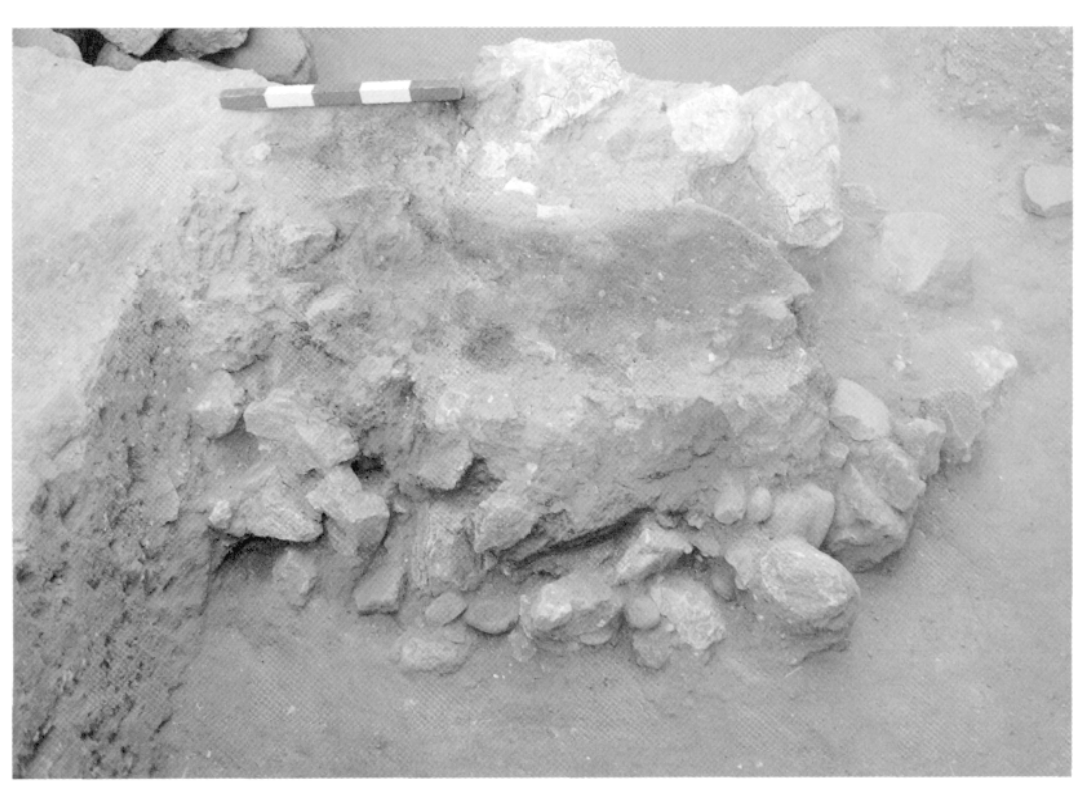

Fig. 20 : Chantier II Nord. H07. Lit de pierres et zone cendreuse 03587 appartenant au premier état de l'alendier 03570. Vue vers le Nord.

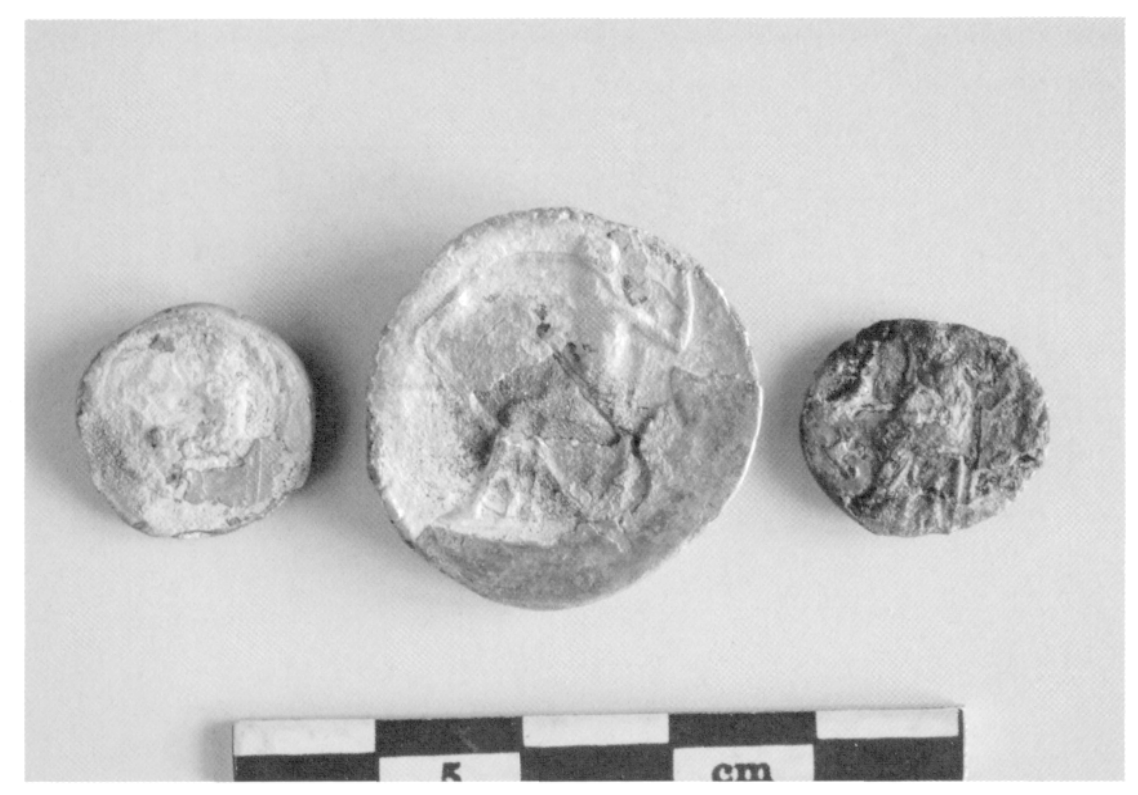

Fig. 19 : Tetradrachme et drachmes d'argent aux types d'Alexandre le Grand. Revers.

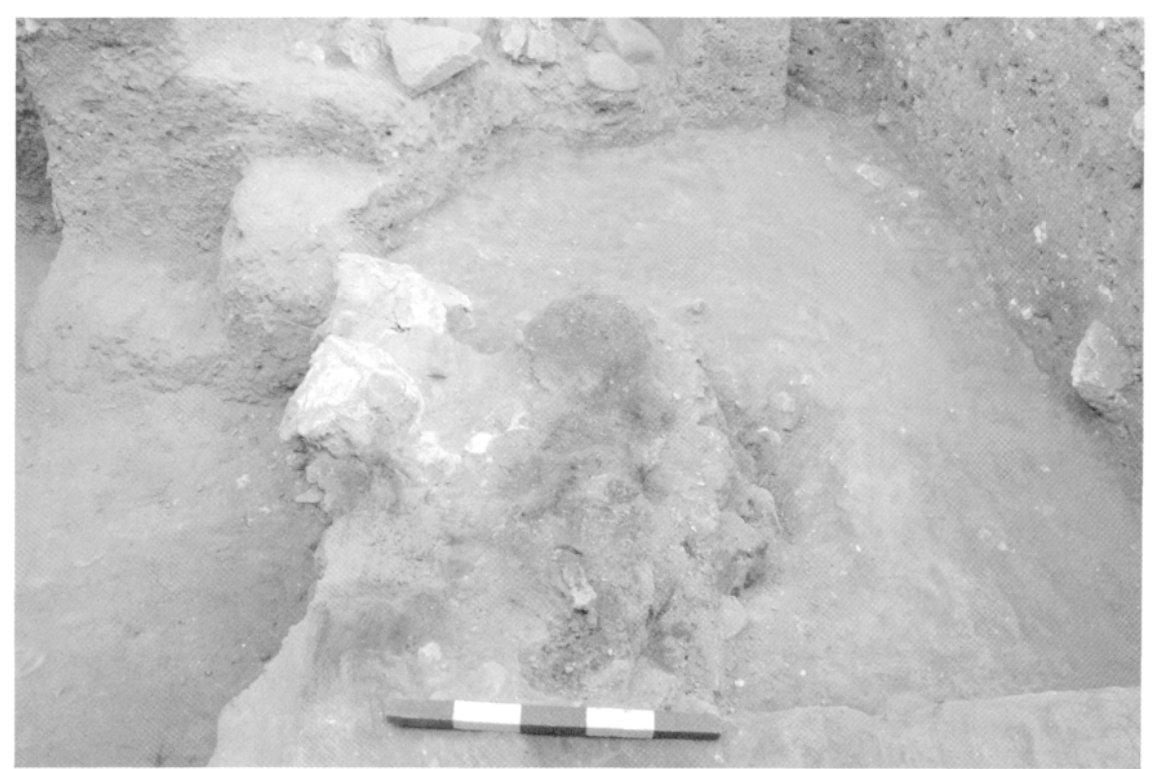

Fig. 21 : Chantier II Nord. H07. Zone cendreuse 03587 correspondant au premier état de l'alendier 03570. Vue vers le Nord. 

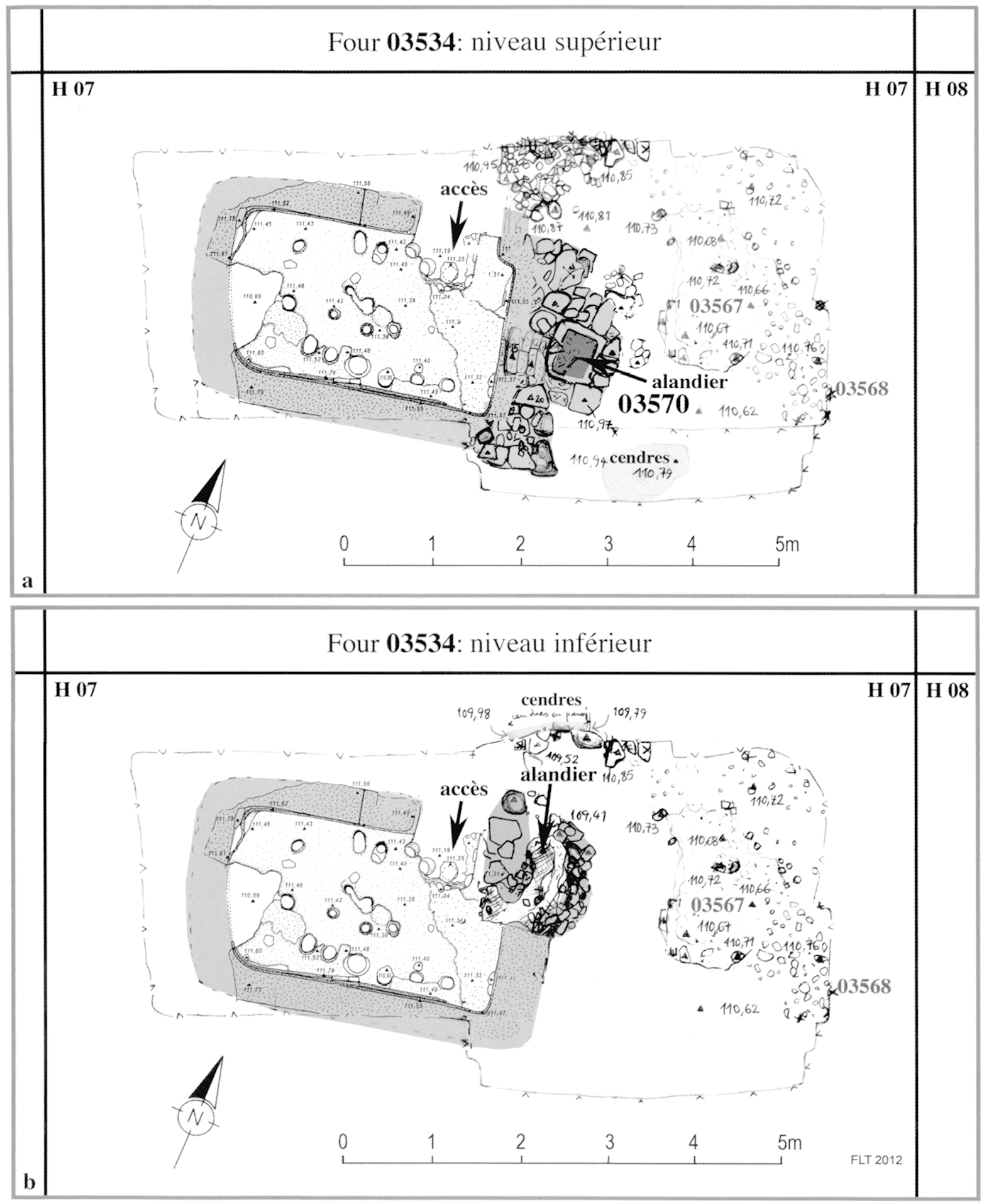

Fig. 22a-b : Chantier II Nord. H07. Four 03534 et alendier 03570. a. Deuxième état, b. Premier état (F. Laroche-Traunecker). 


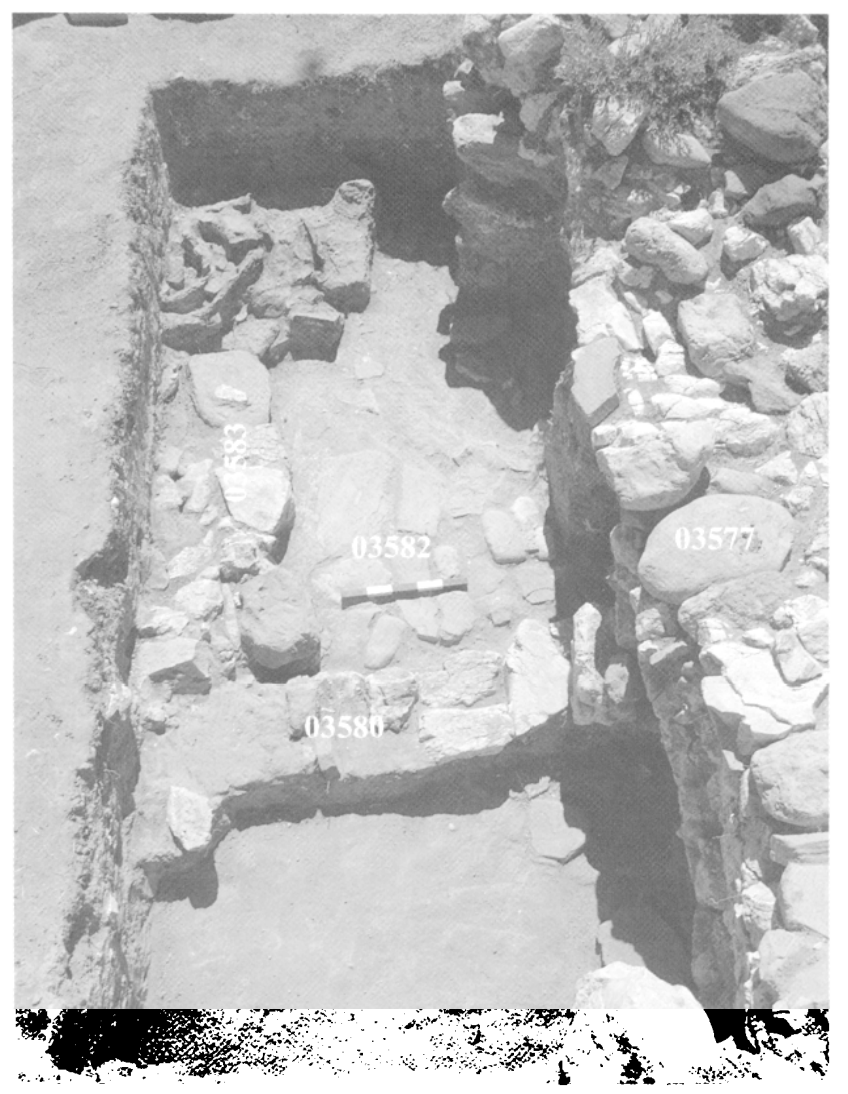

Fig. 23 : Chantier II Nord. Sondage en H07-I07. Installations appartenant à la phase IIa. Vue vers le Sud. On aperçoit au centre les murs 03580 et 03583 et le dallage 03582 (phase IIa); à droite, le mur 03577 (phase IIa, réutilisé à la phase Ic) ; et au fond un tandir datant d'une phase plus récente (Ic ou Ib).

mur 03577 - qui forme la limite ouest de la 'Maison aux pithoi' paraissait avoir, tel qu'il avait été dégagé dans les fouilles anciennes, une épaisseur exagérée et un parement oriental convexe. Les travaux de cette année ont permis de déterminer que cette anomalie était due au déversement du mur vers l'Est à cause de la poussée latérale exercée par les décombres accumulés plus à l'Ouest (notamment ceux du système défensif du Bronze Récent). Ce même phénomène avait été déjà observé un peu plus au Nord dans les murs superposés mis au jour les années précédentes le long de la limite ouest du sondage profond en $\mathrm{H} 07$ (du haut en bas les murs 03558, $03507,03533$ et 03550$)^{15}$.

A la fin des travaux, à $111,70 \mathrm{~m}$, la base du mur 03577 n'a pas été encore atteinte. Elle devrait être beaucoup plus profonde si l'on suppose que le mur
03577 est le prolongement vers le Sud du mur 03507 dégagé dans le sondage profond en H07. Dans ce cas son assise de fondation devrait se situer autour de 112,30 m, donc 0,50 m plus bas. Dans ce cas on pourrait penser qu'il a été construit à la phase IIa et réutilisé à la phase Ic comme son homologue le mur 03507. L'assise de sommet du mur est un peu différente de celles qui se trouvent plus bas par la taille et la nature des blocs. Devrait-on alors supposer que cette assise de sommet correspond à un rehaussement du mur effectué au moment de sa réutilisation à la phase Ic ? Si c'est le cas, le mur 03558 qui s'appuie sur le mur 03507 à l'extrême Nord du sondage profond pourrait lui aussi correspondre à ce même rehaussement survenu à la phase Ic.

Les travaux effectués dans ce sondage ont permis de mettre au jour, en plus du mur 03577, d'autres vestiges - tels les murs 03580 et 03583 , et le dallage 03582 - appartenant à la phase IIa antérieure à la 'Maison aux pithoi' (Fig. 23). Le mur 03580, d'une épaisseur de 0,60 m, est conservé sur une assise de hauteur. Il est construit avec des blocs de pierre (gypse et grès) et des briques crues (ou plutôt du pisé). Perpendiculaire au mur 03577 , il a été dégagé sur près de $2 \mathrm{~m}$ de long jusqu'à la berme est du sondage où il se raccorde avec un angle légèrement obtus au mur 03583 (Fig. 24). Ce dernier en partie engagé dans la berme orientale du sondage, a pu être suivi sur près de $1,50 \mathrm{~m}$ de long. Fait de blocs de pierre de taille moyenne, il présente une maçonnerie assez irrégulière. L'espace délimité par ces trois murs $(03577,03580$ et 03583$)$ est pourvu d'un dallage (03582) de pierres plates de taille moyenne disposées irrégulièrement et recouvertes par endroits d'un mince enduit de chaux. Ce dallage situé à $111,84 \mathrm{~m}$ ainsi que le mur 03583 ont été perturbés par la construction d'un tandır au Sud du sondage à une phase plus récente - phase Ic ou Ib.

\section{OPERATION CHANTIER II SUD}

(sous la responsabilité de D. Beyer, avec Hiba Bizreh puis Sarah Dermech)

Il s'agit du nouveau secteur de fouille, en bordure de pente ouest du site, dans les carrés J04-05 et K04-05 (Fig. 1). Il avait pour but de retrouver le mur prolongeant au Sud le montant de la porte de la première phase du secteur de la 'poterne' hittite (Fig. 2). Cette opération, qui devait être au départ modeste et limitée, s'est révélée très fructueuse, 


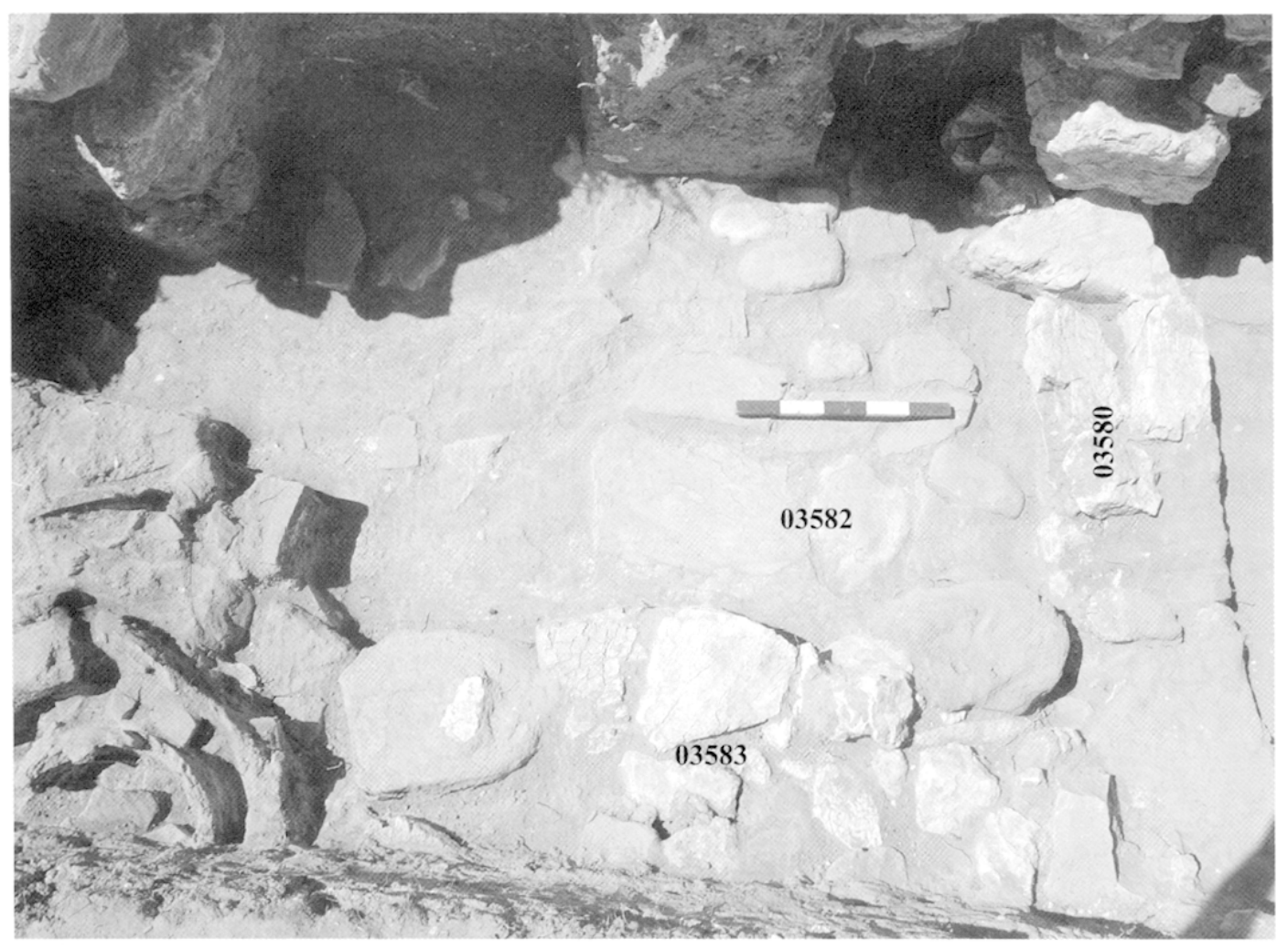

Fig. 24 : Chantier II Nord. Sondage en H07-I07. Installations appartenant à la phase IIa. Vue d'en haut.

grâce à la relative conservation des vestiges et à l'intérêt que présentait la découverte de dispositifs inédits. Lors de l'arrêt des travaux au chantier IV (cf. Partie III), nos forces ont été concentrées ici pour la poursuite de cette opération.

Le secteur correspond au sommet de la pente ouest, sous le point culminant du site (alt. $1299 \mathrm{~m}$ ), où l'on pouvait craindre par conséquent de rencontrer de nombreux vestiges très dégradés de niveaux tardifs.

1. Il n'en a rien été, hormis les restes encore assez imposants (= notre premier niveau) d'un grand mur ou d'une sorte de plate-forme (03807) de briques grises ${ }^{16}$, d'un type inédit à Porsuk, dont on a pu suivre la limite sud-ouest sur une longueur de $15 \mathrm{~m}$ environ (Fig. 25). Cette limite à dire vrai n'est que théorique, car elle disparaît dans la pente, surtout au Nord. Les autres limites ne sont pas connues ${ }^{17}$. Il peut s'agir là des vestiges d'une sorte de fortin couronnant le sommet du höyük, mais durant quelle période? En raison des fortes pentes de tous côtés, aucune couche archéologique n'a pu être retrouvée en relation avec ces briques, au moins dans l'espace de la fouille de cette année. Il n'y a guère que le contenu des briques ou de l'argile des joints qui peut être pris en compte : nous avons ainsi pu récolter un ensemble de tessons de céramiques qui s'avère remonter de manière homogène au Fer Moyen, phase récente (Fig. 26). On peut donc suggérer une datation de ce type pour cette installation (= Porsuk III), mais tout en sachant naturellement qu'elle peut appartenir éventuellement à une phase plus récente.

2. Cette plate-forme 03807 s'était installée sur les vestiges d'un niveau caractérisé par des murs de fortification (= notre second niveau) dont subsistent les restes en pierres de gypse, la superstructure, vraisemblablement de briques, n'ayant pas survécu (Fig. 25, 27-28). La plate-forme 03807 montre ainsi, ici ou là, qu'elle s'était fondée plus ou moins profondément dans les vestiges de ce niveau (Fig. 29), comme le prouve l'impressionnante élévation d'une quinzaine d'assises de briques visible dans la paroi est en J05 (Fig. 30). Mieux : on peut se demander si 


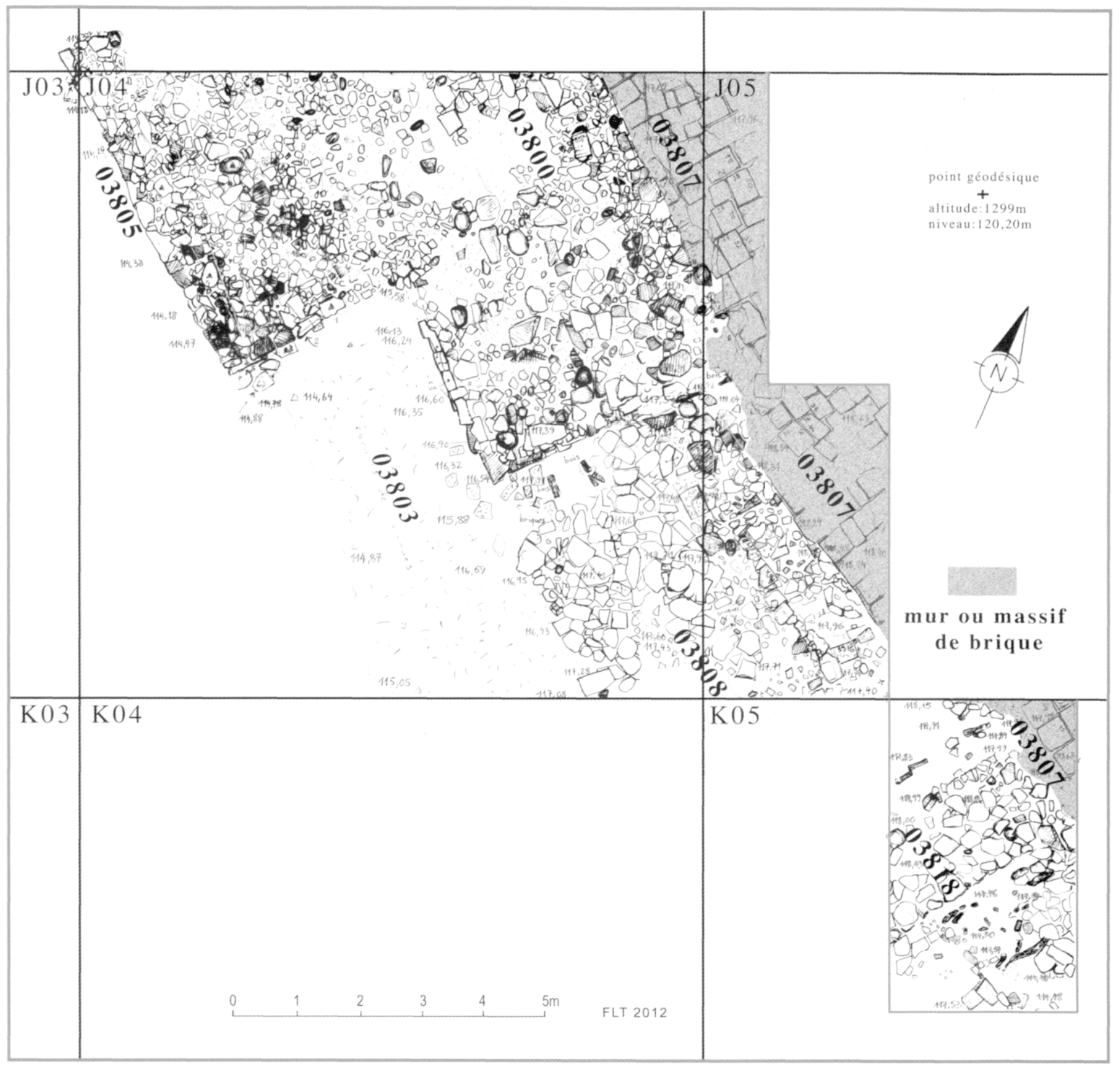

Fig. 25 : Chantier II Sud. Plan des vestiges des deux niveaux de l'Age du Fer (F. Laroche-Traunecker).

les bâtisseurs de la plate-forme n'ont pas été amenés à réparer la paroi nord-est du mur sous-jacent du second niveau (03800) dans l'angle nord-est du carré J04, avant de combler tout le niveau avec leurs briques. Ce tronçon du mur 03800 apparaît en effet nettement mieux conservé (Fig. 31) que les parties situées plus au Sud, dont on a peine à définir clairement les limites (Fig. 25). Il est par conséquent assez difficile de tracer avec précision le rempart révélé par la fouille pour ce second niveau : au Nord, en J04 Nord, la situation est assez claire, avec un épais mur $(03800+03805=7,50 \mathrm{~m})$ esquissant un dispositif en zigzag, ou révélant une tour rectangulaire $(03805)^{18}$ avec des faces bien délimitées malgré l'érosion due à la forte pente : les faces retrouvées, sud-ouest ou sud-est, gardent les vestiges,

18) La face sud-ouest de la tour (03805), la seule entièrement dégagée en surface de pente, presque au-dessus du vide, et empiétant légèrement sur le carré 104 , est longue de $6 \mathrm{~m}$. 


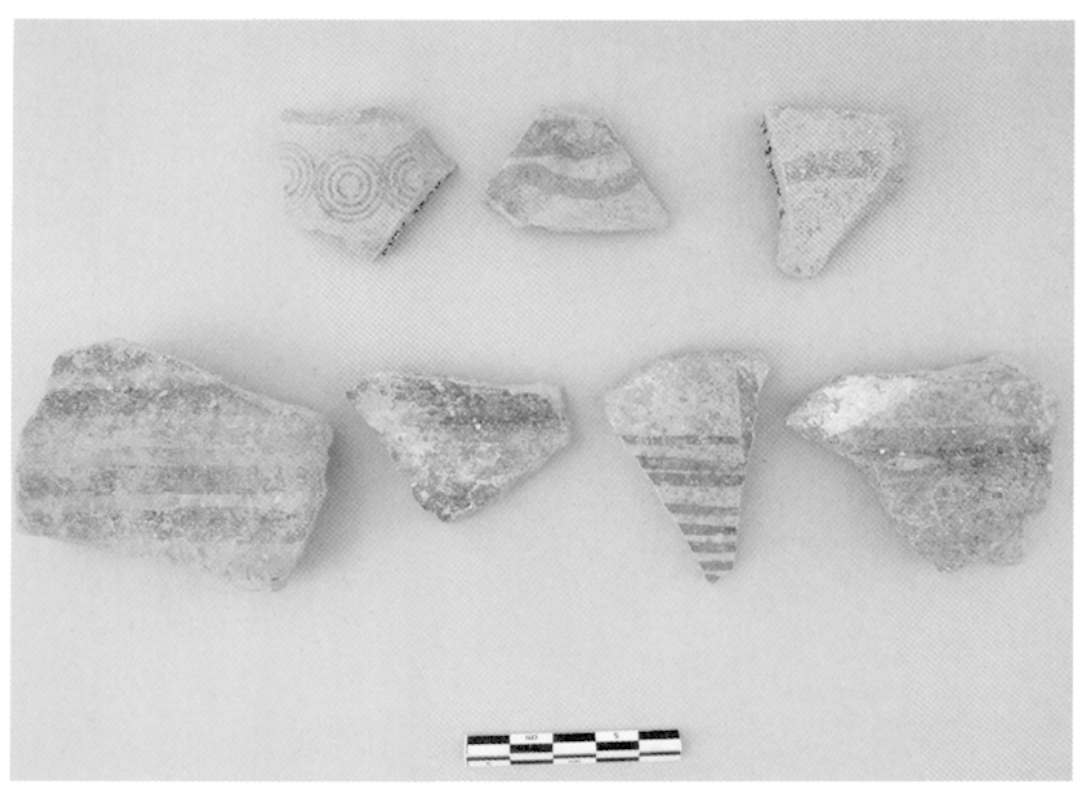

Fig. 26 : Chantier II Sud. Tessons du Fer provenant de la maçonnerie de briques du premier niveau.

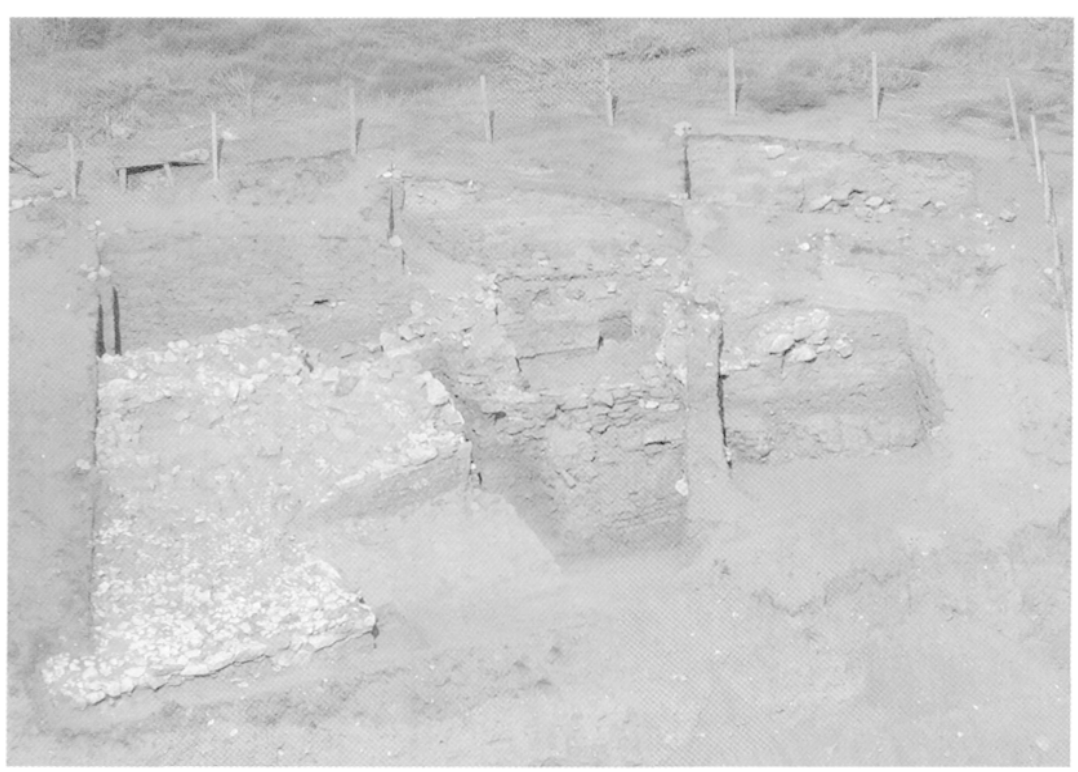

Fig. 28 : Chantier II Sud. Ensemble des vestiges des fortifications du Fer (pierres de gypse) et du Bronze (pierres et briques rubéfiées). Vue vers l'Est.

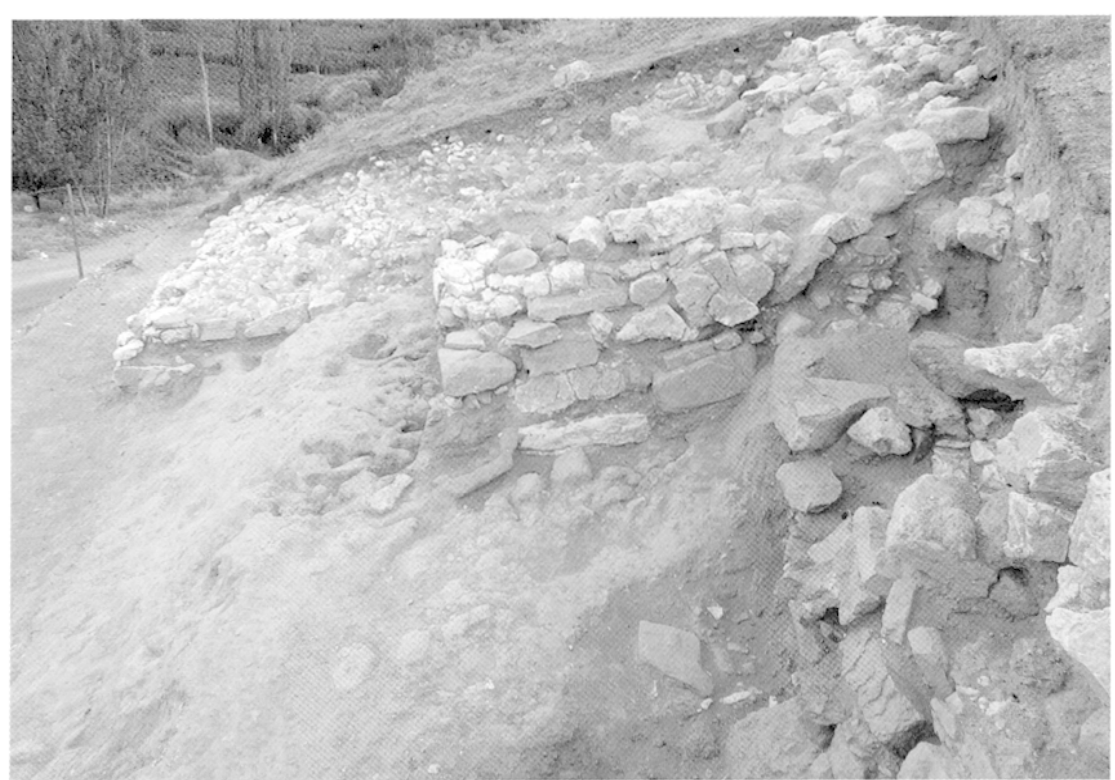

Fig. 27 : Chantier II Sud. Restes de la fortification du second niveau du Fer, au-dessus des vestiges du Bronze. Vue vers le Nord-Ouest.

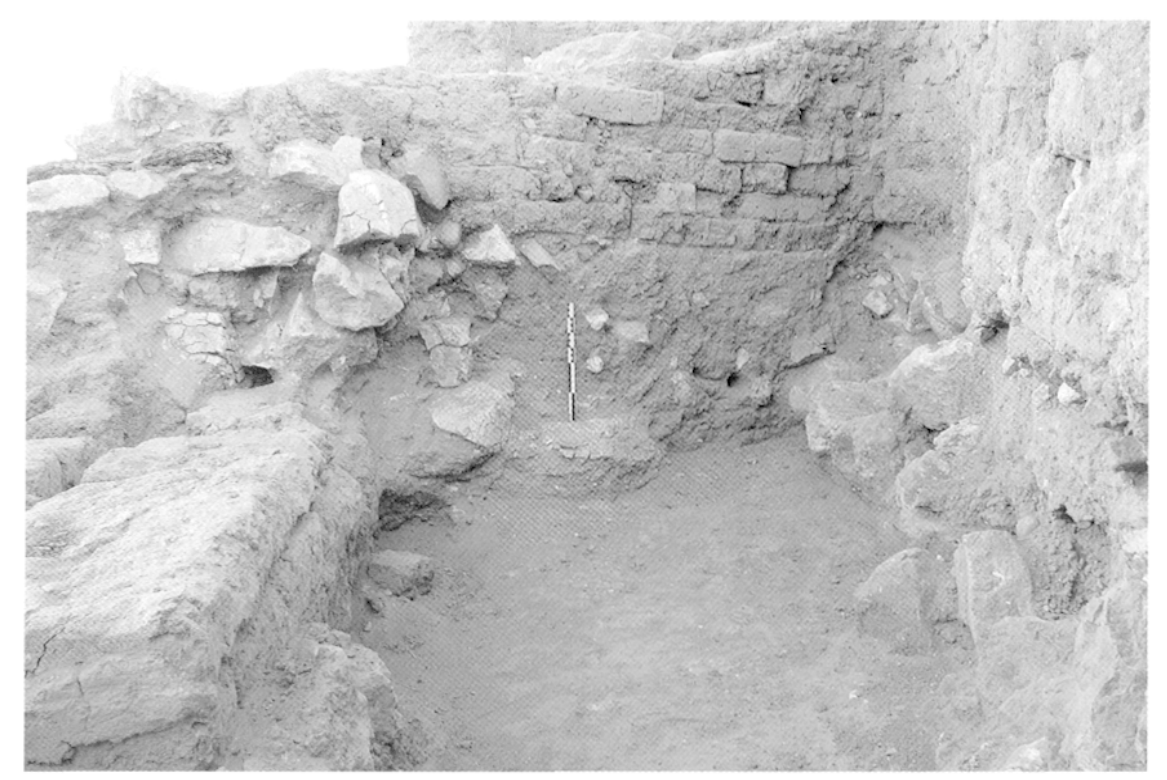

Fig. 29 : Chantier II Sud. Fondations de briques de la plate-forme (?) du premier niveau s'enfonçant profondément dans les niveaux sous-jacents. Vue vers le Nord-Ouest. 


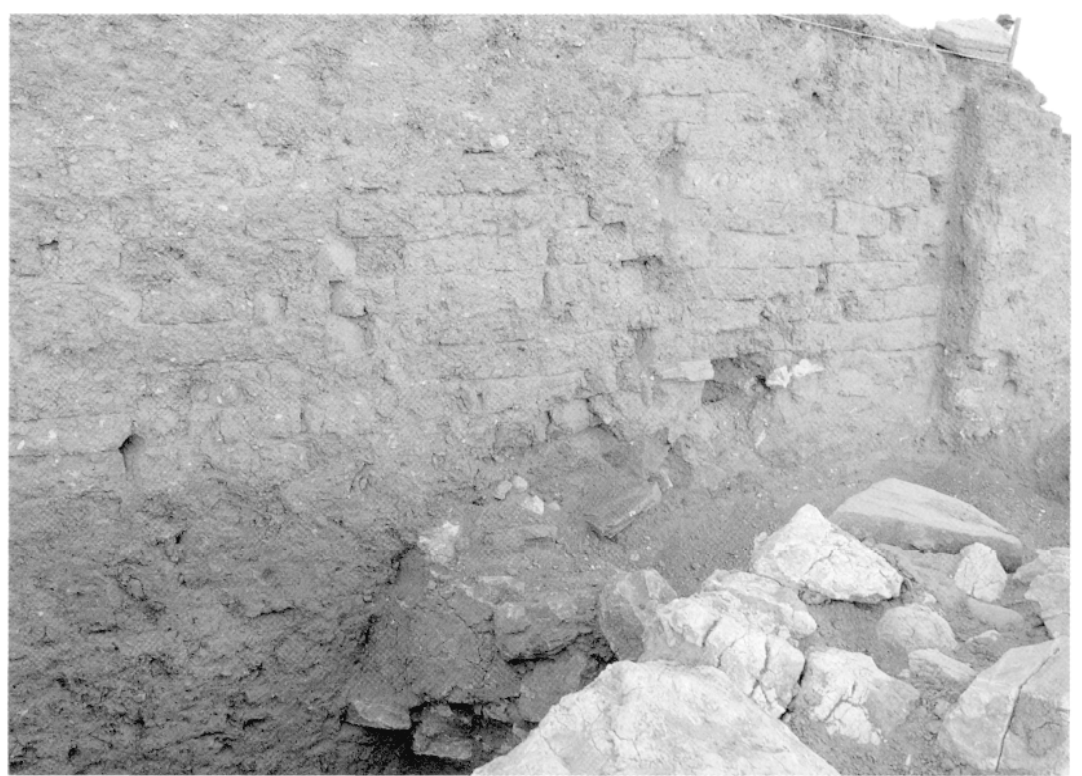

Fig. 30 : Chantier II Sud. Section à travers les briques de la plate-forme (?) du premier niveau. Vue vers le Sud-Est.

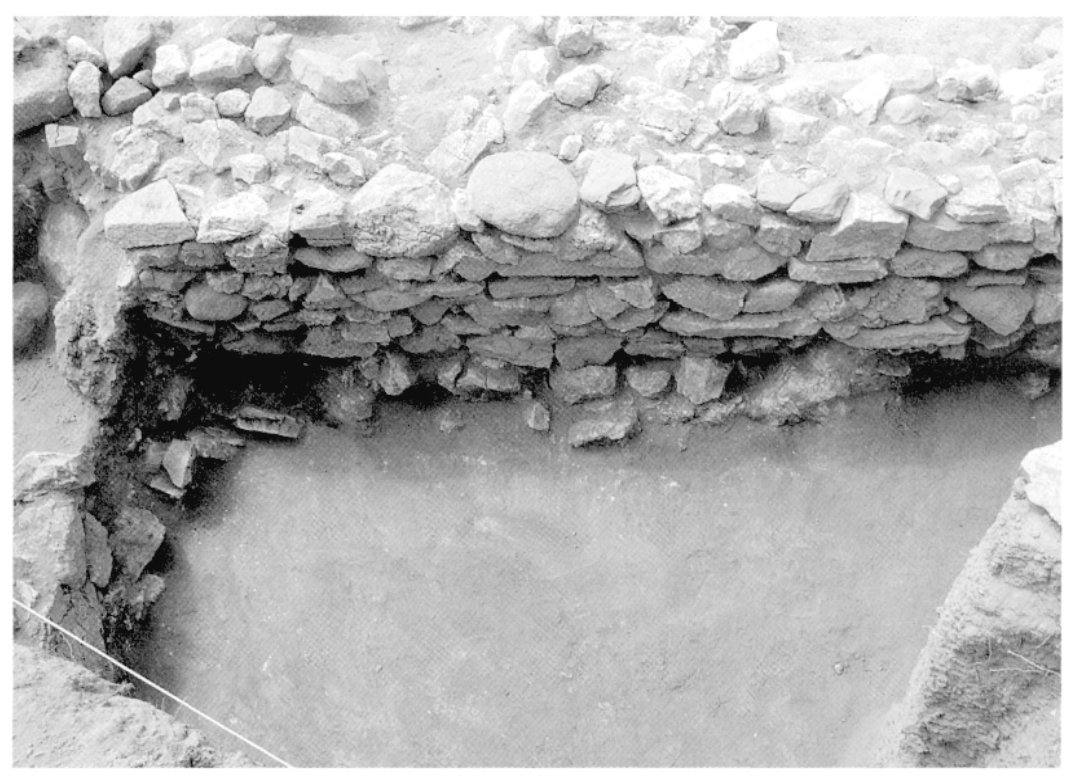

Fig. 31 : Chantier II Sud. Paroi nord-est du mur du second niveau (03800) reconstruite (?). Vue vers le Sud-Ouest.

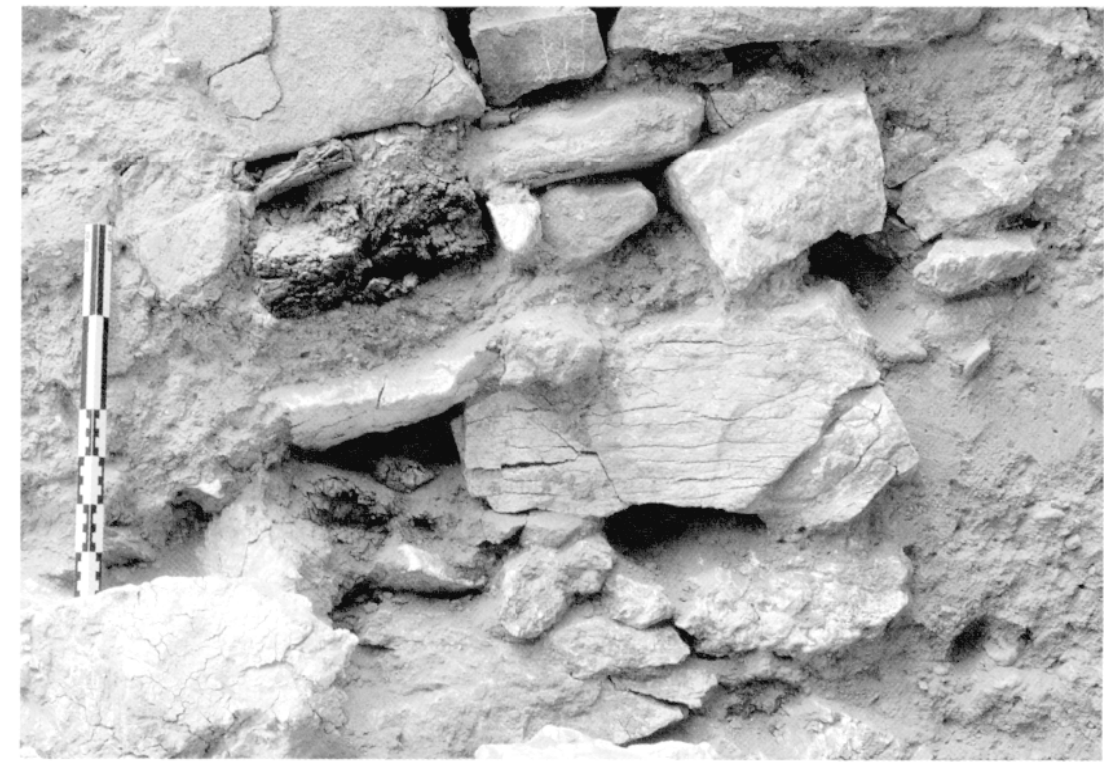

Fig. 32 : Chantier II Sud. Restes de poutrelles du chaînage, en boutisses, à la base du mur 03800 . Vue vers le Nord-Ouest. 


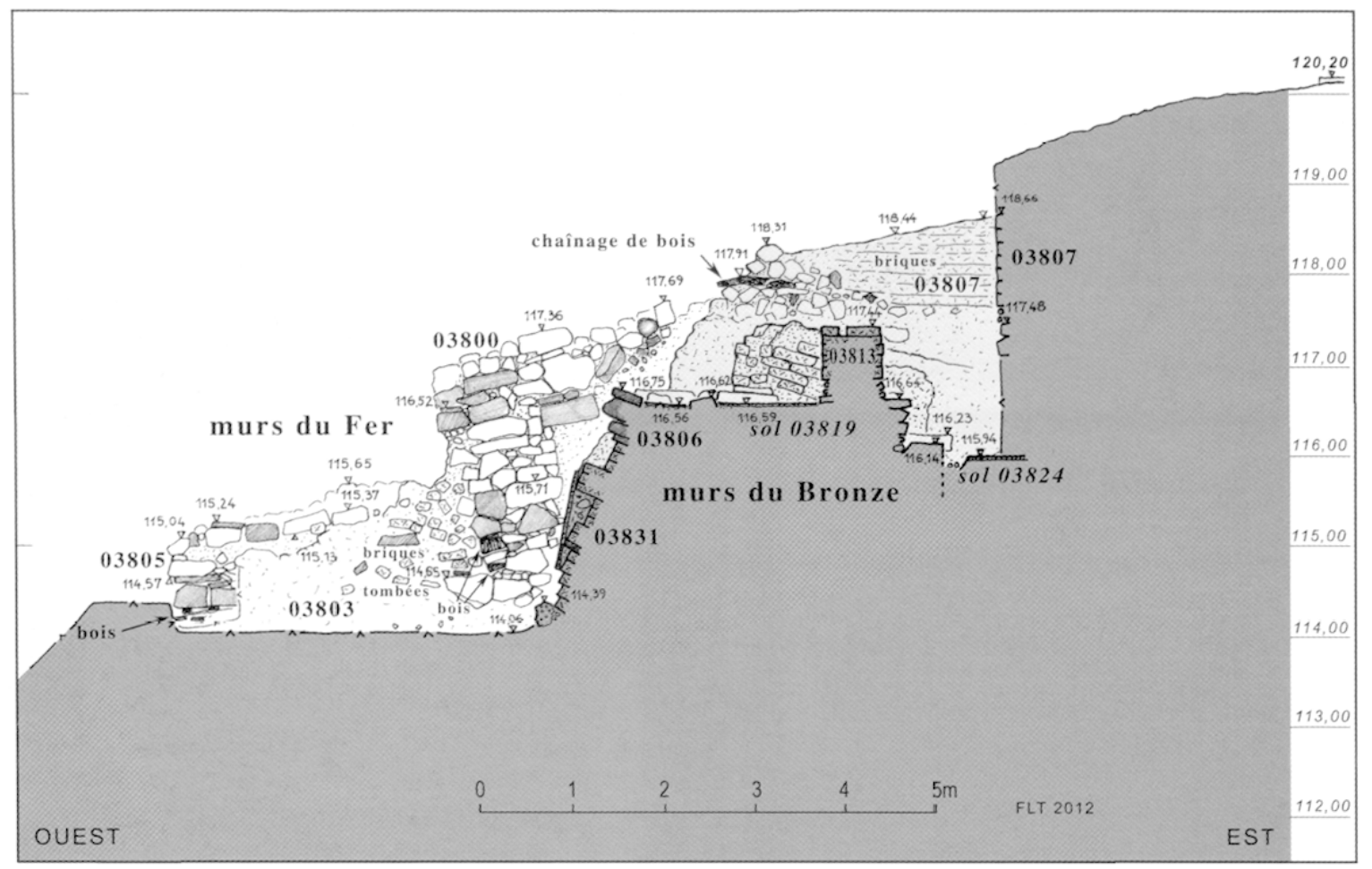

Fig. 33 : Chantier II Sud. Section Ouest-Est à travers le chantier. Les murs du Fer sont en élévation (F. Laroche-Traunecker).

plus ou moins régulièrement disposés, d'éléments de chaînage de bois, la plupart du temps non brûlés. Le renfort des angles sud est à souligner. Les poutrelles de bois, lorsqu'elles sont bien conservées, en boutisses ou longrines, ont en général env. $10 \mathrm{~cm}$ de diamètre ou de côté. Certaines ont été jumelées dans le même logement (Fig. 32). Ailleurs, leur dégradation ou leur disparition ont fragilisé le mur et créé des vides, responsables, à un moment de la fouille, d'un éboulement. Les parements des murs sont faits de blocs de gypse souvent assez grossièrement équarris, avec de rares blocs plus réguliers de grès ou quelques gros galets, technique bien courante à Porsuk, où l'on faisait large usage des ressources locales. L'ensemble de ces éléments apparaît sur la coupe de la Fig. 33, qui montre bien l'ampleur de la pente et l'imbrication des différents niveaux.

Plus au Sud-Est, les vestiges sont beaucoup moins clairs : à la jonction de J04 et J05, ainsi qu'en $\mathrm{K} 05$, le rempart est particulièrement éboulé et ses limites incertaines $(03808,03818)$. Seuls les restes de chaînage de bois, bien orientés NE-SO, attestent l'existence d'un dispositif construit à peu près en place, à moins que l'ensemble ait glissé dans la pente sur 3 ou 4 mètres (?), ce qui paraît sans doute difficile à admettre. Si ce n'est pas le cas, il faut considérer que la partie sud-est du dispositif correspond à une réfection, dans un deuxième temps, du rempart, réfection qui n'aurait guère résisté à l'érosion?

La progression de la fouille dans ce second niveau a permis au moins de comprendre son mode d'installation : si la fouille du côté interne (nordest) n'a pas pu fournir beaucoup de renseignements sur les couches contemporaines, à cause des travaux de la plate-forme du premier niveau et de l'espace exigu des sondages, en revanche, du côté extérieur (sud-ouest), on a pu montrer clairement que les bâtisseurs de ce niveau, qui se sont eux-mêmes appuyés en partie, comme on le verra, sur le rempart antérieur (Fig. 33), ont accumulé un remblai de couches grises de terres à galets et de briques, jetées en vrac (Fig. 34). Il s'agissait pour eux de combler le niveau de destruction de notre troisième niveau et de s'implanter plus à l'extérieur par rapport au rempart antérieur, en rétablissant certainement une sorte de glacis. Dans cette couche hétérogène 03803, qui jouxte souvent, au même niveau altimétrique, la couche rouge de destruction du niveau antérieur, préservée (03804), les bâtisseurs du rempart du second niveau ont parfois fondé très profondément leurs murs, du côté de la pente, comme en témoigne l'angle sud du mur, en J04 SE (Fig. 33-34), seul endroit où la fouille a pu dégager toute la hauteur conservée, ici de 3,5 m env., de la face externe du mur de fortification. 


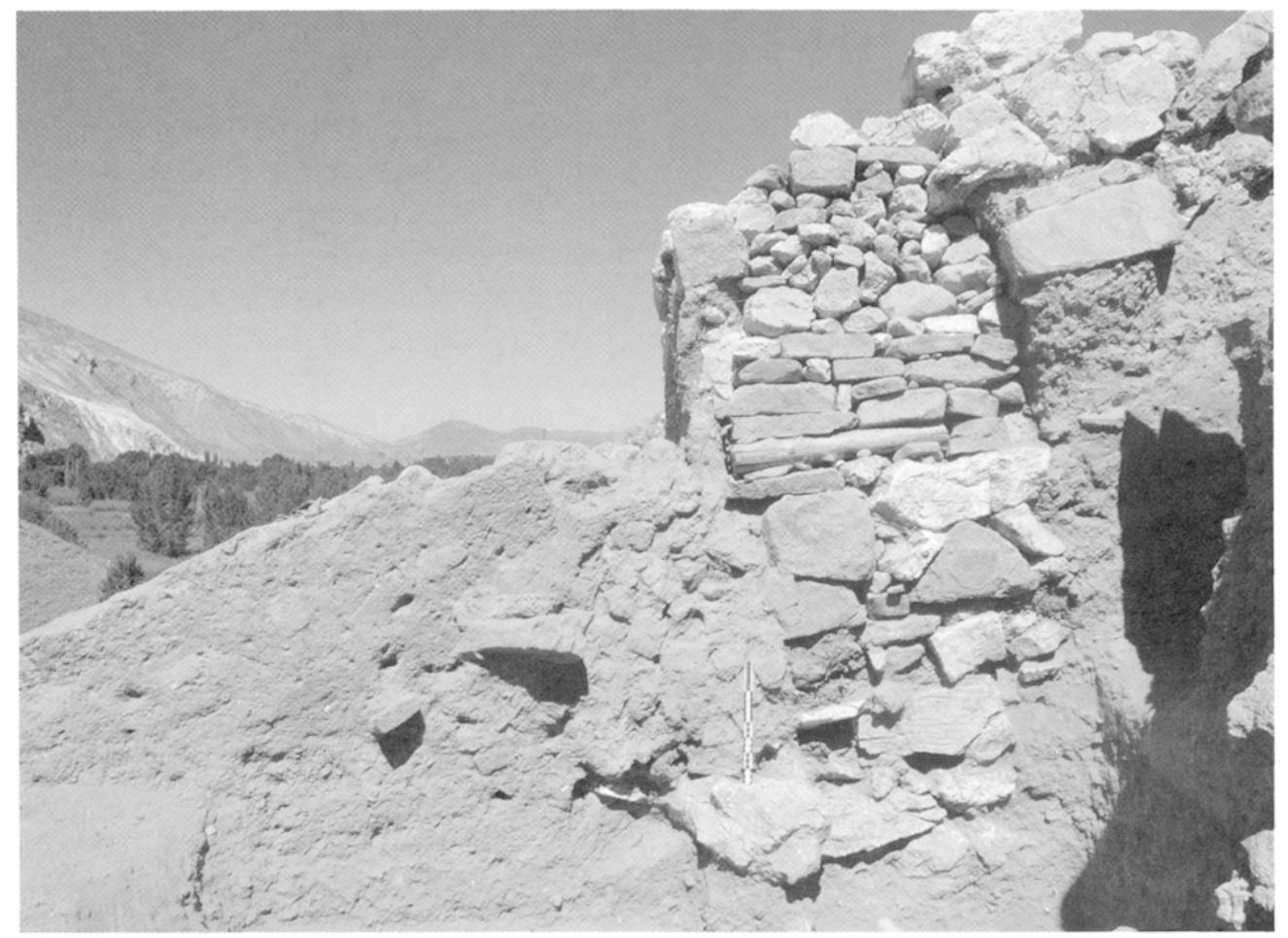

Fig. 34 : Chantier II Sud. Couche de remblai au pied du mur du Fer 03800 . Vue vers le Nord-Ouest.

Comme pour le premier niveau, l'absence des couches et du sol d'utilisation de l'ensemble du dispositif, en raison de l'érosion de la forte pente, rend la datation précise délicate. Les couches de remblai gris 03803 évoquées ci-dessus contenaient un matériel céramique assez homogène du Fer Moyen, phase ancienne (Fig. 35), ce qui n'a pas été fréquent à Porsuk jusqu'à présent. À titre d'hypothèse, on peut proposer une datation de cette période, à laquelle est rattachée la phase Porsuk IV, en attendant une confirmation par analyse ${ }^{14} \mathrm{C}$ sur les poutres du chaînage de bois retrouvées en place. L'ensemble de ce dispositif doit pouvoir compléter fort utilement nos informations sur les fortifications du Fer Moyen à Porsuk, car bien plus au Nord, le mur 15, vraisemblablement contemporain, n'avait pas été découvert bien conservé lors des premières campagnes (Fig. 2).

3. Le troisième niveau mis au jour (Fig. 36) est clairement celui de la destruction violente du Bronze Récent (Porsuk V), marquée par la présence de terre briqueteuse rouge, de briques brûlées et divers autres éléments caractéristiques, quelques pierres de gypse calcinées ou des blocs irréguliers de conglomérat par exemple, mais sans restes de poutres carbonisées, ce qui ne laisse pas d'étonner.

On a pu effectivement retrouver le prolongement vers le Sud-Est du mur sud de la porte hittite du secteur II Nord, mais le mur (03816) semble ici bien plus mince, du moins son épaisseur initiale n'a pu être bien mise en évidence par la fouille, car le dispositif du Fer s'est encastré fortement dans la maçonnerie du mur du Bronze. Le résultat le plus important concerne la découverte d'une grande tour rectangulaire à cheval sur le mur du rempart, d'un type encore inédit à Porsuk, et semble-t-il assez rare dans l'architecture militaire hittite ${ }^{19}$. Longue de $9 \mathrm{~m}$ Nord-Ouest/Sud-Est et large de $6 \mathrm{~m}$ Nord-Est/SudOuest vraisemblablement, elle était en saillie sur la courtine d'environ $2 \mathrm{~m}$, ce qui est le cas pour la tour triangulaire du secteur nord. Mais la particularité de cette nouvelle tour, dont les murs de briques crues ${ }^{20}$ sur soubassements de pierres sont épais d'env. $1,30 \mathrm{~m}$, est d'offrir deux espaces intérieurs parallèles, deux rectangles très allongés reliés par une porte de

19) Dans le système des fortifications de la capitale hittite de Hattusha, bien connu depuis les décennies de recherche de la mission allemande, les tours rectangulaires sont plutôt en saillic sur l'extérieur de la muraille, compartimentée, et elles comportent généralement deux salles rectangulaires allongées, mais perpendiculaires à la courtine, sauf dans le cas du Poternenmauer. Voir les exemples réunis par Naumann $1971: 253$, fig. 324 et 325.

20) Les modules de briques rencontrés atteignent parfois $58 \times 40 \times 12-13 \mathrm{~cm}$. 


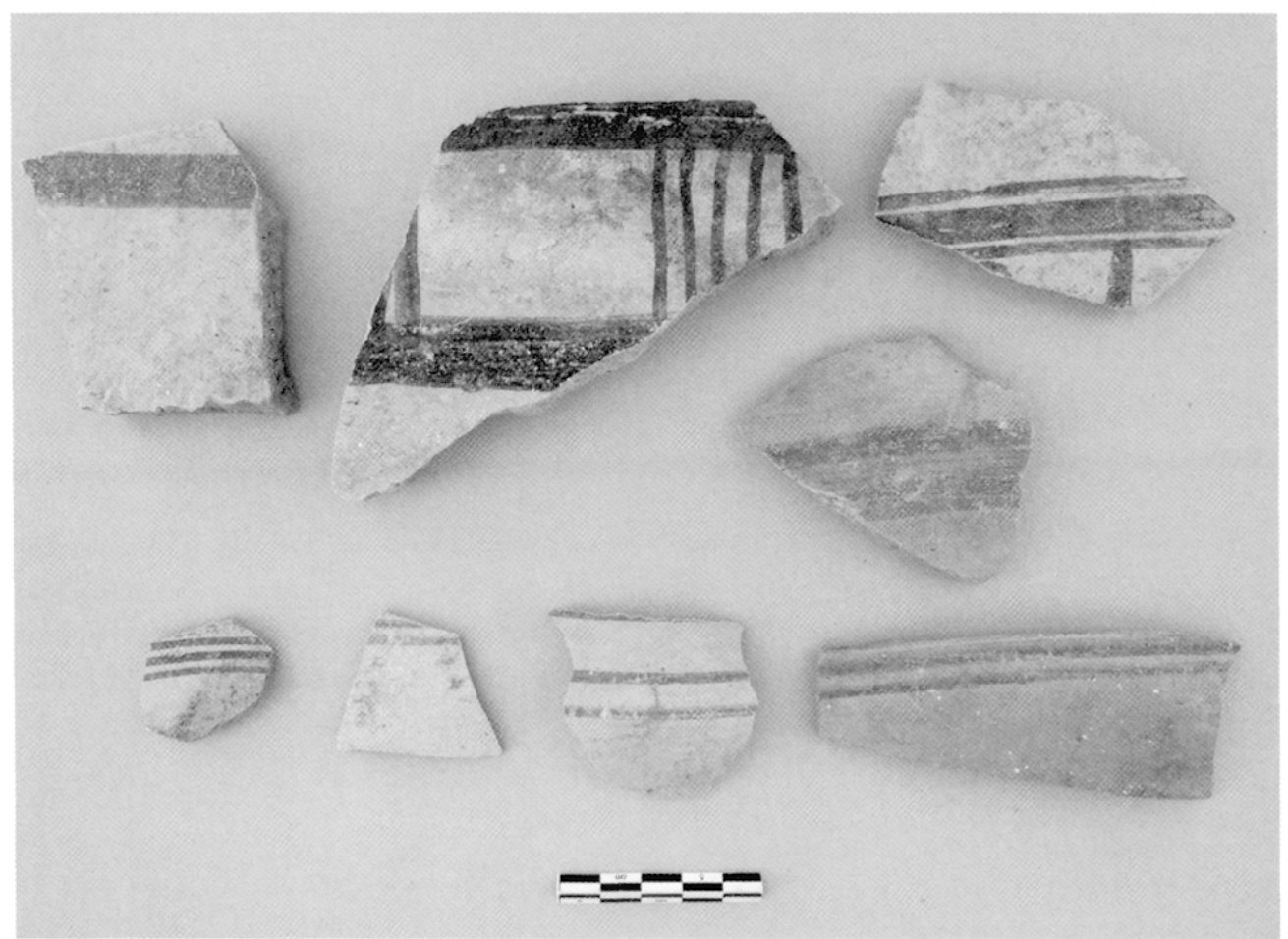

Fig. 35 : Chantier II Sud. Tessons de la phase ancienne du Fer Moyen provenant du remblai 03803.

$80 \mathrm{~cm}$ de large, percée dans un mur de partition 03813 plus étroit $(0,70 \mathrm{~m}$ env.). Ces deux espaces n'ont pas pu être entièrement dégagés, mais leur symétrie lève les incertitudes. La salle la mieux conservée, du côté extérieur, prise entre les murs 03806 , 03815 et 03813 , ne semble avoir que $1,10-1,20 \mathrm{~m}$ de largeur. Mais le sol qui y a été conservé $(03819$, $\Delta$ env. $116,60 \mathrm{~m}$ ), par plaques argileuses cuites par l'incendie (Fig. 37), se prolongeait vers l'Ouest, audessus du soubassement de pierres du mur 03806, au moins dans la partie dégagée ${ }^{21}$, et ceci largement jusqu'au parement du mur. Cette particularité invite à suggérer qu'il y avait ici une sorte d'espace ouvert partiellement sur l'extérieur, sans doute une sorte de chambre de tir avec archère permettant aux assiégés d'envoyer divers projectiles contre les assaillants $^{22}$. Dans la porte, quelques marches permettaient la liaison avec la salle voisine, un peu plus large (env. $1,50 \mathrm{~m}$ entre les murs 03813 et 03825 ), et dont le sol était situé plus bas $(03824, \Delta$ env. $116 \mathrm{~m}$ ). Dans cet espace comme dans le précédent, aucune trace de poutres d'un plafond, d'un escalier ou d'une simple échelle, permettant d'accéder au niveau supérieur, à la plate-forme sommitale et éventuellement au chemin de ronde. Un accès existait sans doute vers l'intérieur de la cité, mais les limites de la fouille n'ont pas permis de le vérifier. De même que nous n'avons pas eu le temps de vérifier si la courtine se poursuivait normalement vers le Sud ou si la fortification marquait ici un angle, ce qui semble être plutôt le cas.

Le matériel retrouvé dans la couche de destruction, même sur les sols, est rare. Cependant, les quelques tessons à engobe rouge soigneusement lustré (Red Slip Ware) indiquent clairement le Bronze Récent, donc normalement la phase Porsuk V. Certains constituaient les restes très épars d'un bras de libation ${ }^{23}$, en partie décoré en relief d'un doigt humain (Fig. 38). Contre la base de la superstructure de briques de la face NO du mur 03815 étaient restés accrochés plusieurs fragments d'une grande coupe incomplète de bronze (Fig. 39-40), cassée et déformée par la chute des matériaux du mur. point.

21) Malheureusement, la forte dégradation de l'angle formé par 03806 et 03815 n'a pas permis des observations précises sur ce

22) De nombreux blocs de conglomérat, de tailles diverses, ont été retrouvés un peu partout dans la couche de destruction extérieure. Ils peuvent naturellement avoir été utilisés dans la maçonnerie, à tel ou tel endroit, mais nous ne les connaissons pas en place. On peut donc aussi suggérer une utilisation défensive.

23) Ce type d'objet est bien connu dans le Proche-Orient du Bronze Récent, interprété parfois comme un encensoir et souvent comme un bras de libation. Cf. Kepinski 1977. On peut s'étonner d'en rencontrer des fragments dans ce contexte militaire. 


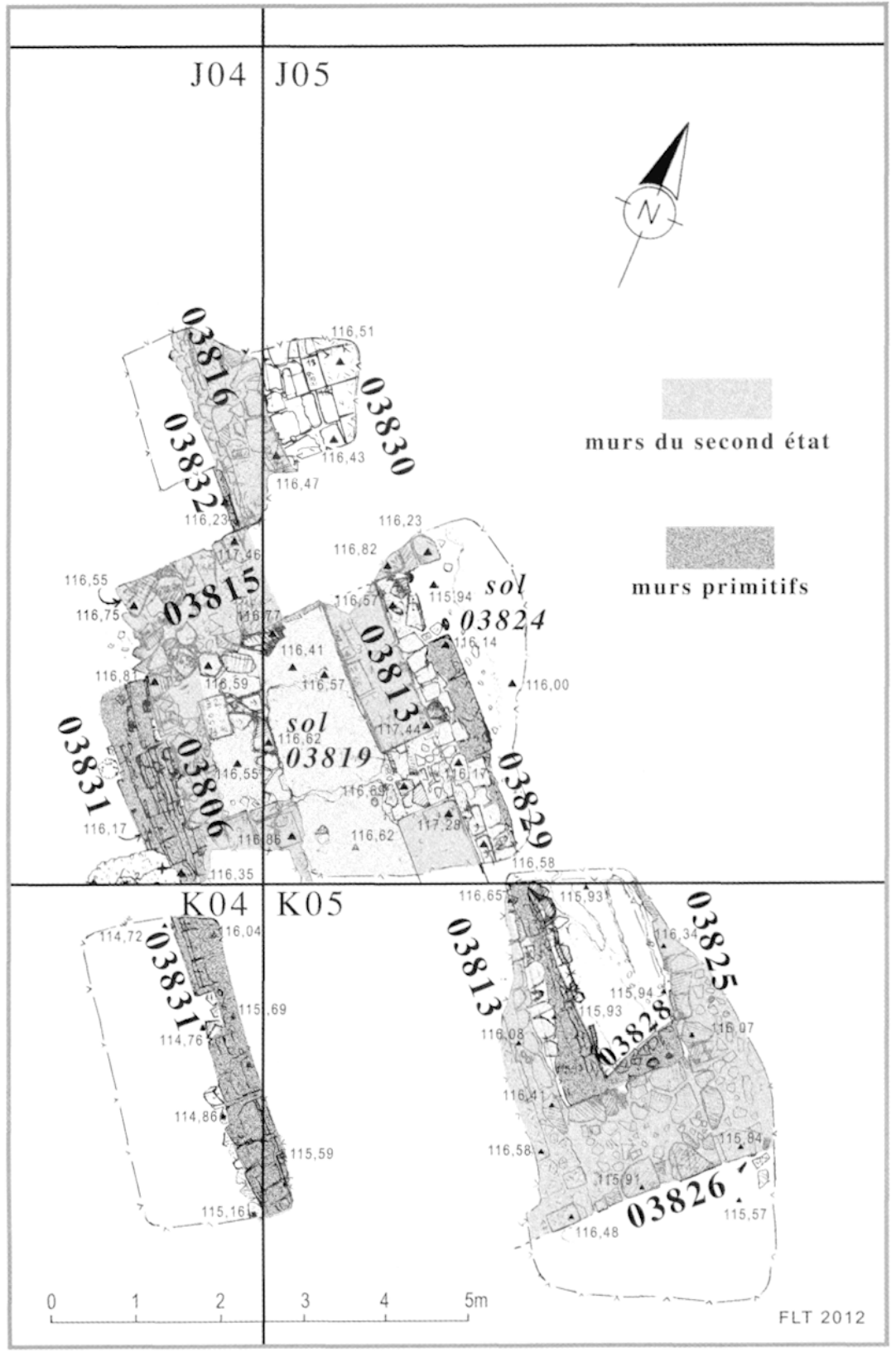

Fig. 36 : Chantier II Sud. Plan des murs du Bronze Récent (Porsuk V) (F. Laroche-Traunecker).

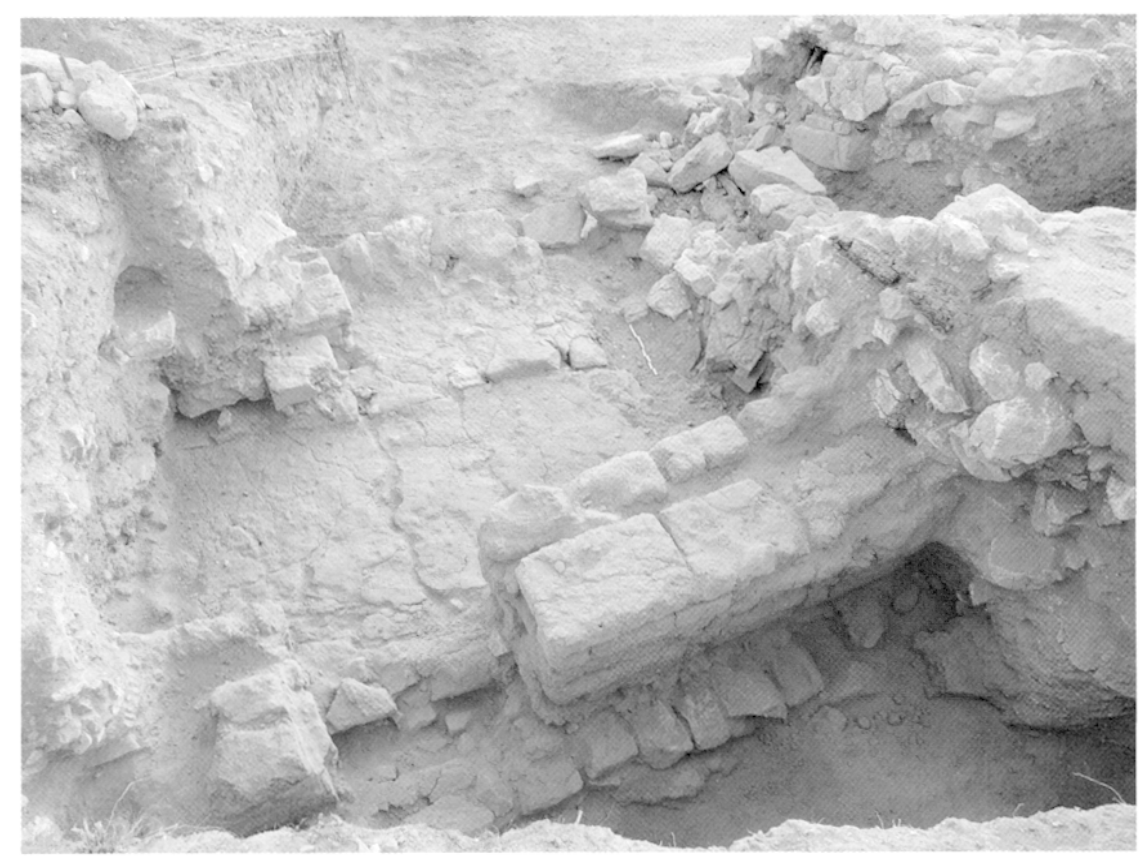

Fig. 37 : Chantier II Sud. Restes des briques brûlées et du sol de la tour rectangulaire de Porsuk V sous les pierres des murs du Fer. Vue vers l'Ouest.

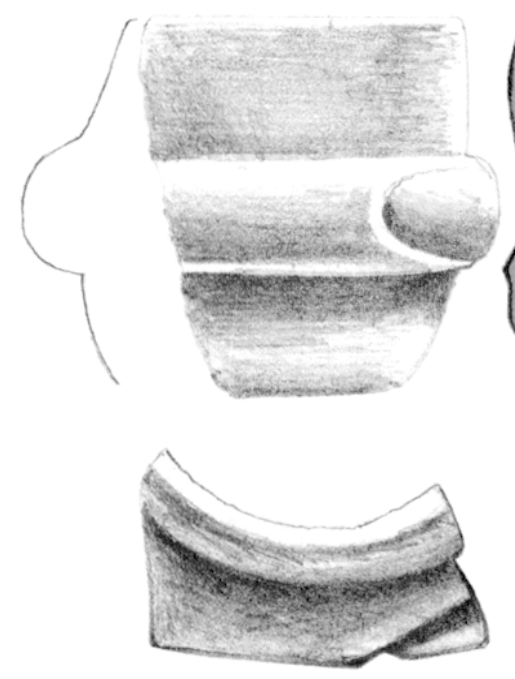

$3 \mathrm{~cm}$

Fig. 38. Chantier II Sud. Fragment d'un bras de libation (Porsuk V) avec doigt en relief (A. Beyer) 


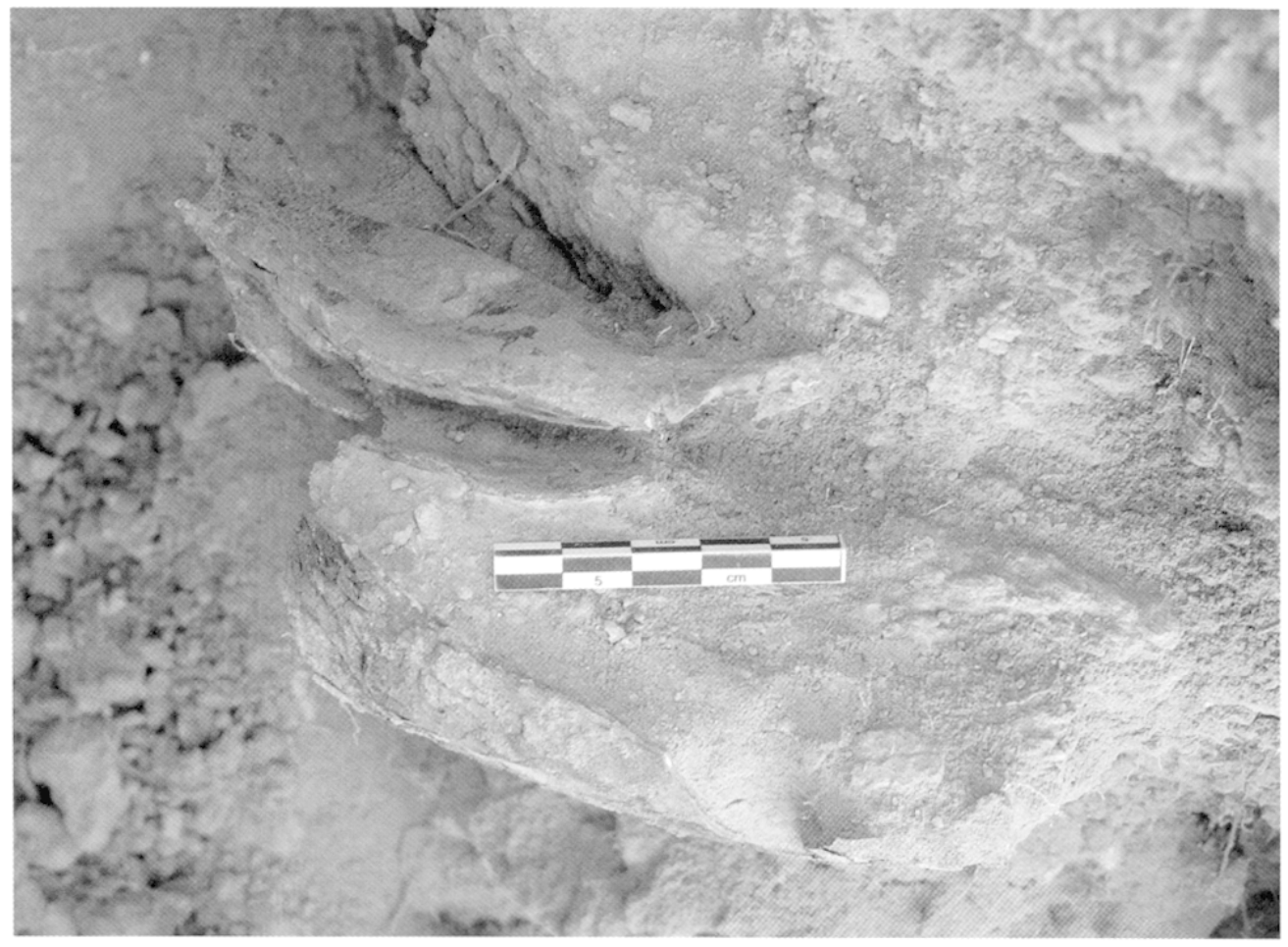

Fig. 39 : Chantier II Sud. Fragments d'une grande coupe de bronze tombée contre la paroi du mur 03815 (Porsuk V). Vue vers le Sud-Est.

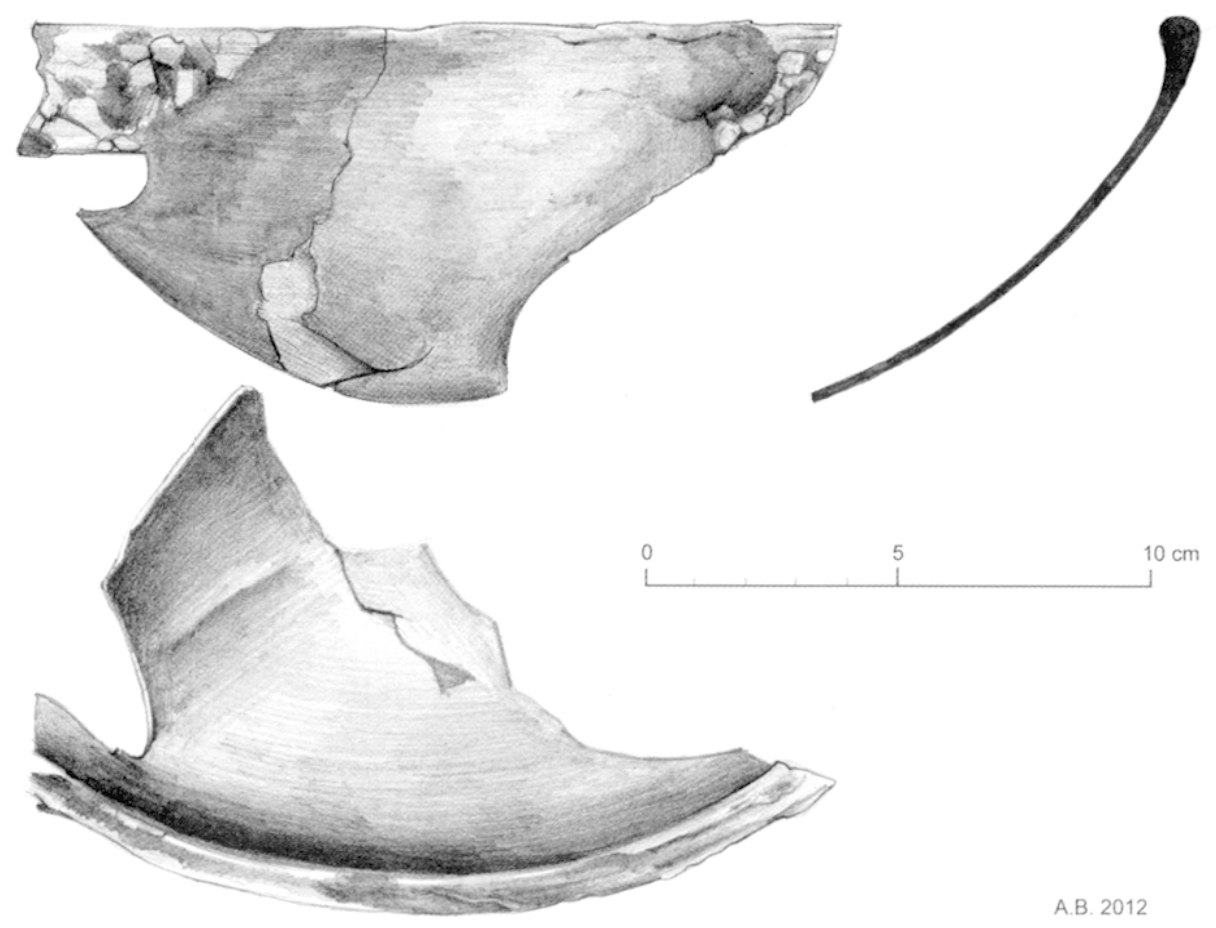

Fig. 40 : Chantier II Sud. Dessin d'un des fragments de la coupe de bronze (A. Beyer). 
4. Le dernier niveau retrouvé correspond à la phase ancienne du dispositif du Bronze, la phase qui vient d'être évoquée n'étant qu'une réfection, après destruction violente, de la fortification initiale. Celle-ci apparaît en foncé sur les documents des Fig. 33 et 36. Autant qu'on puisse l'affirmer, le plan général de la tour rectangulaire est très semblable, car la plupart des murs de la phase Porsuk V s'appuient sur le réseau des murs sous-jacents. Ces derniers se caractérisent, à nouveau, par une superstructure de briques crues sur soubassement de pierres, lorsque l'observation a pu être faite, c'està-dire surtout sur la face externe de la tour, où le mur 03806, conservé sur une soixantaine de centimètres de hauteur, est installé sur le mur 03811 . Celui-ci a été dégagé aussi bien en J04 qu'en K04, sur une hauteur maximale de $2 \mathrm{~m}$, sans que la base ait été atteinte ${ }^{24}$. Les briques de ce mur, parfois encore protégées par des restes d'enduit, ont fortement versé vers le Nord-Est, c'est-à-dire vers l'intérieur de la tour (cf. Fig. 41 et 33), mais aussi, surtout en $\mathrm{K} 04$, vers le $\mathrm{SE}$, dans la pente sud, où le parement du mur semble s'être disloqué en plusieurs sections. On notera que les modules des briques de ce niveau sont plus minces (ép. $9-10 \mathrm{~cm}$ ) que ceux de la phase plus récente. Cette remarque avait déjà été faite dans le secteur de la 'poterne hittite' au Nord. Dans l'état actuel de la fouille, les différences notées dans le plan général sont les suivantes :

- au Nord-Ouest, le mur 03815 de la phase récente ne repose pas sur un mur antérieur, mais sur la couche de destruction, avec débris habituels, de la phase ancienne. Il y a donc eu un agrandissement de la tour vers le Nord au moment de sa reconstruction ;

- au Sud-Est, le mur ancien 03828, dont la face nord-ouest a été partiellement mise au jour sous le mur 03826 , montre une orientation plus précisément nord-nord-est/sud-sud-ouest. Il est lié très certainement à un mur situé au moins partiellement sous le mur 03825 , mais que nous n'avons pu retrouver, car sans doute plus décalé vers l'est.

Le matériel provenant de cette couche de destruction, malheureusement extrêmement rare, ne permet pas une datation précise de ce niveau architectural, d'autant que nous n'avons pas pu atteindre sa base, et donc le sol d'origine de l'ensemble du dispositif. Dans l'immédiat, il est raisonnable du suggérer que nous sommes en présence du plus ancien niveau de Porsuk, c'est-à-dire de Porsuk VI, appartenant à la période de fondation de la cité, le XVII ${ }^{\mathrm{e}}$ siècle av. J.-C.

\section{OPERATION CHANTIER IV, SECTEUR NORD-EST, CARRES H/G-41/42}

Les travaux ont été menés par Julie Patrier, avec la collaboration, sur le terrain, de Sarah Dermech. Les fouilles effectuées cette année sur le chantier IV ne concernaient qu'une seule opération qui s'est concentrée sur une zone à la limite entre quatre carrés (G41, H41, G42, H42) mais dont la majeure partie se déroulait en $\mathrm{H} 41$.

Il s'agissait ici de reprendre l'excavation d'une zone explorée l'année précédente afin, d'une part, d'éclaircir la relation entre les différents secteurs déjà étudiés auparavant pour les niveaux récents (hellénistiques) et, d'autre part, de permettre d'atteindre plus rapidement les niveaux de l'Age du Fer et du Bronze. En effet, dans ce secteur situé à l'intérieur du site, le niveau romain et des niveaux hellénistiques avaient déjà été fouillés précédemment (Fig. 4).

Les travaux avaient porté en 2011 sur la zone H/l-41/42 et nous avaient préparé le terrain dans la partie est que nous avons fouillée, à savoir la zone à l'extérieur du grand bâtiment hellénistique délimité par le mur 01603. En revanche, la partie ouest des carrés en question a été laissée à un niveau supérieur ${ }^{25}$. A l'Est de notre secteur, le sondage mené en 1971 par L. Pfirsch ne nous a pas laissé les informations suffisantes pour permettre de faire le raccord avec notre chantier. En revanche, la reprise des fouilles, notamment l'élargissement de ce sondage en H42 dans les années 2000 , nous a permis de compléter quelques plans ${ }^{26}$.

Nous avons donc débuté nos travaux au niveau sur lequel s'étaient arrêtées Isabelle Chalier et Françoise Kirner en 2011, approximativement sur un sol (01664 ?, aux alentours de l'altitude relative

24) La recherche en profondeur a été interrompue, de crainte d'un éboulement important de ces murs particulièrement chahutés par la répétition des destructions et fragilisés par une technique souvent sommaire de construction : plaques de grès pouvant glisser les unes sur les autres assez facilement, comme les briques, d'ailleurs, pierres de gypse plus rares, mais grossières. En revanche, nous n'avons pas de traces d'un chaînage de bois. Il est néanmoins vraisemblable qu'il ait existé, comme partout ailleurs, et que sa destruction ait aussi contribué à déstabiliser le mur.

25) Cf. Beyer et al. 2012 : 196-199. Pour le début des fouilles en H4l lors de la campagne de 2009, cf. Beyer et al. $2010: 215-$ 220. Le site n'a pas fait l'objet de fouilles en 2010.

26) Voir les rapports précédents d'Isabelle Chalier dans Anatolia Antiqua (fouilles en H/K-39/42 : Beyer et al. $2005: 297-305$; fouilles en G/H/l-41/42 : Beyer et al. 2006:217-225; fouilles en H42, niveaux récents : Beycr et al. 2007 : 301-306; fouilles en H42, niveaux du Fer et du Bronze : Beyer et al. $2008: 327-333$ ). 


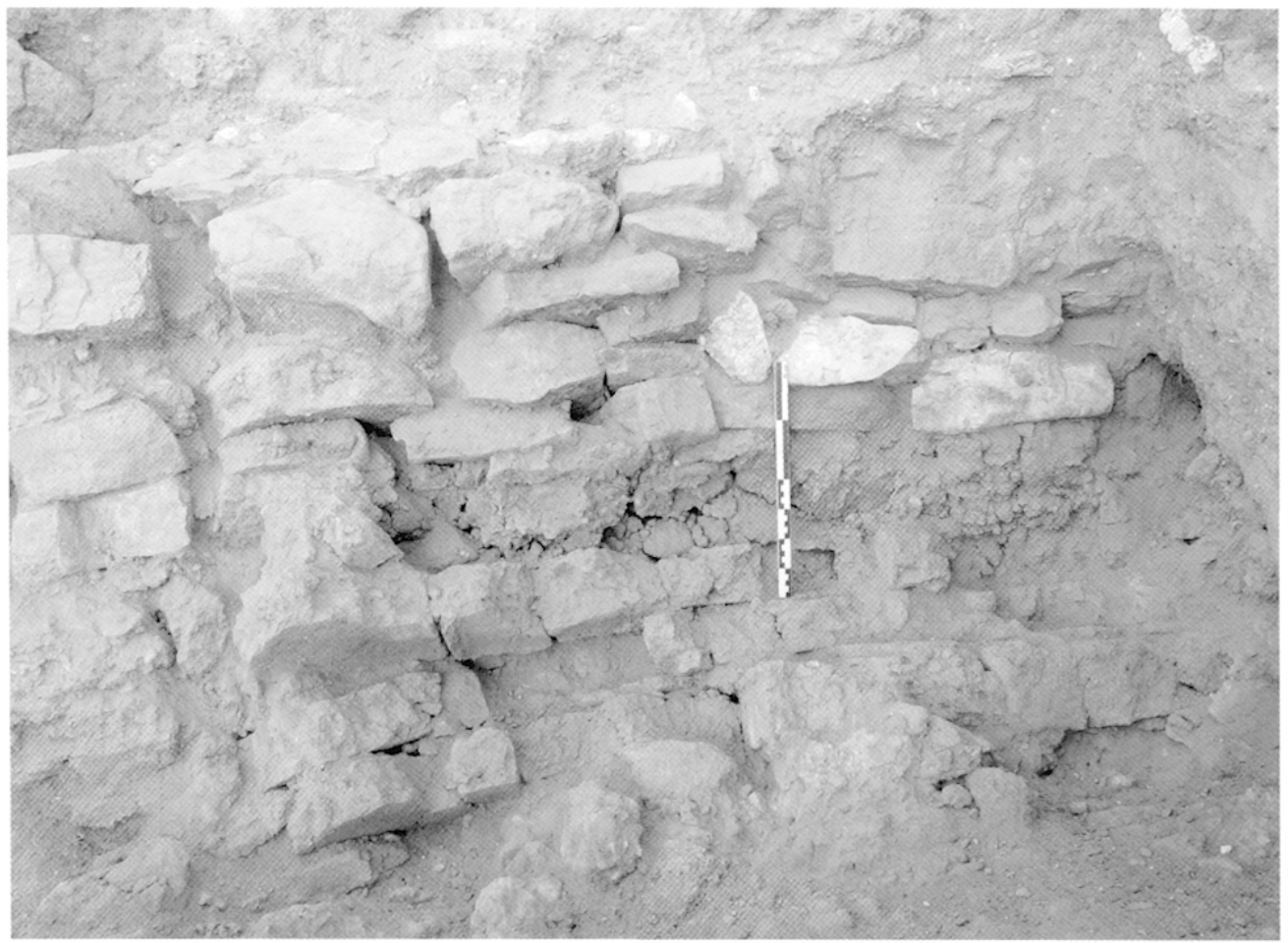

Fig. 41 : Chantier II Sud. Mur 03811 de la face externe de la tour (Porsuk VI ?), avec les assises de briques en fort pendage vers l'Est. Vue vers le Sud-Est.

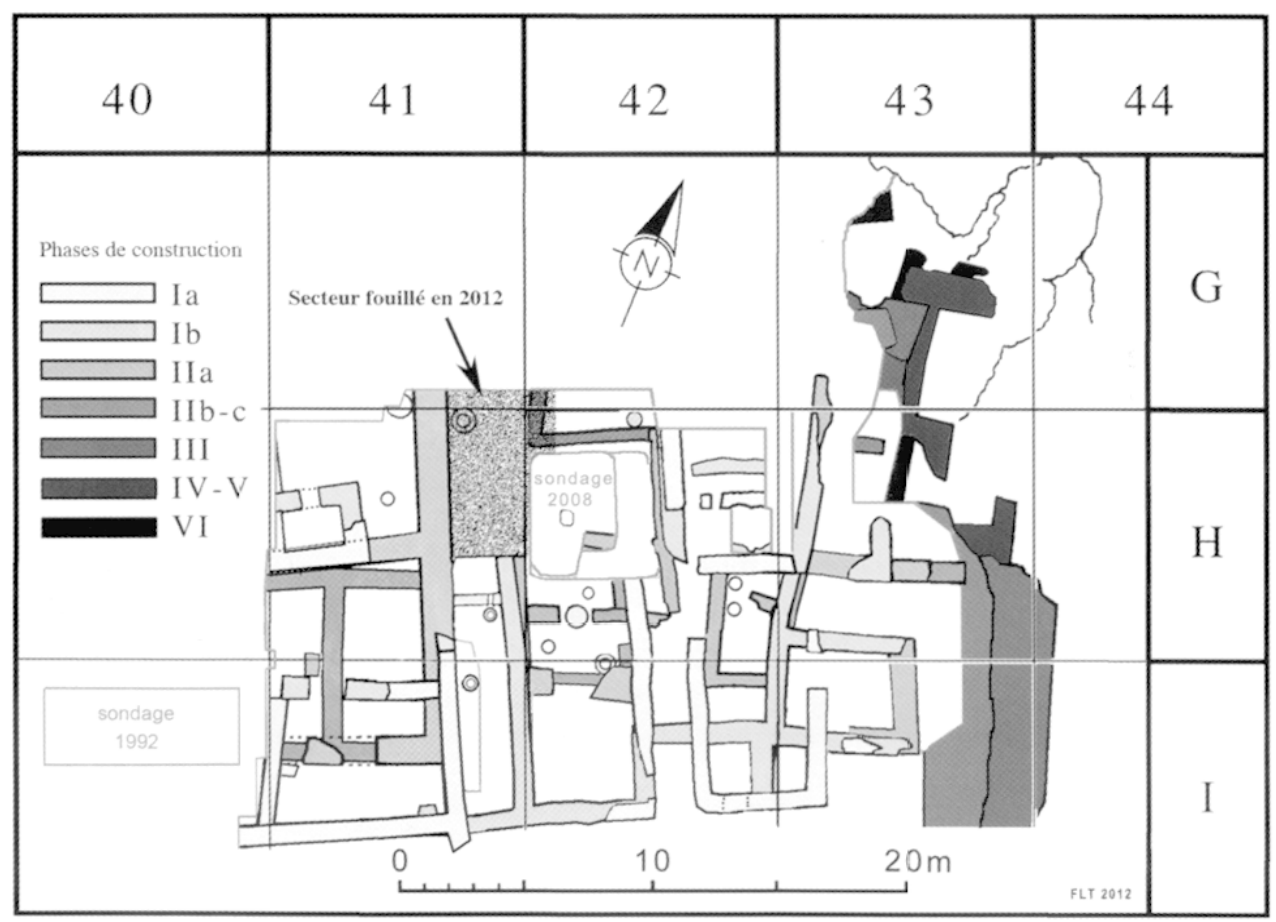

Fig. 42 : Chantier IV NE. Plan schématique avec emplacement du sondage (F. Laroche-Traunecker). 


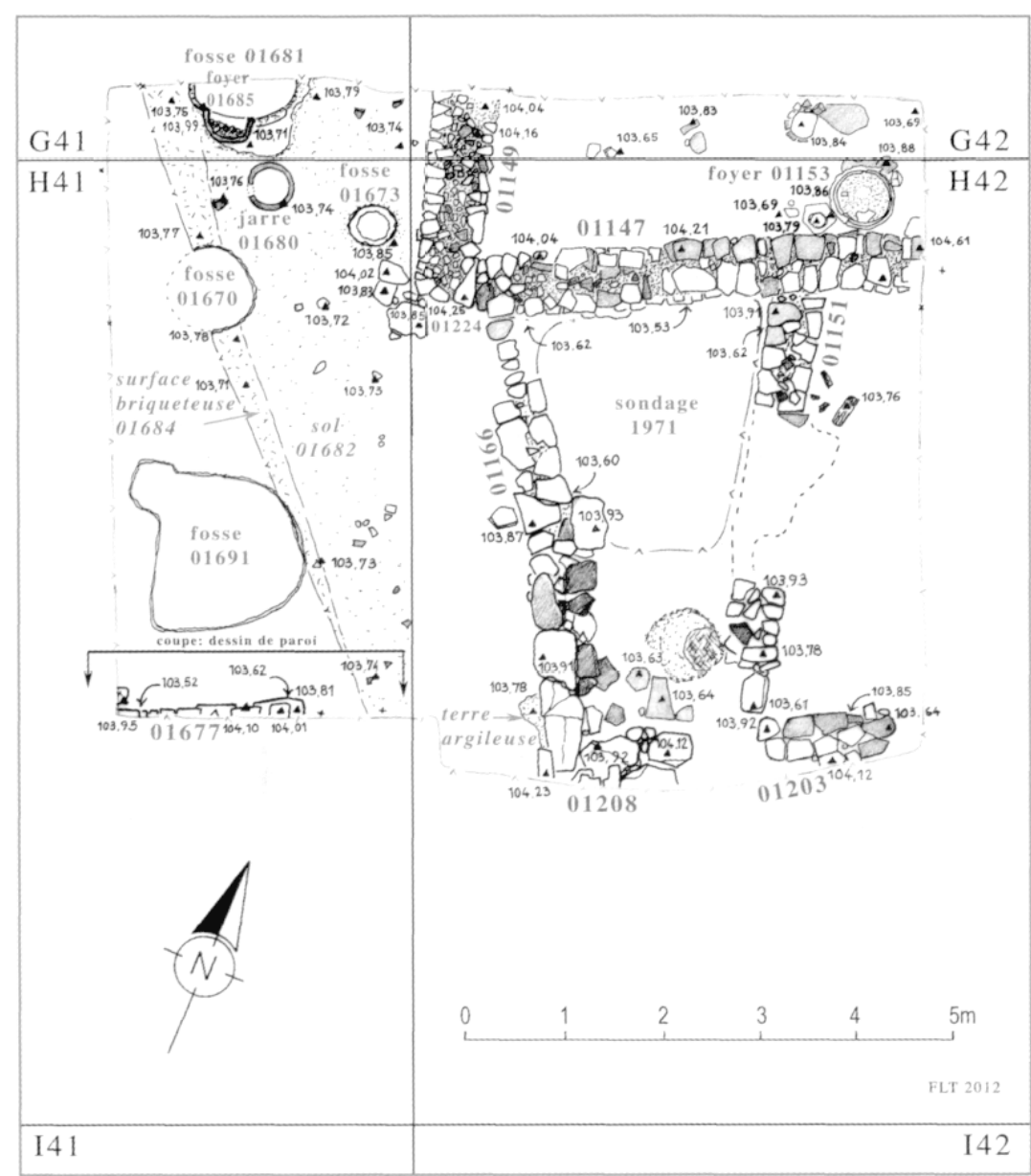

Fig. 43 : Chantier IV NE. Plan du 'niveau 5' (F. Laroche-Traunecker).
$103,80 \mathrm{~m})$. L'opération s'étendait sur une surface initiale d'environ $6,50 \times 3,30 \mathrm{~m}$ qui a par la suite été augmentée d'une zone d'environ $1,50 \times 2,40 \mathrm{~m}$.

La fouille a présenté plusieurs difficultés qui ont ralenti notre progression : tout d'abord, l'évacuation des déblais rendue délicate au fur et à mesure de la descente ; mais aussi la nature des couches découvertes. En effet, ce secteur a livré, sur une hauteur importante, une succession de fosses et d'éboulis qui ont grandement compliqué sa compréhension. Par ailleurs, l'analyse de la céramique a montré que ces niveaux perturbés présentaient un mélange de tessons hellénistiques et de l'Age du Fer ne permettant pas d'établir une datation assurée. Plusieurs états ont tout de même pu être distingués.

Ainsi, après avoir démonté des vestiges laissés en témoin, à savoir le mur 01158 et la jarre 01612 , nous avons pu débuter les travaux sur une surface relativement plane, correspondant au niveau dit ' $4 b$ ' par les fouilleurs précédents ${ }^{27}$. Outre quelques fosses, un 'niveau 5' (Fig. 43) relativement clair semble se dessiner aux alentours de l'altitude relative 103,79$103,74 \mathrm{~m}$ avec un sol 01682 , une jarre 01680 dont le col apparaît à la hauteur de ce sol et un foyer 01685 (Fig. 44). La jarre 01680 était encore recouverte par une dalle de pierre qui servait de couvercle mais la jarre elle-même était entièrement vide. Relativement bien préservée dans sa partie supérieure, elle était complètement cassée dans sa partie inférieure et le fond n'était plus en place (il a été découvert à l'intérieur de la jarre) (Fig. 45) (dimensions : d. int. de l'embouchure : $36 \mathrm{~cm}$; d. ext. de l'embouchure : 49 $\mathrm{cm}$; d. int maximal $90 \mathrm{~cm}$; h. minimale conservée : $82 \mathrm{~cm}$ ). Le sol 01682, blanc-grisâtre avec inclusions de gypse, part en biais par rapport à la zone de fouille. Il semble être bordé, à l'Ouest, par une couche 01684 , de nature différente (jaune briqueteux). Ce niveau est perturbé par quatre fosses plus ou moins importantes $(01670,01673,01681$ et 01691$)$. Un deuxième plan (Fig. 46) du 'niveau 5b' permet de voir l'état au niveau du fond de la fosse de la jarre. Seuls les fosses et un éboulis $(01686$, altitude 


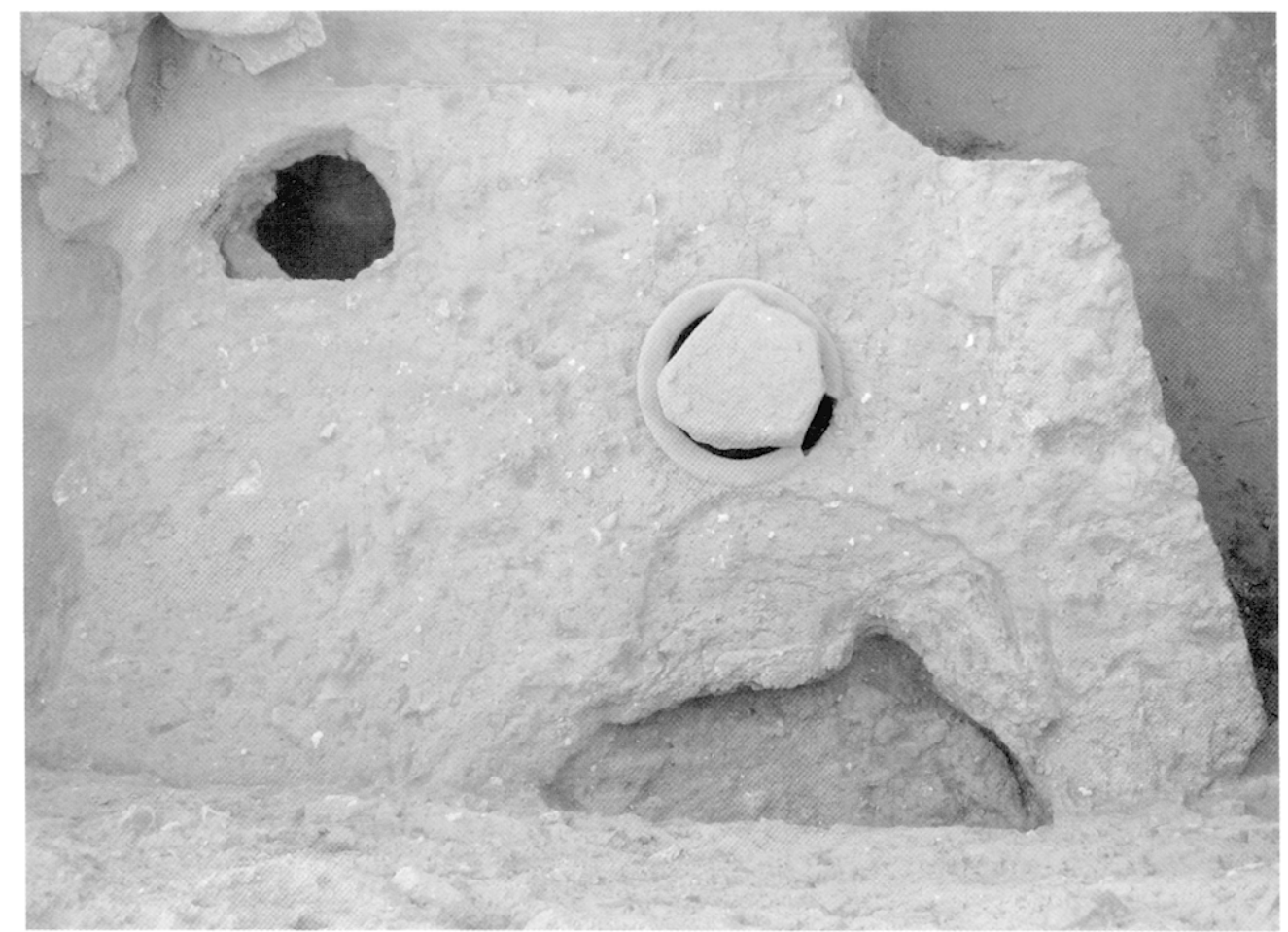

Fig. 44 : Chantier IV NE. Sol 01682 avec jarre enterrée 01680. Vue vers le Sud.

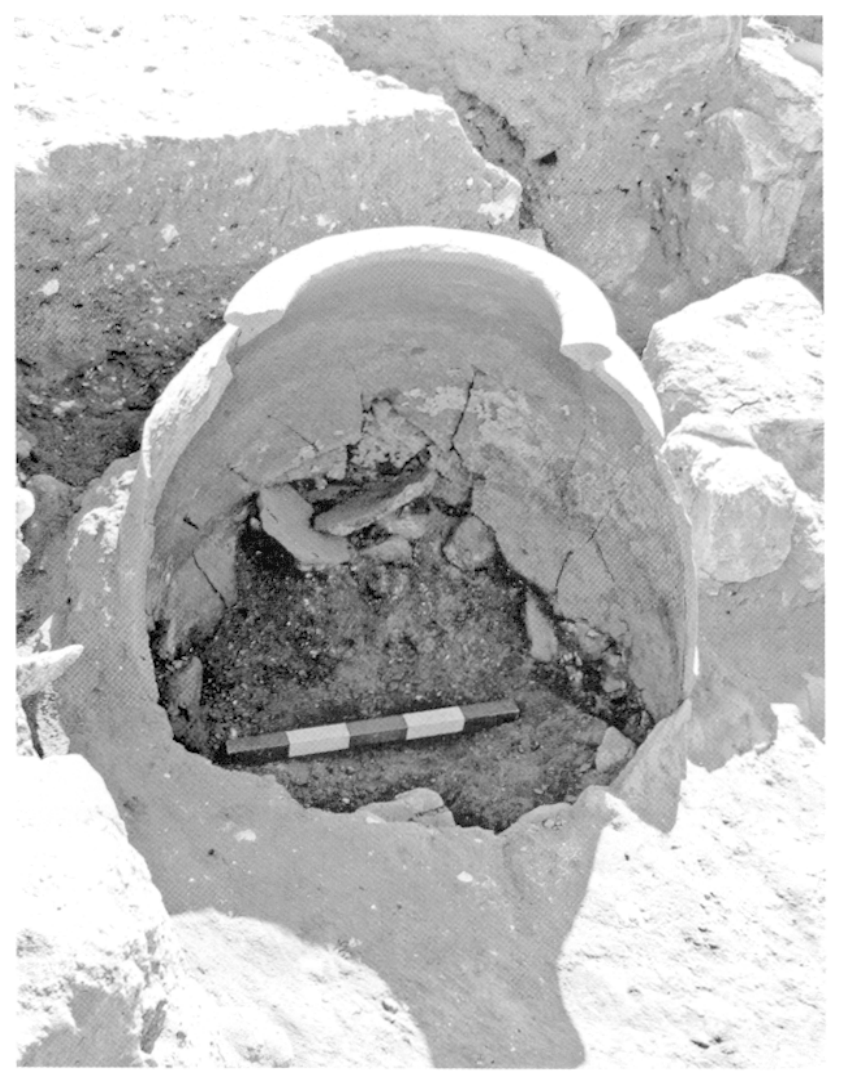

Fig. 45 : Chantier IV NE. La jarre 01680 après dégagement. Vue vers le Sud-Ouest. entre 103,70 et $103,50 \mathrm{~m}$ ) recouvrant une zone brûlée avec inclusions de cendres (01687) y apparaissent. Ce niveau correspond parfaitement à ce qui avait été trouvé auparavant en $\mathrm{H} 42^{28}$. A un niveau légèrement inférieur, un troisième état semble se dessiner où apparaît principalement le mur 01696 (Fig. 47-48), qui permet de compléter le plan du carré $\mathrm{H} 42$, où apparaissait déjà quelques fragments de bois carbonisés et peut-être un mur 01214 ("niveau 6"). Ce niveau marque le début d'un éboulis 01699 qui se poursuit de l'altitude 102,98 à 102,35 m (?) environ et d'une zone grandement perturbée par plusieurs fosses. L'éboulis a livré une sorte d'astragale travaillée, polie et percée qui pourrait être un élément de parure ou plutôt de jeu (01699.0001) (Fig. 49). Dans l'état suivant (Fig. 50), le seul dispositif bien attesté se trouve être un mur 01702 (altitude supérieure : 103,20-102,98 m), utilisé manifestement sur une période importante ('niveaux 7-8'). Le haut du mur conservé semble en effet fonctionner avec un sol 01701 trouvé uniquement au Nord (altitude environ $102,93 \mathrm{~m}$ ) sur lequel se trouvent des tessons et des pierres à plat. Le niveau correspondant en H42 est également perturbé mais deux murs apparaissent dans la moitié est du carré (01212 et 01214). Notre mur 01702 se poursuit en profondeur (4 à 5 assises selon les endroits, altitude inférieure

28) Voir les fouilles menées par Isabelle Chalier et Françoise Kirner en 2005 (Beyer et al. $2006: 220$, pl. 9c). 


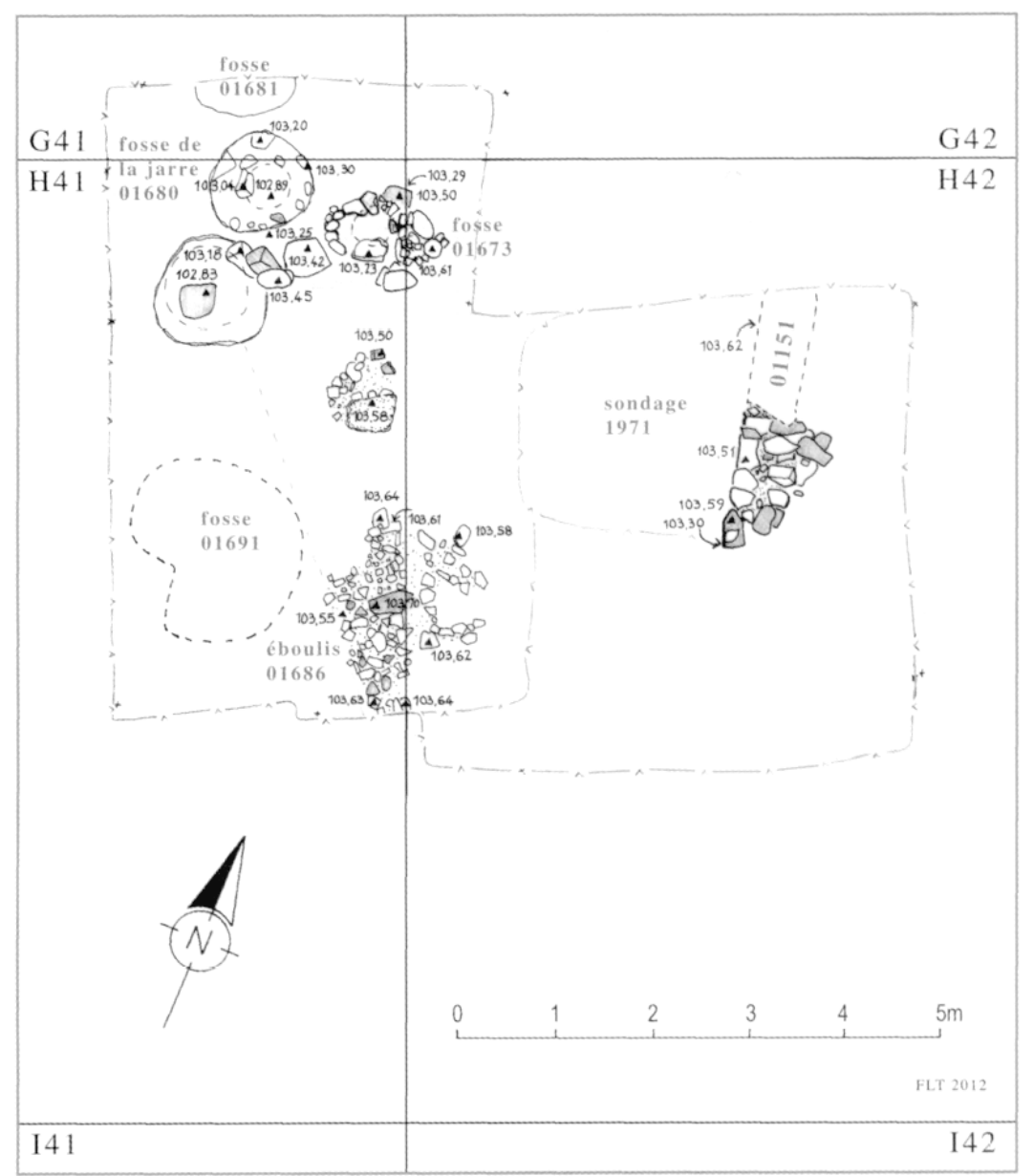

Fig. 46 : Chantier IV NE. Plan du 'niveau 5b' avec emplacement des fosses (F. Laroche-Traunecker).

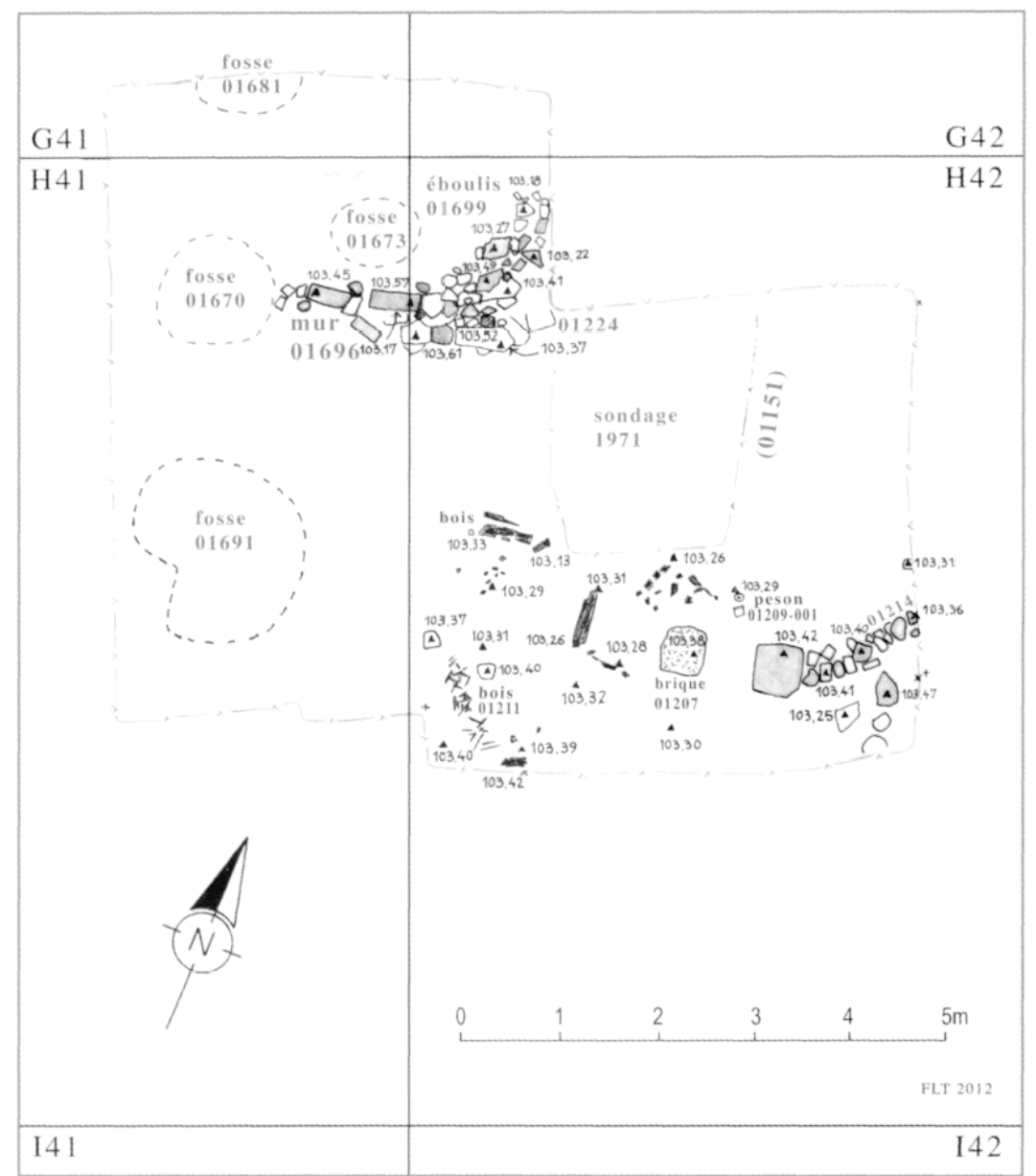

Fig. 47 : Chantier IV NE. Plan du 'niveau 6', avec le mur 01696 (F. Laroche-Traunecker). 


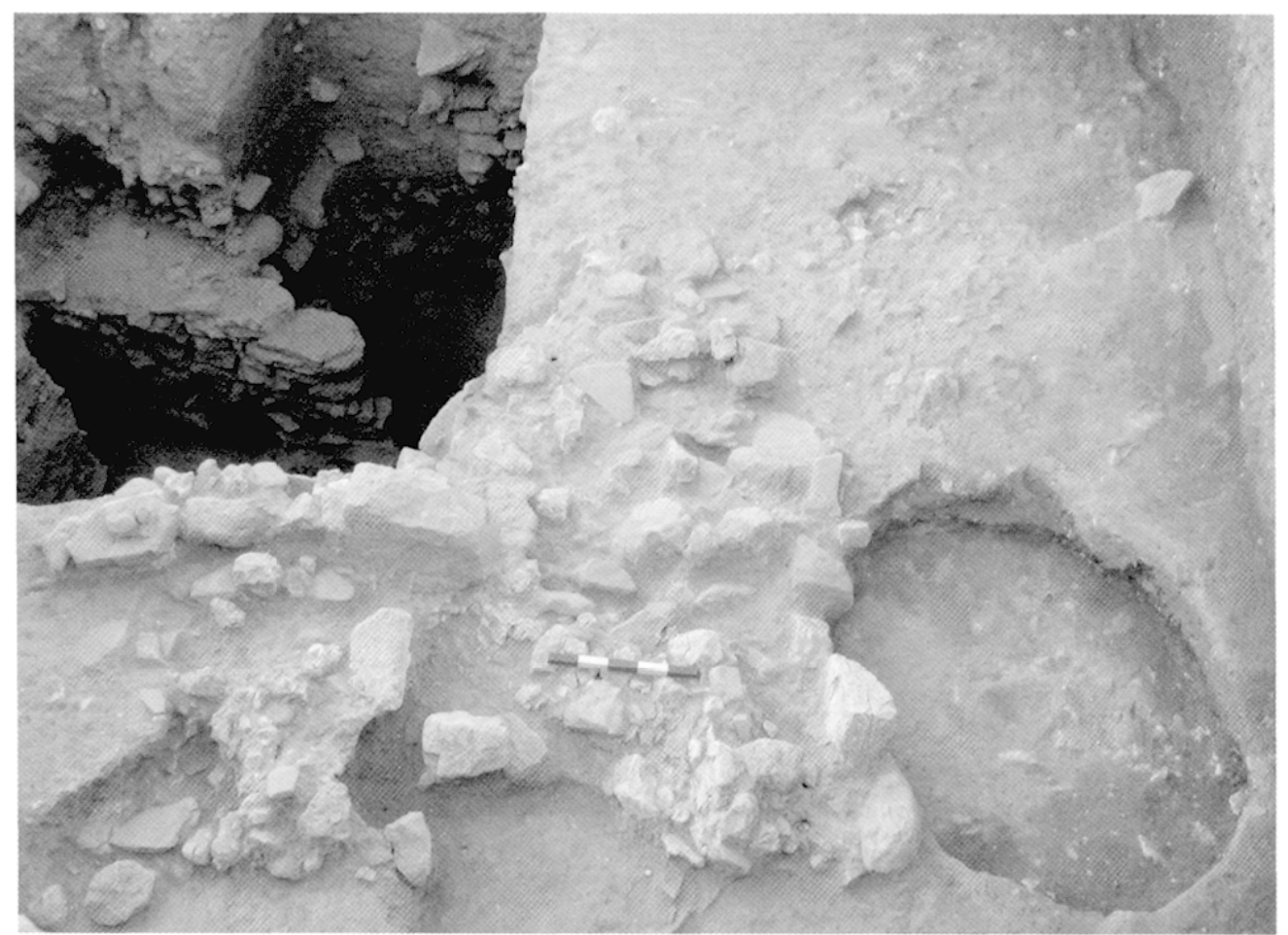

Fig. 48 : Chantier IV NE. Restes du 'niveau 6' avec le mur 01696. Vue vers le Sud.
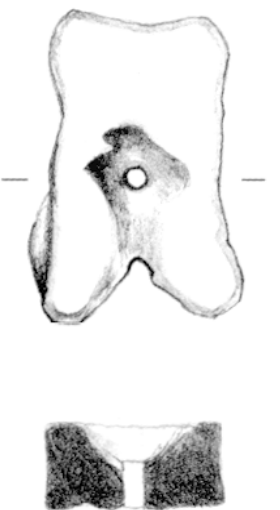

Fig. 49 : Chantier IV NE. Astragale polie et percée, élément de jeu ? (A. Beyer).

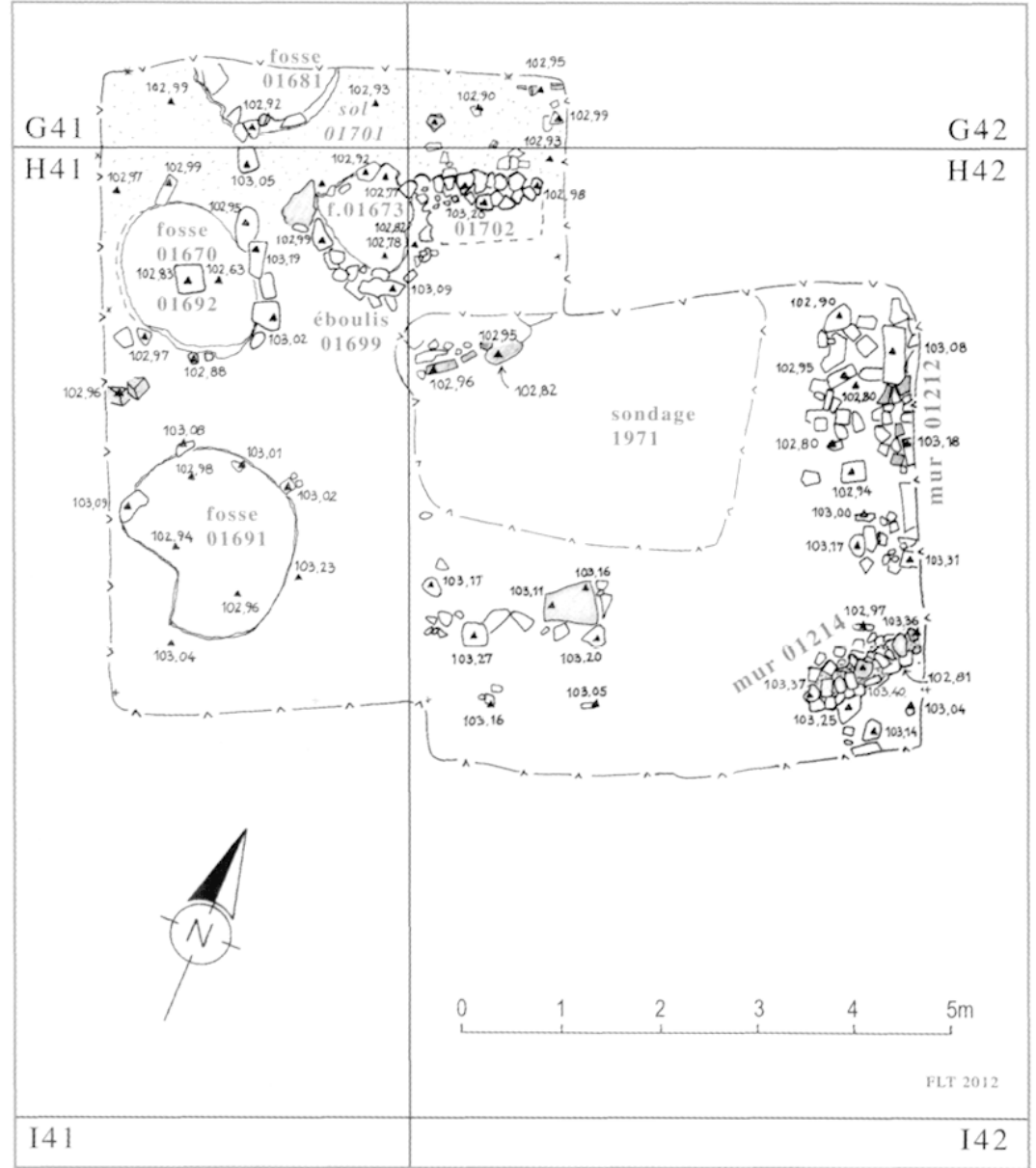

Fig. 50 : Chantier IV NE. Plan du 'niveau 7' avec mur 01702 (F. Laroche-Traunecker). 


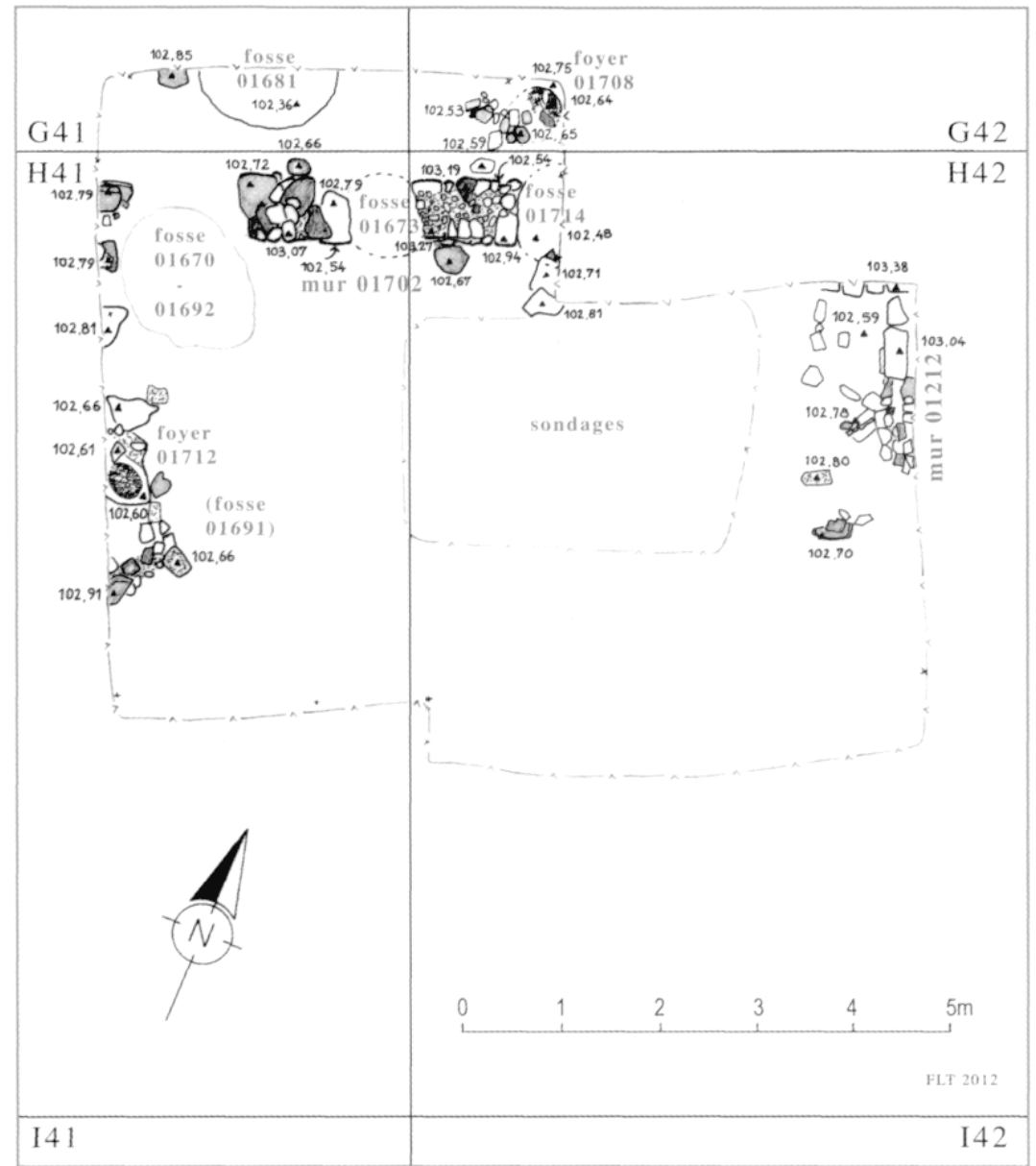

Fig. 51 : Chantier IV NE. Plan du 'niveau 8', avec foyer 01708 et fosses (F. Laroche-Traunecker).
102,54 m) jusqu'au 'niveau 8' (Fig. 51) auquel appartient un foyer 01708 (Fig. 52) qui a livré un peson (01708.0001). Une fosse importante coupe ce mur 01702 à l'Ouest (01673); une seconde, plus petite, à l'Est semble également apparaître (01714). Le mur 01702 est principalement composé de gypse (L. visible : $2,98 \mathrm{~m} ; 1 .: 70 \mathrm{~cm}, \mathrm{~h} .:$ env. $70 \mathrm{~cm}$ ). A ce niveau, apparaît également un petit foyer 01712 . En $\mathrm{H} 42$, on retrouve encore le mur 01212 , situé le long de la berme est.

Le dernier état repéré 'niveau 9' (Fig. 53) comprend un sol (01709), décelé du côté nord du mur 01702 mais se situant à une altitude plus basse que sa base et peut-être le début d'un nouveau mur (ceci sera à vérifier lors de la prochaine campagne). La zone située au Sud du mur 01702, après le démontage complet de l'éboulis 01699, a livré une zone plus complexe avec de nombreux éléments correspondant à une destruction : nombreuses zones brûlées rouges et noires, zones cendreuses, terre cuite par l'incendie, poches briqueteuses (l'ensemble de la zone a été appelé 01707) et deux zones de cailloutis dont 01710 en bordure sud de la zone de fouille. Un lambeau de sol 01711 semble remonter par-dessus la zone bri- queteuse. Presqu'en limite entre cette zone brûlée 01707 et le sol 01711, une sorte de petit muret apparaît (01713), composé d'un mélange de pierre (grès) et de briques, dégagé jusqu'ici sur deux assises. La fonction de cette zone nous échappe encore.

Le matériel découvert dans ce secteur est assez varié. Comme cela a été mentionné, la céramique est très mélangée, allant de la céramique hellénistique à de la céramique datée du Fer Moyen. Parmi ces derniers, quelques exemplaires spécifiques peuvent être relevés, comme un motif de 'moulin à vent' (Fig. 54). Parmi les petits objets, on notera tout d'abord la découverte d'un certain nombre de pesons (01676.0006) dont un pyramidal (01703.0004) (Fig. 55), de plusieurs scories de fer et de fragments de bronze ou de fer, souvent informes. Mais le matériel métallique a aussi livré quelques épingles en bronze (01676.0003, 01679.0002 et 01683.0004), un anneau en bronze (01671.0003), un ciseau en fer (01694.0001), un anneau en fer (01703.0001) (Fig. 57), une pointe ou un poinçon en fer (01693.0002), un clou en argent (Fig. 56) et une agrafe en plomb (01676.0007) (Fig. 58). On notera enfin la présence 


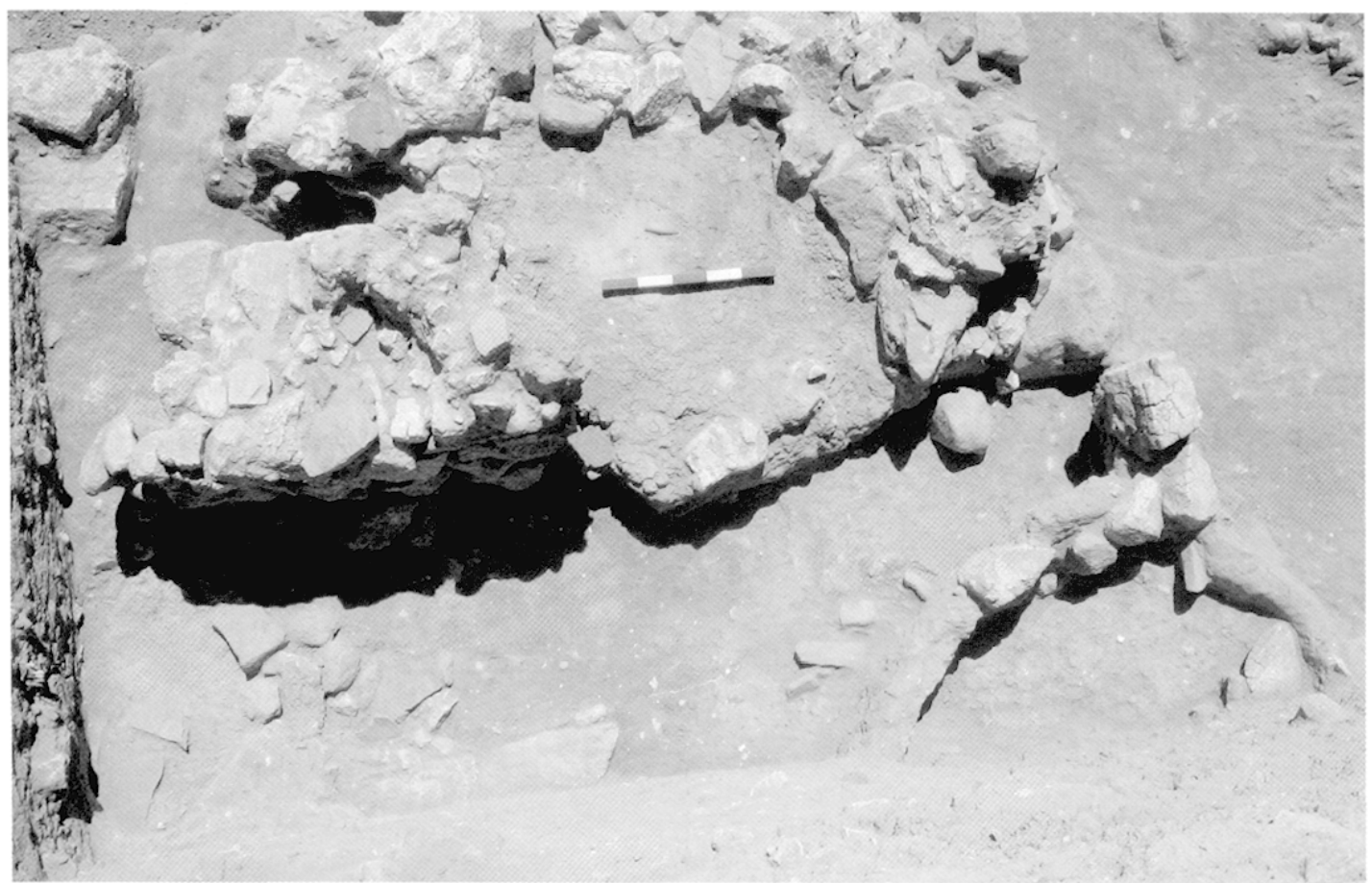

Fig. 52 : Chantier IV NE. Vue du 'niveau 8', avec le foyer 01708 et la fosse 01673 coupant le mur 01702 . Vue vers le Sud.

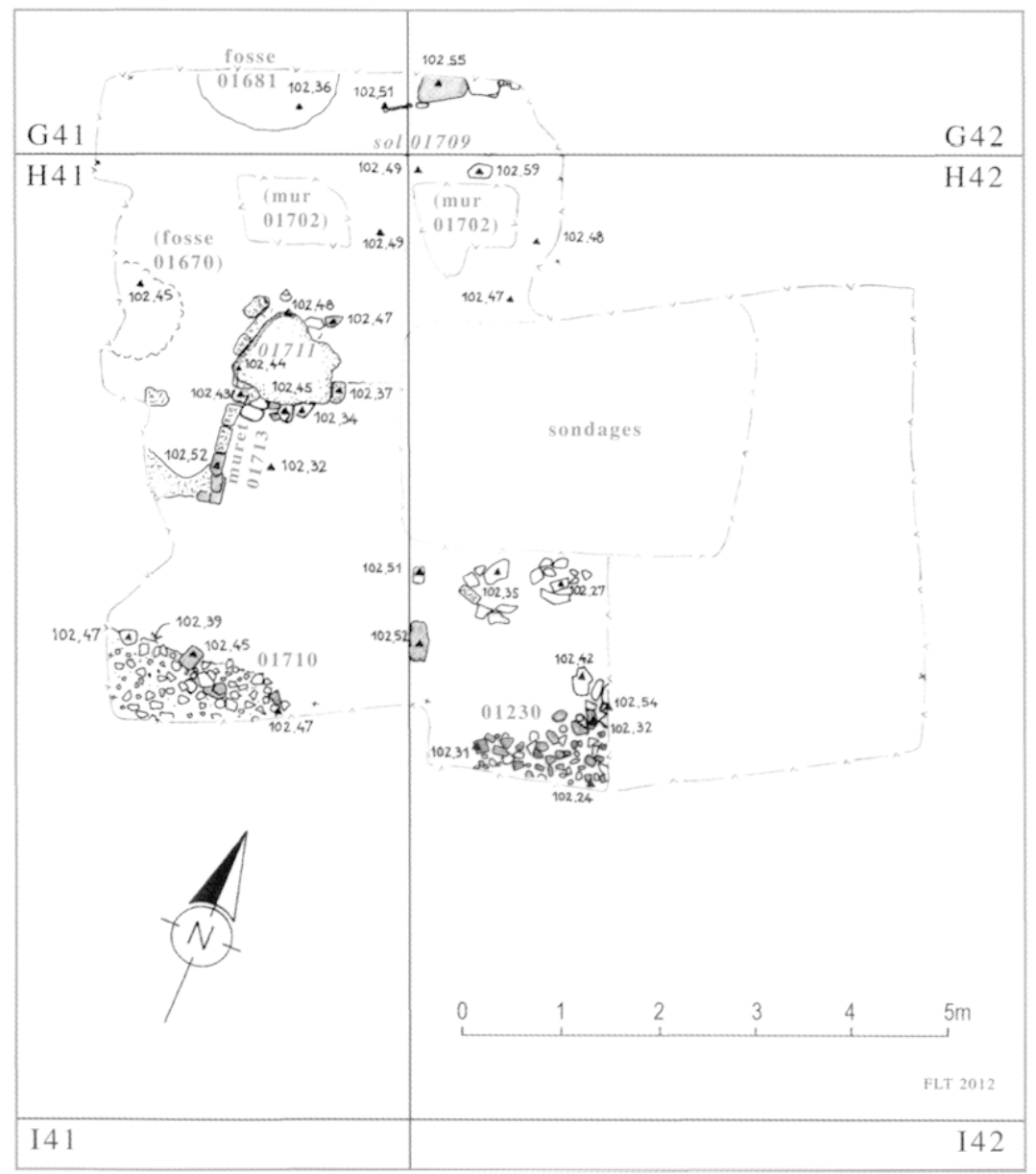

Fig. 53 : Chantier IV NE. Plan du 'niveau 9'

(F. Laroche-Traunecker). 


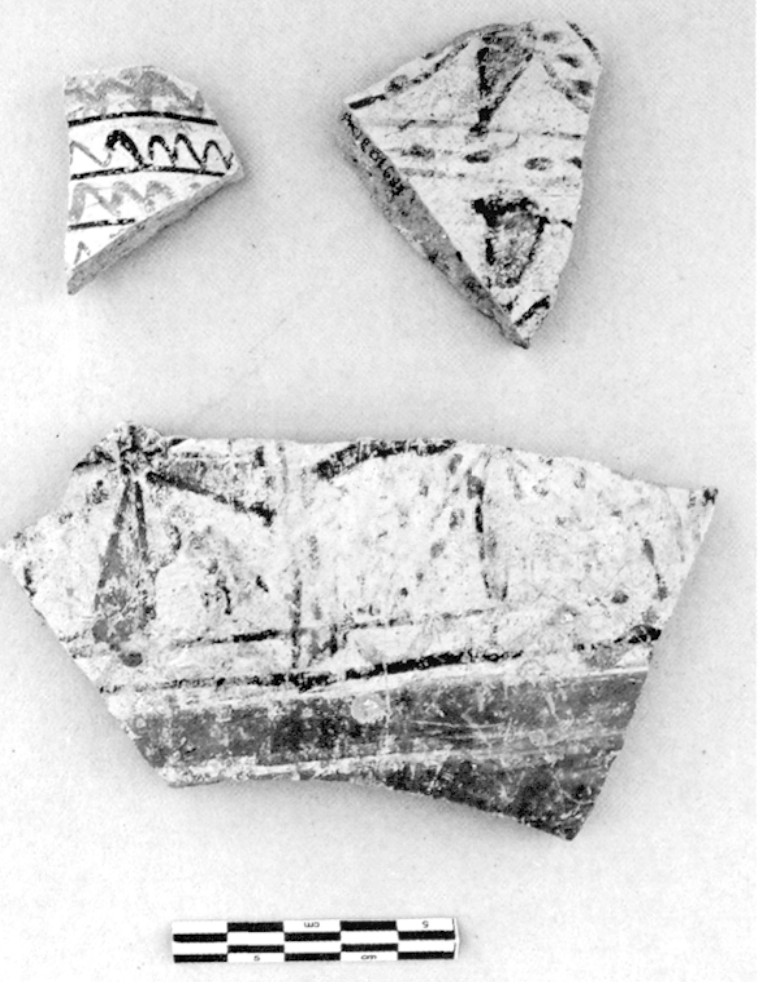

Fig. 54 : Chantier IV NE. Tessons du style 'moulin à vent' du Fer Moyen.
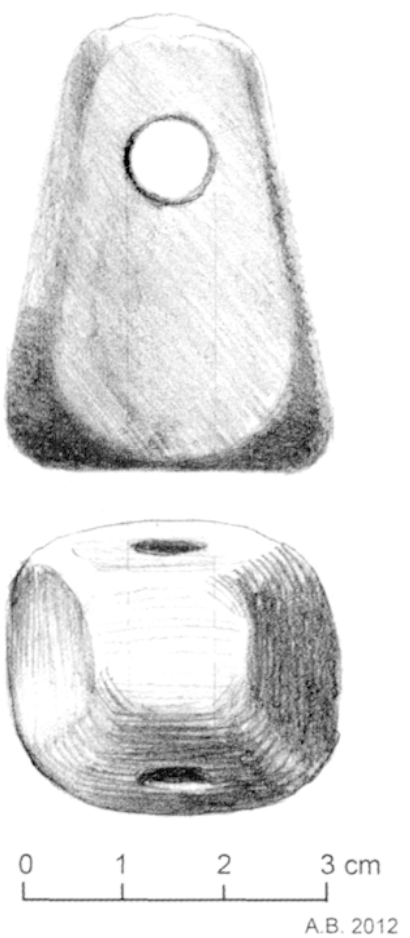

Fig. 55 : Chantier IV NE. Peson pyramidal 01703.4 (A. Beyer).

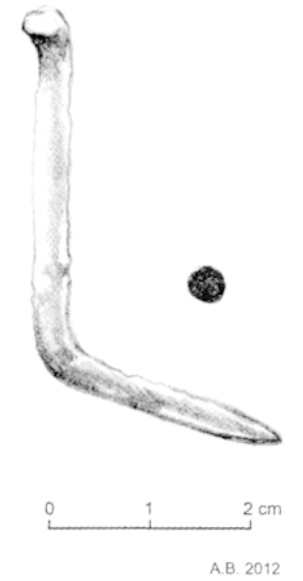

Fig. 56 : Chantier IV NE. Clou d'argent 01691.2 (A. Beyer).

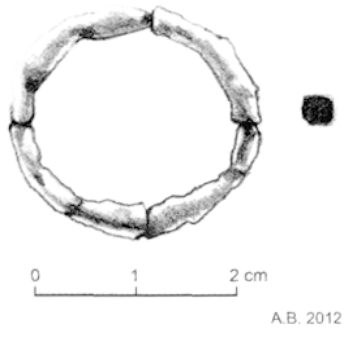

Fig. 57 : Chantier IV NE. Anneau 01703.1 en fer (A. Beyer).

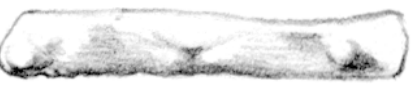

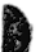

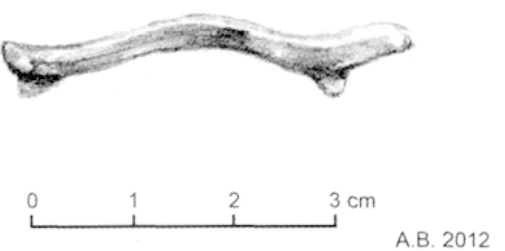

Fig. 58 : Chantier IV NE. Agrafe 01676.7 en plomb (A. Beyer). 

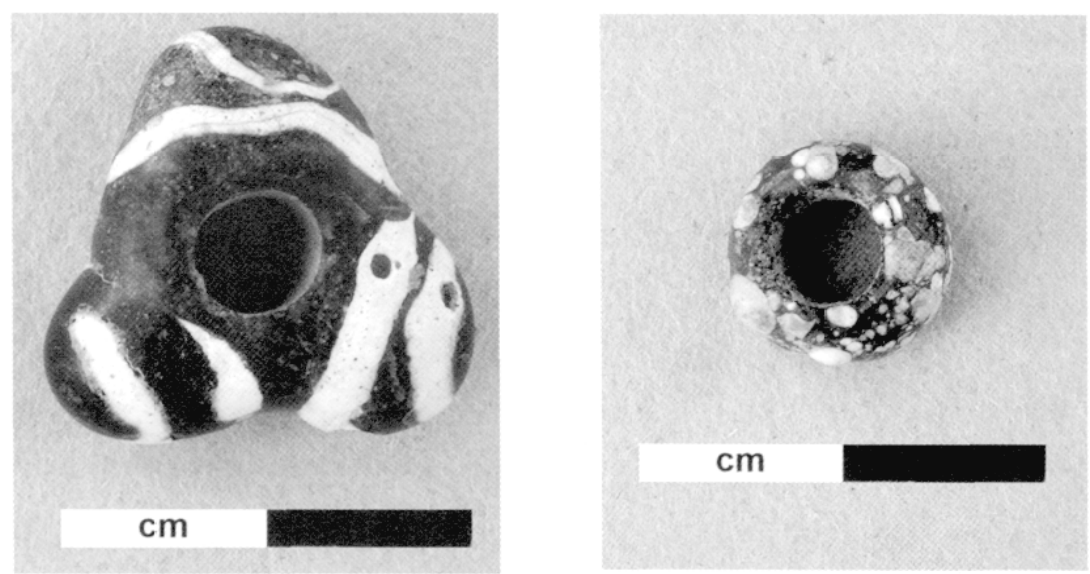

Fig. 59 a-b : Chantier IV NE. Perles de verre 01700.2 et 01703.6.

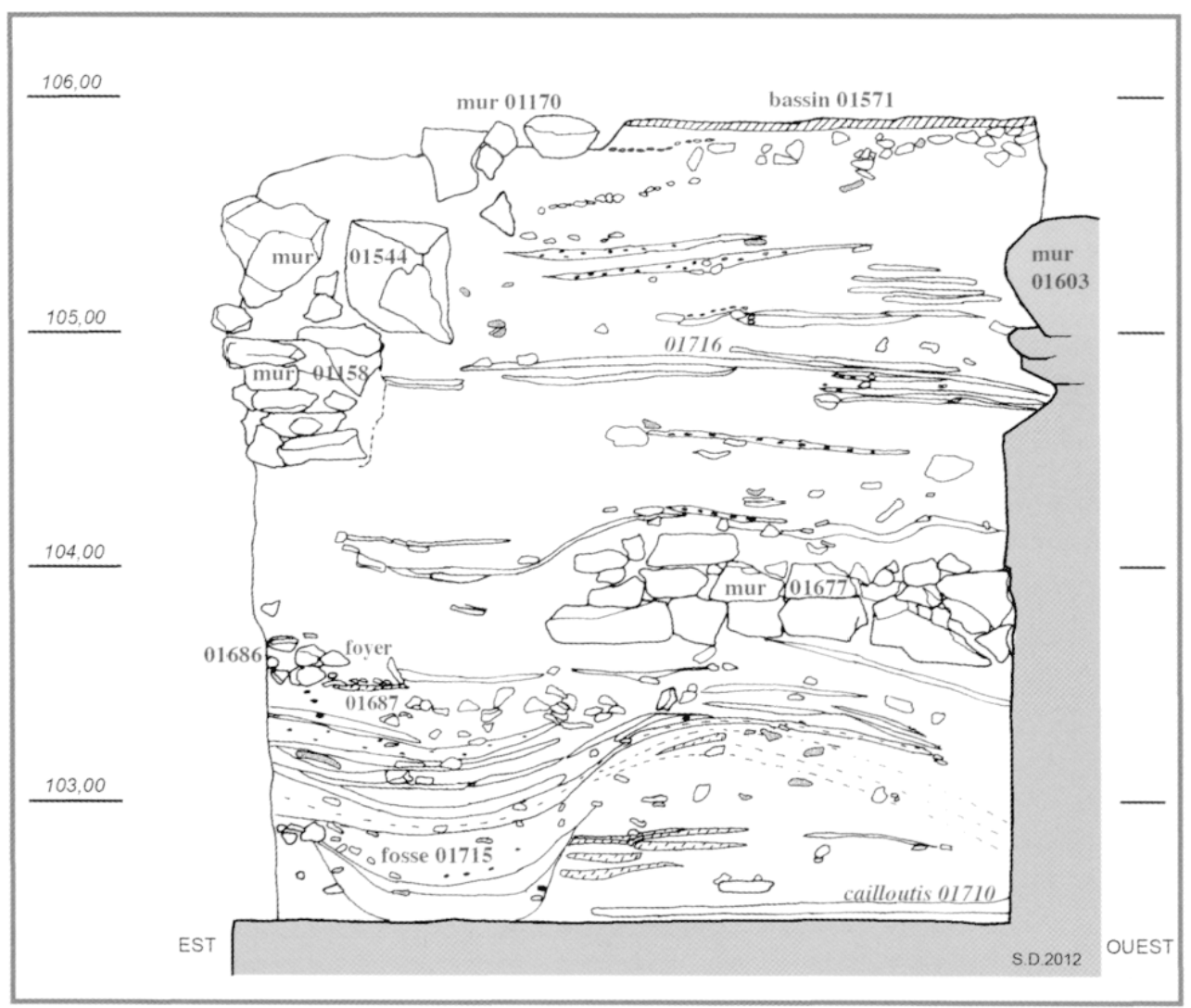

Fig. 60 : Chantier IV NE. Relevé de la paroi sud du sondage (S. Dermech).

de perles $(01700.0002 \text { et } 01703.0006)^{29}$ (Fig. 59) et de bouchons.

Enfin, dans le but précédemment évoqué de relier les différents secteurs déjà fouillés dans cette zone, la coupe de la paroi sud de notre zone de fouilles a été réalisée par $\mathrm{S}$. Dermech sur environ 3,35 $\mathrm{m}$ de haut (Fig. 60). Elle nous permet de mettre au jour le mur 01677 que nous n'avons pas pu fouiller en plan, celui-ci n'apparaissant que dans la paroi (Fig. 43). Celui-ci est construit en gypse et s'élève encore sur trois assises (L. : $1,90 \mathrm{~m} ; \mathrm{h} .: 47 \mathrm{~cm}$ ), entre $\Delta 104,07$ et $103,57 \mathrm{~m}$. Cette coupe nous a par ailleurs permis de mettre en évidence la couche 01716 , couche rouge-orangé d'épaisseur inégale pro-

29) Une perle semblable avait été trouvée au chantier II par Aksel Tibet lors de la campagne de 2005 (cf. Beyer et al. $2006: 243$, pl. 28a). 


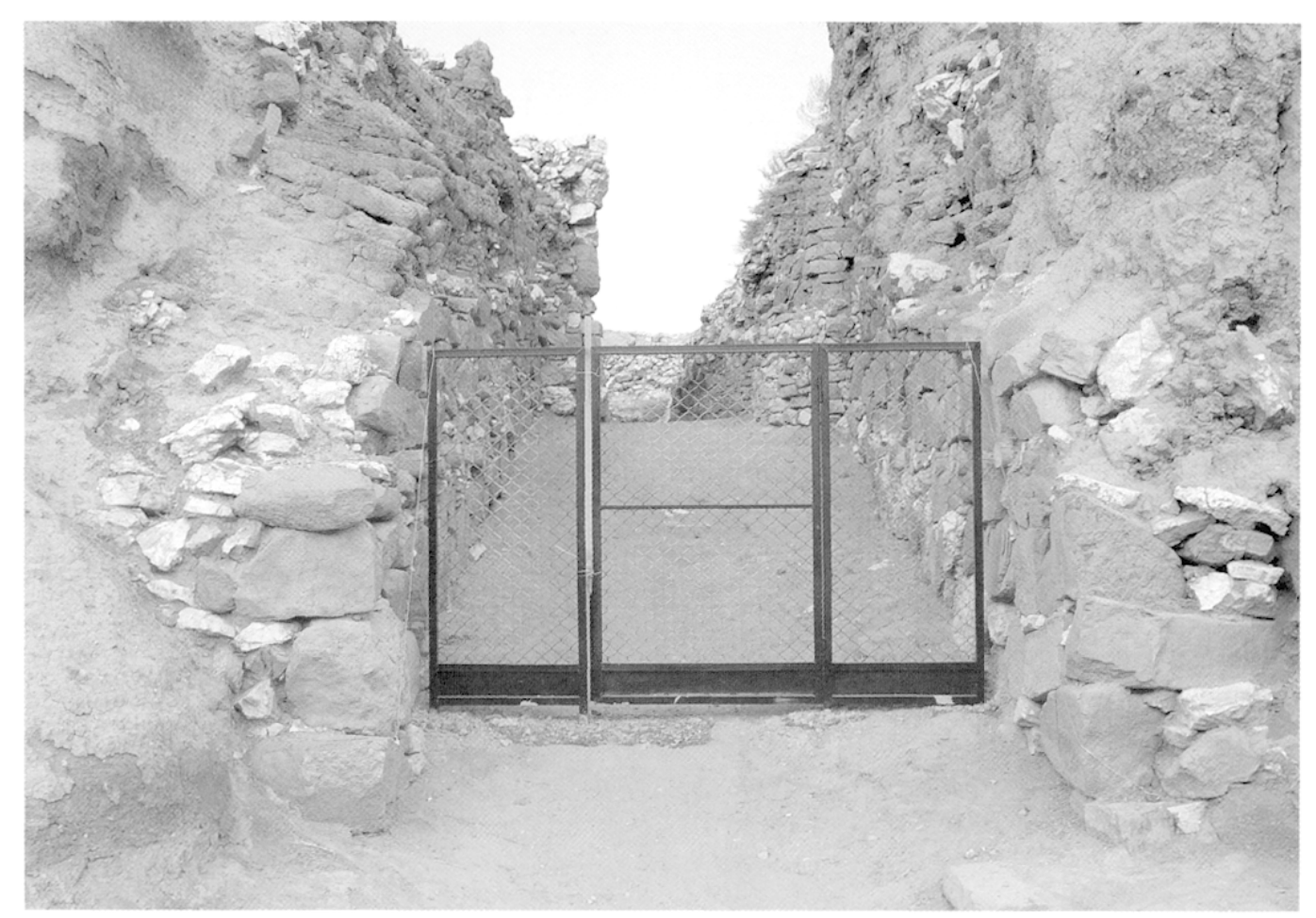

Fig. 61 : Chantier II. Porte métallique de la 'poterne hittite'. Vue vers l'Est.

bablement fouillée en 2011 (altitude supérieure $104,85 \mathrm{~m}$, niveau hellénistique ?) qui est l'une des seules couches à mettre en relation (?) les deux murs 01603 et 01158 . Enfin, une fosse (01715) est bien visible dans la paroi. Elle permettrait éventuellement de suggérer que nous nous trouvons dans un espace extérieur.

\section{TRAVAUX DE PRESERVATION, RESTAURATION ET VALORISATION}

On notera que cette campagne a vu la réalisation d'un certain nombre de travaux en complément de la fouille proprement dite.

Il s'agit tout d'abord de travaux de restaurationconsolidation de certains murs, aussi bien au chantier II qu'au chantier IV. En utilisant les blocs de pierres provenant des structures anciennes démontées lors des campagnes précédentes nous avons construit en particulier un mur de soutènement à l'intérieur de la 'Poterne' (chantier II) à la hauteur de la porte primitive des fortifications du niveau VI pour empêcher l'éboulement du montant sud qui présentait un porte à faux menaçant. Nous avons aussi comblé avec des pierres de remploi une grande cavité qui s'était formée par l'action des eaux de pluie dans le parement nord de la Tour Nord visible à l'intérieur du sondage profond ouvert en G06. Le parement a été ensuite doublé d'un mur moderne construit avec les pierres provenant des structures anciennes dé- montées, et le sondage profond a été comblé pour prévenir tout risque d'effondrement ultérieur.

Dans le secteur II, ont été installés quelques compléments à la couverturc dc plaques de tôle de la tour NE. Pour ce qui est de la protection de ce secteur des fortifications, il convient de reprendre à zéro le dossier de la couverture du dispositif défensif du chantier II, 'poterne hittite' et tours avec murs de briques. Ce dossier est techniquement délicat, car il conviendra de tenir compte des derniers dégagements dans ce secteur à fortes pentes et de l'existence de vents violents, surtout ceux qui sont en provenance du plateau, au Nord-Ouest.

La clôture existante a été améliorée et une nouvelle clôture protégeant le nouveau secteur des remparts sud du chantier II (Fig. 28) a été implantée.

A l'entrée de la 'poterne hittite' (Fig. 61) a été installée une porte métallique à deux battants.

Dans le domaine de la signalétique, deux panneaux didactiques ont été placés à l'entrée du site (Fig. 62) et au sommet de la butte du chantier II ; un panneau supplémentaire, consacré au chantier IV, est prévu pour 2013.

Dans le dépôt situé sur le site, placé régulièrement sous scellés, des travaux ont été réalisés pour gagner de la place et améliorer le rangement du matériel archéologique (céramique et ossements de faune). 


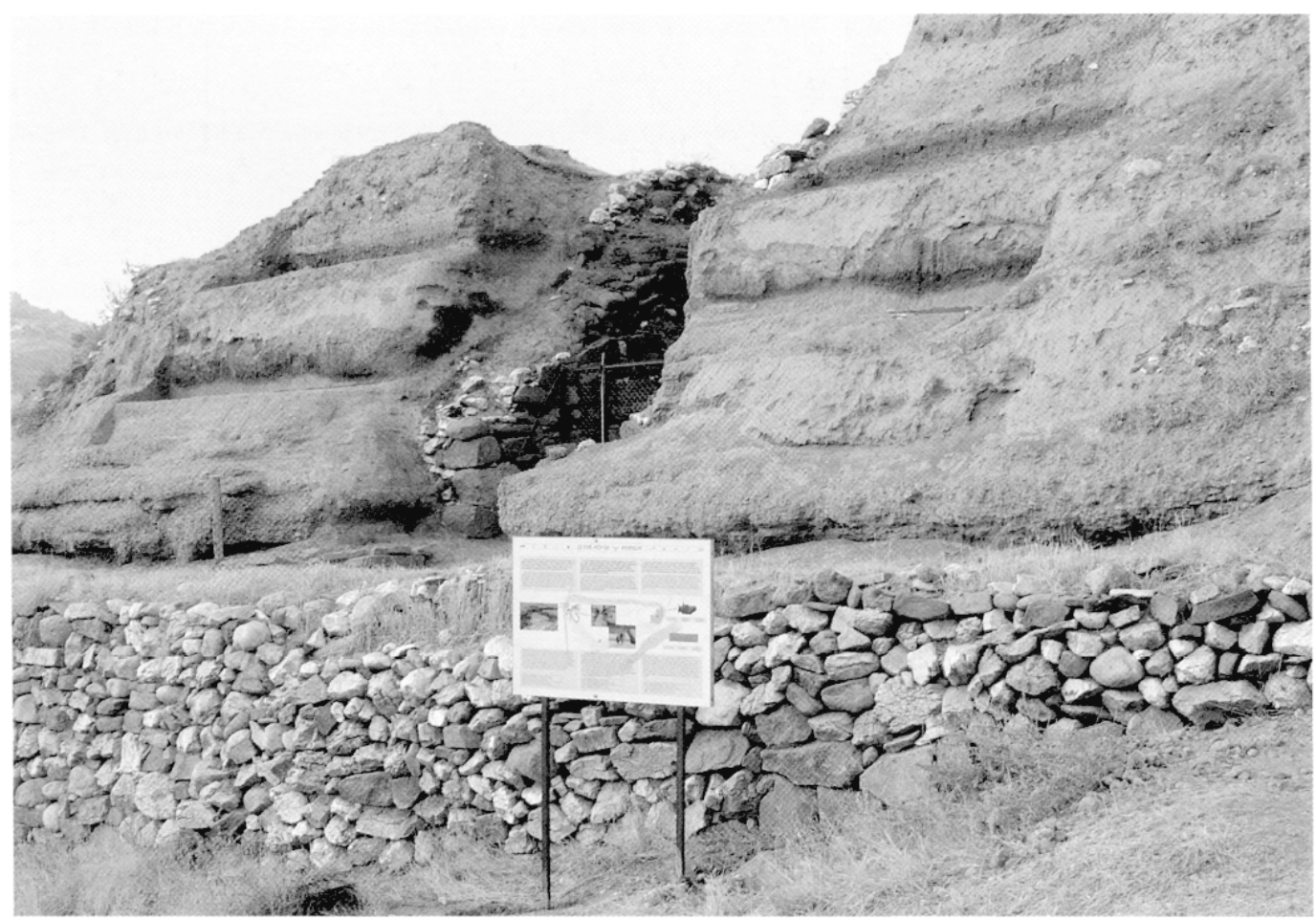

Fig. 62 : Chantier II. Panneau didactique à l'entrée du site.

\section{BIBLIOGRAPHIE}

Augé, C., Davesne, A. et Ergeç, R., 1997 : "Le début des tétradrachmes d'Athènes du 'nouveau style' : un trésor trouvé près de Gaziantep en 1994", Anatolia Antiqua V : 45-82.

Beyer, D. et al., 2005 : "Porsuk (Zeyve Höyük) : rapport sommaire sur la campagne de fouilles de 2004", Anatolia Antiqua XIII : 295-318.

Beyer, D., Chalier, I., Laroche-Traunecker, Fr., Lebreton, S., Patrier, J. et Tibet, A., 2006 : "Zeyve Höyük (Porsuk) : rapport sommaire sur la campagne de fouilles de 2005", Anatolia Antiqua XIV : 205-244.

Beyer, D., Chalier, I., Laroche-Traunecker, Fr., Patrier, J. et Tibet, A., 2007 : "Zeyve Höyük (Porsuk) : rapport sommaire sur la campagne de fouilles de 2006", Anatolia Antiqua XV : 289-314.

Beyer, D., Chalier, I., Laroche-Traunecker, Fr., Patrier, J. et Tibet, A., 2008 : "Zeyve Höyük (Porsuk) : rapport sommaire sur la campagne de fouilles de 2007", Anatolia Antiqua XVI : 313-344.
Beyer, D., Chalier, I., Laroche-Traunecker, Fr., Lebreton, S. et Tibet, A., 2009 : "Zeyve Höyük (Porsuk) : rapport sur la campagne de 2008", Anatolia Antiqua XVII : 317-349.

Beyer, D., Chalier, I., De Backer, F., Laroche-Traunecker, Fr., Lebreton, S. et Tibet, A., 2010 : "Campagne 2009 de la mission archéologique de Zeyve Höyük (Porsuk)", Anatolia Antiqua XVIII : 215-242.

Beyer, D., Chalier, I., Kirner, Fr., Patrier, J. et Tibet, A., 2012 : "Zeyve Höyük (Porsuk) : rapport sommaire sur la campagne de fouilles de 2011", Anatolia Antiqua XX : 177-203.

Kepinski, Chr., 1977 : "Un objet 'en forme d'avantbras'", Méthodologie et critiques I. Problèmes concernant les Hurrites, Paris : 71-114.

Metcalf, W.E. (éd.), 2012 : The Oxford Handbook of Greek and Roman Coinage, Oxford.

Naumann, R., 1971 : Architektur Kleinasiens, Tübingen. 